Transgressing Boundaries and Cultural Haunting in Chinese American and Chinese Canadian 'Talk Stories'

by

Elpida Morfetas

\begin{abstract}
A thesis in fulfillment of the requirements
for the Master of Arts degree

in English Language and Literature

in the Faculty of Graduate Studies and Research of

Carleton University
\end{abstract}

May 2002

Thesis supervisor: Professor Brenda Carr 
National Library of Canada

Acquisitions and Bibliographic Services

395 Wellington Street Ottawa ON K1A ON4 Canada
Bibliothèque nationale du Canada

Acquisitions et services bibliographiques

395, rue Wellington

Ottawa ON K1A ON4

Canada
The author has granted a nonexclusive licence allowing the National Library of Canada to reproduce, loan, distribute or sell copies of this thesis in microform, paper or electronic formats.

The author retains ownership of the copyright in this thesis. Neither the thesis nor substantial extracts from it may be printed or otherwise reproduced without the author's permission.
L'auteur a accordé une licence non exclusive permettant à la Bibliothèque nationale du Canada de reproduire, prêter, distribuer ou vendre des copies de cette thèse sous la forme de microfiche/film, de reproduction sur papier ou sur format électronique.

L'auteur conserve la propriété du droit d'auteur qui protège cette thèse. $\mathrm{Ni}$ la thèse ni des extraits substantiels de celle-ci ne doivent être imprimés ou autrement reproduits sans son autorisation.

\section{Canadä}


The undersigned recommend to the Faculty of Graduate Studies and Research acceptance of this thesis

\title{
Transgressing Boundaries and Cultural Haunting in Chinese American and Chinese Canadian 'Talk Stories'
}

\author{
By
}

Elpida Morfetas

in partial fulfilment of the requirements for the degree of Master of Arts

$$
\text { Wrenola (an reblino }
$$

Thesis Supervisor

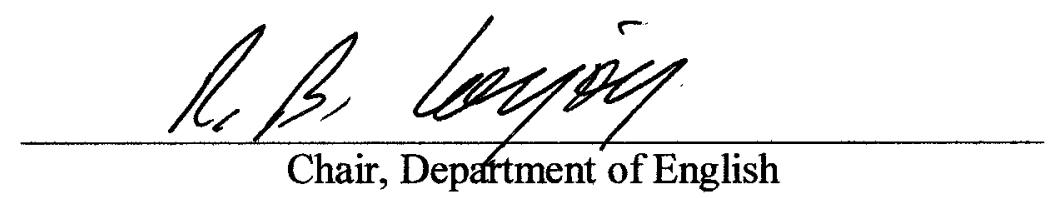

Carleton University

May 2002 


\begin{abstract}
My thesis examines cultural, gender and family boundaries of identity in Chinese American Maxine Hong Kingston's The Woman Warrior and Chinese Canadians Wayson Choy's The Jade Peony and Sky Lee's Disappearing Moon Cafe. I begin this project by exploring how historical forces shaped these works and by identifying similarities and differences between Chinese American and Canadian contexts. Each work features protagonists who are transgressive figures or bordercrossers engaged in acts of narrative revision and memory reconstruction. All three works include the figures of outlaws and ghosts and reflect the theme of 'cultural haunting,' Evidencing successes and failures in boundary transgression, the protagonists challenge family and cultural secrets and revise culturally dictated norms of identity formation around gender roles, family, community and history. My study also examines three concepts central to each work: Chinese oral storytelling traditions; the interconnectedness of storytelling, memory and community; and interdependent identities.
\end{abstract}




\section{Acknowledgements}

I would like to extend the warmest thanks to Dr. Brenda Carr for all the vital advice and encouragement she has given me during the entire time I worked on this thesis. I also want to acknowledge the help and support of Dr. Patricia Smart and Dr. Robert Hogg. Thanks ('Euxaristo') also to my family -- Evangelos, Sophia, Olympia and Nicole Morfetas -- as well as my friends, Deb McGuigan, Julie Harrison, Chris Aggelis, Nick Angelopoulos, and George Sofianos. Their help, support and patience has been invaluable. 


\section{Table of Contents}

\section{Page}

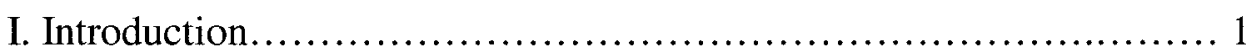

II. Chapter One

'Ghosts have no memory anyway:' Ghosts, Warriors, and Outlaws

in Maxine Hong Kingston's The Woman Warrior.

III. Chapter Two

The Power of the 'Dark Storyteller:' Family and Connected Identity in Wayson Choy's The Jade Peony...

IV. Chapter Three

A Chinese Canadian Saga: Family 'History as Mystery'

in Sky Lee's Disappearing Moon Cafe. 101

V. Afterword........................................................ 147

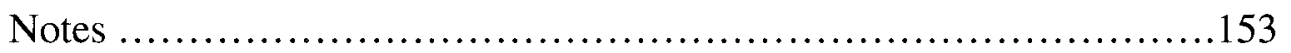

Works Cited and Consulted...................................... 158 


\section{Introduction}

\section{Transgressing Boundaries and Cultural Haunting in Chinese American and Chinese Canadian 'Talk Stories'}

In February 2001, This magazine produced a special feature issue titled, "Yellow Fever: Occidental Tourists, New Slants on Asian Chic, and the Politics of Peril." Here, Ann Shin writes about how Asian stereotypes caused "death by embarrassment" for many Asian school children of her generation (18). She satirizes white North American creations of Asian stereotypes by illustrating how non-Chinese can 'try on' popular "personality types:" those who feel a need for power can be "Dragon Ladies or Fu Manchus" while "submissives can be Geishas or Coolies" (19). Shin also gives examples of how Asian cultural items are ever present in North American consumer culture: Japanese tea sets, Sushi and its accoutrements; Chinese food; Asian art and chinaware; Tamogotchi and Hello Kitty characters; Japanese anime; Chinese silk dresses and embroidered purses. These items are alternately placed in categories of "kitsch," "exotic" or "cool." Even settings such as Chinatown can also be considered 'kitsch.' Shin writes “it's a much more successful franchise than Disneyland. There's one in every city around the globe. Billions served." Though one might believe the age of these harmful stereotypes has passed, Shin reminds readers that "kitsch is the diminutive of foreign. Because it can be considered cute or quirky, it's no longer scary"(19).

Though the feature issue is mainly focused on Chinese and Japanese Canadians, such stereotypes are the residue of a long history of a "politics of peril" shared by many Asian groups. The "yellow peril" was a term first used by white policy makers in Canada and the United States to refer to the perceived social, political or military threat of Asian peoples. 
Due to a long history of state-sanctioned discrimination against Canadians and Americans of Chinese ancestry, it is necessary to examine the history that contextualizes the main themes present in Chinese Canadian and Chinese American literatures. My thesis will investigate how Chinese American Maxine Hong Kingston and Chinese Canadians Wayson Choy and Sky Lee respond to this history of misrepresentation, stereotypes and discrimination, how each writer defines him/herself within and against his/her community and hybrid cultures and, finally, how these identifications manifest themselves in their autobiographical fiction, respectively The Woman Warrior, The Jade Peony and Disappearing Moon Cafe.

My thesis examines cultural, gender and family boundaries of identity in these three works. I begin by exploring how historical forces shaped these works and by identifying similarities and differences between Chinese American and Canadian contexts. Each work features protagonists who are transgressive figures or 'bordercrossers' engaged in acts of narrative revision and memory reconstruction. All three works include the figures of outlaws and ghosts and reflect the theme of 'cultural haunting' which illustrates the need to acknowledge the importance or 'presentness' of the past. Evidencing successes and failures in boundary transgression, the protagonists challenge family and cultural secrets and revise culturally dictated norms of identity formation around gender roles, family, community and history.

Historically, several "pushing" and "pulling" forces were responsible for bringing the majority of Chinese to North America (Chao Beyond Silence 5). The 'pushing' forces were a series of natural disasters, famines and local wars that forced people from southern China to immigrate to North America; the 'pulling' forces were the stories of great fortunes that motivated Chinese peasants to leave for greater economic opportunity seeking the 
"Gold Mountain" (gun shan): "a synonym for the California gold rush, which was extended later to include Canada, [gun shan] suggests hope, prosperity, and stability" (Chao 5). Unfortunately, not all workers would strike gold and many Chinese miners had to take frontier jobs to survive. Another "pulling force" was the active recruitment of Chinese migrant workers for hard manual labour, such as mining and railway construction. Chinese immigrants were wanted as workers but at the same time both the Canadian and U.S. governments made every effort to inhibit settlement and bar them from citizenship by enacting exclusionary laws. In 1852, approximately 20,000 Chinese labourers came to work in the mines of northern California while in the same year the California State Legislature enacted a Miner's tax directed at the Chinese (Western Literature Association 1119). In Canada, the Canadian Pacific Railway (CPR), built between 1880 and 1885, was dependent on Chinese labourers, even going as far as recruiting them from Hong Kong and China. They were low-paid and often assigned the most dangerous tasks (Chao 6). The United States Congress passed its series of exclusion laws against Chinese immigrants from 1882 to 1902 and Canada's national legislature passed its harshest legislation, the Chinese Exclusion Act, on July 1, 1923. In Wayson Choy's The Jade Peony this date is referred to as the "Day of Shame" by Chinese Canadians of that generation. The Act was designed to severely prohibit Chinese immigration for the next twenty-four years. Restricting the entry of women and children, the Act extended the gender imbalance in a community of too many 'bachelor' men. It was not until as late as 1981 that the ratio between men and women in the Chinese community in Canada was leveled (Chao 10-11).

Because of poor working conditions, many Chinese Canadians lost their lives due to accidents and illness. According to community figures, 4,000 workers died while building 
the CPR and were not given the dignity of a proper burial. In 1891, without the aid of the Canadian government, the Chinese Consolidated Benevolent Association of Victoria recruited 'bone-collectors' and "arranged for a collection of more than 300 unidentified corpses from the Fraser and Thompson canyons to be returned to China for a proper burial" (Chao 6). The "search for bones" becomes a recurring literary trope in the works of contemporary Chinese Canadian and Chinese American writers and poets; it is a metaphor for recovering 'forgotten' or lost aspects of the past and for honoring the contributions of community members. It is a collective means of remembering the 'ancestors'. Many Chinese Canadian writers have identified themselves as "activists and archivists" so their "need to re-claim the community history preceded their literary endeavours" (Chao 27).

Chinese American literature has a history that is much longer than Chinese Canadian literature. It is not that America has a longer tradition of a Chinese presence, but that Asian American Studies programs were created to provide writers the necessary resources, critics and readers with exposure to these works. Theorists often dispute when Chinese American literature began and what forms its canon. Some go back as far as to include folk lyrics published in San Francisco's Chinese newspapers in the 1860 s or the early Chinese immigrants carving homesick messages on the walls of the Chinese detention barracks on Angel Island during the first half of the twentieth century. But the Angel Island poems, later published in the collection Island (1980), were not simply lamentations on the loss of home. Sau-Ling Cynthia Wong notes that the "angry and poignant voices of these early Chinese immigrants constitute a powerful counterdiscourse to the myth of America as a nation open to all immigrants" (Cheung 42-43). Shirley Geok-Lin Lim suggests that these writings also reflect the "outrage, humiliation, fear, and feelings of vengeance that these detainees 
harbored" (Cheung 294-5). ${ }^{1}$ The early records contradict any stereotype of the Chinese as 'passive' or 'complacent.' These early immigrant writings also reflect a certain social class and gender; many immigrants were male labourers from Guangdong Province in southern China (Cheung 41).

It is significant to note that the early contributions were folk lyrics based on oral compositions, an important tradition that re-appears in the works of Chinese American writers in the 1970s and 1980s. Chinese American writers such as Maxine Hong Kingston and Amy Tan illustrate the use of "talk story," a form of oral transmission, in their works as a way of passing on stories, legends and histories from mother to daughter (Cheung 42). Based in oral Chinese storytelling traditions, talk story is a vehicle from the past carried through several generations. It is also a tool for imaginatively renegotiating the past and creating new possibilities for the future, as illustrated by the narrator in The Woman Warrior, by Kae in Disappearing Moon Cafe and by Jook-Liang and Sek-Lung in The Jade Peony. Kingston, Choy and Lee make use of this traditional Chinese form of storytelling which has its roots in Chinese secular, oral and colloquial traditions. 'Talk story,' in its use as a noun, is a means of passing time, entertaining and gossiping, but also a method for relaying history (often one of exclusion and great hardship) as well as transmitting warnings. "Talking story," the verb used here in its gerund form, is the actual act of telling. Through this process of oral storytelling many histories, legends, values and traditions are transmitted. Early Chinese American writing forms a body of what Sau-Ling Cynthia Wong terms "anti-Exclusion literature." The first fictional work is a novella titled Kuxuesheng (1960), about a Chinese student who travels to America (Cheung 43). This 1905 work is the earliest example of a theme that persists in contemporary Chinese American literature: the 
experience of living between two cultures, expressed through the metaphor of 'doubleness' (Cheung 44). The struggles inherent in having a double identity are noted by Kingston, Choy and Lee's narrators.

The next phase in Chinese American literature is represented by those writers who struggled to 'translate' or 'interpret' Chinese culture for white readers. One of the first writers of Chinese ancestry to write in English can be claimed by both Canada and the United States since she lived and wrote in both countries. Sui Sin Far (Edith Maude Eaton), a Eurasian writer who composed novels in the early 1900 s is considered by critics to be an 'ambassador of good will' (Cheung 44). Due to the "translating" intent of some early writers, they were considered to be in the role of cultural mediator (Cheung 45).

Writers using their works to explain their culture to a white reading public would carry through to the years of the Second World War, a time often cited as a turning point in the lives of both American and Canadian men and women of Chinese ancestry. It is no coincidence that Wayson Choy chose to base The Jade Peony around this time period. The first major generation of American and Canadian children born of Chinese ancestry were 'coming of age' at this time. There was also new interest in China as North Americans now viewed China as their ally in war. Further, with the Exclusion Act being repealed in 1943, new occupations were opened to Chinese Americans and more women were able to enter both the United States and Canada a trend which corrected the gender imbalances in the Chinese community (Cheung 46). In the post-war years, Chinese American women writers began to express how their experiences were vastly different from those of Chinese American men: 
...the female writer's relationship to American culture is much more vexed than the male's, for, given her subjected position in Chinese patriarchy, the woman's first contacts with Western ways typically had some liberating effects, however the imperialistic or racist aspects of Westernization might play out in the long run...This complex interaction of gender, racial, ethnic, and class politics is at the root of the conflict between feminism and cultural nationalism that was to erupt in the 1970s (Cheung 46-47).

Throughout the history of this literature, there were strong autobiographical elements even in fictional works. It is clear these writers felt the need to express their experiences and daily living conditions. Chinese American works such as Pardee Lowe's Father and Glorious Descendant (1943) and Jade Snow Wong's Fifth Chinese Daughter (1945) made significant contributions to the American autobiographical genre. It is unfortunate that although these works are mentioned in discussions of Chinese American literature, they are often ignored in discussions of autobiographical traditions in the United States. Autobiographical works by ethnic minority writers are often excluded from discussions of ethnic minority autobiographical studies and in analyses of the autobiographical genre. ${ }^{2}$ Jill Ker Conway's When Memory Speaks: Exploring the Art of Autobiography (1998) is a collection of essays that reflects upon three thousand years of autobiographical writings in both Europe and North America. Although she examines several contemporary autobiographies, this work does not include the contributions of any ethnic minority writers, past or present, other than American slave narratives. Conversely, the autobiographical genre is rejected by some Chinese American critics and is "suspect because of its association with the Chinese [Christian missionary]tradition of confession" (Wong 35). Chin sees it as a genre that promotes "admission of guilt, 
submission of myself for judgment" and "“approval by outsiders" (Wong 35). However, scholars have traced the autobiographical genre to Chinese literature. ${ }^{3}$ Further, it can be argued that the genre gives a voice to writers whose texts could be used to counter the stereotypical depictions of Chinese people and Chinese culture. Poet Marilyn Chin acknowledges the interplay of two traditions which infuse her works:

Chinese American writers who draw from two cultural histories must extract from multiple sources. Not only do we serve as cultural translators, we synthesize the form and content of the two great traditions that came before us. The result is a cross-fertilization of culture, creating new models to accurately portray Chinese American identity. No one cultural style can adequately express my experiences. I must sample and draw from East and West, modern and ancient...the autobiographical means to proclaim identity is a reversal of the current postmodern criticism which declares that stylistic innovation is dead. The signifiers are not empty but allude to referents that hold generation and personal meaning because the Chinese American poet must reclaim lost voice, simultaneously debunking and reconstructing the past to reflect her own mirror image. My task is to constantly reinvent my particular history through the truth of my experiences (Sontag 316).

The post-war era again brought changes to North American views on the Chinese; they were cast as 'bad Asians' when the People's Republic of China was established in 1949. The political and social changes that occurred during this period were captured in a new realist tradition that reflected the lives of working-class Chinatown. Due to the civil rights and feminist movements, the 1960s and 1970s saw new interest in works by women and non-Western writers and what can be termed 'literatures of displacement' and 'border-crossing.' The Woman Warrior (1976) is the main introduction American 
readers received to a generation of writers who created works with displacement and border-crossing as common themes.

When The Woman Warrior was published, Chinese American critics like Frank Chin raised heated debates over its genre status: they asked whether it is a work of fiction, autobiography, or fictionalized autobiography. ${ }^{4}$ Though promoted as an autobiography by her publisher, Kingston's text is a hybrid form exhibiting some autobiographical features. Wong sees The Woman Warrior as "at best only nominally autobiographical" and more concerned with accurately depicting the protagonist's inner/psychic realities as opposed to recording the realities of her external life (31-32). Most of what is in Kingston's work is "recollection, speculation, reflection, mediation, imagination" (Wong 32). White readers who read autobiographical works by Chinese American writers in the early 1950s may have used the works to navigate their way through Chinese culture. This is not an accurate way to understand the general features of any culture. In an essay titled "Cultural Mis-Readings by American Reviewers" Kingston herself cautions against readers viewing The Woman Warrior as a testament on Chinese culture or Chinese American culture and by mistaking 'fiction' for 'fact.'

Kingston, Choy and Lee's works all activate conventions of autobiography as they cross between fiction and non-fiction. This genre continues to attract ethnic minority writers; even their novels are cast in the autobiographical mode. A focus on questions of personal, social and family identity is shown to be critical for those who were raised in an immigrant culture. Also, the preservation of cultural memory, honouring ancestral traditions in a new context is considered vital. Marilyn Chin states "I must proclaim my 
identity, because the privileged majority, at best, has always misunderstood who I am and, at worst, wished to wipe me out of my existence. Therefore, I must button down my ethnic pride and assert myself with a clear, loud voice and claim my place on this land" (Sontag 305).

Not all surveys of Chinese American literature make note of Chinese Canadian literary traditions. In one of her surveys of this literature, Wong includes a paragraph which begins "No survey of Chinese American literature would be complete without mentioning Chinese Canadian literature, which is becoming increasingly vibrant and visible" (Cheung 54). Wong mentions contemporary writers such as Evelyn Lau, Sky Lee, Yuen Chung Yip, Bennett Lee, Jim Wong-Chu and Fred Wah. Other critics find it is acceptable to include Chinese Canadian literature under the American term. Of course there is a distinct Chinese Canadian literary tradition that begins before the 1980s and 1990s.

Just as the Chinese in America had the "wooden wall poems" written in the barracks of Angel Island in San Francisco Bay, the Chinese in Canada also wrote "wall poems" about life in exile on the quarantine cells where they were detained after entering Canada (Lee Many-Mouthed Birds 2). Scholarly and conventional, the poems are among the earliest examples of literary expression by the Chinese in Canada. Bennett Lee notes that following these poems are other works produced in Chinese, such as "poems, novels, articles, reminiscences and miscellaneous essays published here and abroad, some by prominent overseas writers who have lived here and others by long-time residents"(2).

Among contemporary writers, Lee notes the following recurring themes among contemporary Chinese Canadian writers, themes which are shared by Chinese American 
writers: questions of identity and questing through the personal and collective past; the recognition of lost culture, language, history, identity and an awareness of duality that comes from living between two or more cultures. Mainstream audiences started to become increasingly aware of Chinese Canadian writings when writers and artists gathered to create anthologies, such as Inalienable Rice (1979) and Many Mouthed Birds (1991), to promote and discuss their works. As Lien Chao states, the anthology form is the best way of reflecting different genres, showcasing new writers and "introducing an emerging literature into the mainstream"(34). For Chao, these anthologies represent an 'epic struggle' and the writer's resistant voices breaking the community's hundred years of silence. ${ }^{5}$ In his introduction to Many-Mouthed Birds: Contemporary Writing by Chinese Canadians, Bennett Lee cites reasons for the absence of "formal literature" by writers of Chinese descent despite the fact that the Chinese began to settle in Canada over one hundred and fifty years ago:

...Chinese Canadians were, for a long time, denied full participation in Canadian society by discriminatory legislation beginning in 1875 with disenfranchisement, then a series of head taxes on Chinese immigrants which escalated from $\$ 50$ to $\$ 500$ per head, and culminating with the exclusionary provisions of the Chinese Immigration Act of 1923 which in effect banned entry to Canada to all but a few Chinese. This legislation was not repealed until after the Second World War. The resulting isolation from the social, political and cultural mainstream of Canadian life spanned nearly a century and forms an important, although sometimes forgotten, part of our history (Lee 1-2).

Sky Lee's Disappearing Moon Cafe is considered to be the first novel about the experiences of Chinese Canadian immigrants (Chao 93). Lee affirms this collectivity as 
she states "most of my work as an artist has been very much community-based" (Silvera 387). Though the writing is community-based, at the same time, writers like Sky Lee realize they are writing against the 'establishment' represented by mainstream literary culture in Canada and traditional literary genres in English. In writing Disappearing Moon Cafe, Lee states, "I was adhering to my own set of standards, and it was like really trying to push literature over a kind of established edge" (Silvera 395). As an artist and "a separatist," Lee explores "cultural alternatives" and thereby does not allow herself to give full allegiance to any one community: "Everybody's coming out with fantastic, inspiring ideas. So that kind of leaves me free as an artist to just fly off on my own tangent, I don't have to worry about being a representative of the community or whatever any more, I'm just like an artist on my own" (Silvera 397).

In the 1950s, writing by the new generation of local-born Chinese Canadians was not a chosen profession and "was tolerated as long as it remained culturally inoffensive...but was otherwise discouraged as a risky and impractical endeavour" (Lee 2). This aspect is especially important in explaining one of the main themes recurring in the post-war generation's literary works: breaking a form of silence and reacting to the exclusionary measures imposed by Canadian society, the local community and family.

Narratives such as those by Kingston, Choy and Lee are involved in two concurrent tasks: speaking against official history by foregrounding alternate versions while also breaking family and cultural secrets. The primary focus of these works seems to be on breaking the wall of silence in their own traditional culture; a focus on all gender taboos, prohibitions, constraints, and hidden experiences is part of this. Sky Lee's Disappearing Moon Cafe is about confronting taboo aspects of culture, in this case incest, and breaking 
silence or voicing what had been forbidden. Both The Woman Warrior and Disappearing Moon Cafe begin with the main character's mother telling a 'forbidden' or secret story at a significant point in the life of a daughter: for Kingston's narrator, it is at the time when she begins to menstruate and for Kae it is when she gives birth to her son.

Characters are engaged in a battle against silence in these works because being voiceless is an oppressive condition; however, silence can also be seen in a positive light since it exists as a necessary prelude to speech. Silence and speech are not always impermeable opposites, but are often interrelated and one can always transform into the other. Silence is often viewed as an absence and being quiet or speaking very little, especially in dominant North American and Western European cultures, is often equated with being weak or unintelligent. There is little acknowledgement of the power inherent in silence as the prelude for coming to voice. In The Woman Warrior the theatrical curtain which opens onto a spectacle of performance is used as a metaphor for coming to voice. Kingston's narrator discusses this power in visual terms (the black curtain) when the narrator does not initially feel the necessity to speak as a young girl at school:

My silence was thickest - total - during the three years that I covered my school paintings with black paint. I painted layers of black over houses and flowers and suns, and when I drew on the blackboard, I put a layer of chalk on top. I was making a stage curtain, and it was the moment before the curtain parted or rose...I spread them out (so black and full of possibilities) and pretended the curtains were swinging open, flying up, one after another, sunlight underneath, mighty operas.

During the first year I spoke to no one at school, did not ask before going to the lavatory, and flunked kindergarten. My sister also said nothing for three years, silent in the playground and silent at lunch. There were other Chinese girls not of our family, but most of them 
got over it sooner than we did. I enjoyed the silence (165-66).

This motif of silence versus speech is commonly found in Chinese Canadian and Chinese American literature. Lien Chao sees it as an important development since "silence versus speech is an interrelated paradigm...it is important for the marginalized to see that silence can be transformed to a voice in the dominant discourse, and so leads to social changes" (22).

It is essential to contextualize any study of the history and main themes of Chinese American and Chinese Canadian literatures within the history of the terms themselves. The usage of "Asian American," "Chinese American," and "Chinese Canadian" is relatively recent. The American terms came as one of the many results of the American civil rights movement in the 1960s (Cheung 2). More so than any other period in American history, this was a time when African Americans and many other ethnic minority groups became more vocal and exhibited pride in their histories and cultures. In interviews, Kingston states that she prefers to use 'Chinese American' as opposed to the hyphenated term: "We ought to leave out the hyphen in 'Chinese American,' because the hyphen gives the word on either side equal weight...Without the hyphen, 'Chinese' is an adjective and 'American' a noun; a Chinese American is a type of American"' (KingKok Cheung 6). ${ }^{6}$ The 'hyphenated-American' implies less than full participation as an American citizen. The desire for Chinese Americans to be recognized as 'Americans' was a common theme of early Chinese American works and as such this need to 'claim America' is an important theme in Kingston's China Men. In this country, the term "Chinese Canadian" was first used by the media after World War II in referring to 
Canadian soldiers of Chinese heritage. Though this formal term was in use, the men were not granted Canadian citizenship rights. Several hundred Chinese Canadian men served in the army and it was mainly because of their contributions that the Exclusion Act was repealed in 1947 (Chao 11-12).

Later use of 'Asian American' or 'Asian Canadian' as umbrella terms cannot hope to encompass all the differences and distinctions represented by them. Today, writers, artists and critics take issue with these terms. In the introduction to Yellow Light: The Flowering of Asian American Arts, Amy Ling asks some very important questions about Asian American artists and their identity:

For some, the term Asian American is in a formative, contested state, with many questions still unresolved. How is an Asian American artist defined - by subject matter? By place of birth? By place of burial? By blood and race, and what percent? By culture? By selfdefinition? By length of time in the United States, and how long? By political intent? Must one's own identity be the subject of one's work? (Of course not.) (7).

Ling realizes that these questions reflect many "contradictions" and "ambiguities:" not one answer really applies for all artists (except the final one about identity and subject matter). In the end, Ling comes to the following conclusion: "I believe that in people, as in nature, the borderland is the place of the richest diversity and the most nurturing creativity. Asian America is a 'borderland,' rich in its variety of permutations of ethnicity, race, and culture and in the paradoxes of multiculturalism, multivocality, and multinationalism"7 (8).

Second-generation immigrant children are born between cultures. In the case of these 
works, many of the protagonists are either Chinese or Canadian/American-born inhabitants with an understanding of the complexities and confusion with regard to boundaries. In The Woman Warrior, Kingston's narrator speaks of the borderland experience of first generation immigrant children and the process of having to distinguish between the 'real' culture and the transported one:

Those of us on the first American generations have had to figure out how the invisible world the emigrants built around our childhoods fit in solid America. The emigrants confused the gods by diverting their curses, misleading them with crooked streets and false names. They must try to confuse their offspring as well, who, I suppose threaten them in similar ways - always trying to get things straight, always trying to name the unspeakable.... How do you separate what is peculiar to childhood, to poverty, insanities, one family, your mother who marked your growing with stories, from what is Chinese? What is Chinese tradition and what is the movies? (The WW 5-6).

The Woman Warrior, The Jade Peony and Disappearing Moon Cafe all have protagonists who are children or who reflect on their childhood as a means of trying to sort out the complexities of forging a new identity in a border-crossing situation, negotiating between old and new cultures. These characters are often in the process of attempting to keep some of the old traditions and/or cultural beliefs while also finding the space to adapt to new possibilities. For instance, clearly all three writers illustrate the idea of the extended family as an important notion which challenges the nuclear family pod and also individualism as the hallmark of actualized adult identity.

The protagonists in these works all seek to delve into family and cultural history to construct a workable bordercrossing identity, and show they understand the necessity and 
interconnectedness of storytelling and memory in forming and maintaining a strong sense of identity. In After Virtue Alasdair MacIntyre states that a human being in both actions and practice is "essentially a story-telling animal."(216). By telling children stories of their culture, they are prepared to enter into their roles in society. Further, the teller's focus is not exclusively on his/her own individual story but on narrative as a collective inheritance. MacIntyre is right to state that the key question one should ask is " Of what story or stories do I find myself a part?'”(216). The narrative concept of selfhood requires two aspects. The first is that a person live out the story of his/her own birth to death as a subject of his/her own history. The second aspect is that the story of one's life is correlative and reflects the tellings of others:

I am part of their story, as they are part of mine. The narrative of any one life is part of an interlocking set of narratives. Moreover this asking for and giving of accounts itself plays an important part in constituting narratives. Asking you what you did and why, saying what I did and why, pondering the differences between your account of what I did and my account of what I did, and vice versa, these are essential constituents of all but the very simplest and barest of narratives. Thus without the accountability of the self those trains of events that constitute all but the simplest and barest of narratives could not occur, and without that same accountability narratives would lack that continuity required to make them and the actions that constitute them intelligible (218).

A beautiful metaphor that joins all three narratives is the act of knot-making. Knots are an enduring symbol in Chinese culture. Like storytelling, the act of knot-making requires the ability to 'weave' together disparate strands (i.e. voices) into a cohesive unit or whole. Knots and the act of creating them can be viewed as a metaphor for the act of storytelling itself. In Maxine Hong Kingston's The Woman Warrior, her narrator likens herself to the 
outlaw knot-makers of ancient China she has heard her mother speak of: "[i]f I had lived in China," Kingston's narrator states, "I would have been an outlaw knot-maker" (163). The knot-maker is an outlaw just as the speaker is engaged in telling what has been forbidden. Jook-Liang's grandmother, Poh-Poh, attempts to teach her granddaughter the ancient art of knot-making in The Jade Peony as the elderly woman reflects on her own past. Sky Lee uses knots as a metaphor for all the intricacies, beauty and complications of storytelling that Kae struggles with in Disappearing Moon Cafe. Her quest is ultimately one of untying the knots of family and community narrative. The knot metaphor suggests the complexity of the intersecting versions of the story that comprise personal, family and communal memory. Recent research on human memory has proven that it does not occur without a cycle of creation-examination-destruction. There is a popular idea of memory as a 'video-recorder' without much interference from the one who experiences the memories, but Nicola King states this notion is "contradicted by recent work on the 'neural networks,' which create and destroy memories in a continuous process" (King 25). This changes the belief that anyone can recover their past in some purified form since the past is constantly being 'rewritten' as one changes through time. This cycle of memory (creation-examination-destructionrecreation) is reflected in Kingston's narrative in terms of the many 'possibilities' inherent in one story:

Whilst it seems that different events are remembered in different ways - some almost immediately represented in narrative, others remaining 'snapshots,' others still remembered only 'in the body' - and that different people remember in different ways - some visually, some in language, very young children differently from adults assumptions about the nature of memory shape not only notions of personal identity but also the relationship of 
culture to its past, and the nature and structure of the narratives that reconstruct the past (King 28).

King demonstrates that "remembering the self" is not a case of restoring an original identity, but a continuous process of 're-membering', of putting together moment by moment, of reconstruction" (175).

Memory is also necessary in not only preserving the past, but in creating alternate, and equally viable, versions of the past. Many ethnic minority groups have used the notion of 'remembrance' and personal memory to transmit history. In From Memory to Transformation: Jewish Women's Voices, Sarah Silberstein Swartz and Margie Wolfe write, "more than any single event in recent Jewish history, the Holocaust illustrates the necessity of remembrance and the value of personal memory in sustaining culture and heritage" (ii). In a recent collection of essays on the nature of time and memory, Umberto Eco comments on memory's revisionist nature but maintains its importance for those who wish to preserve their version(s) of the past:

Without memory there is no survival. If you were dealt a great blow to the head and the areas of the brain which preside over your memory were damaged, you would no longer have an identity. Societies have always relied on memory for the same reasons...Every civilization discovers its identity when a great poet composes its founding myth. And when some act of censorship wipes out a section of a society's memory, it undergoes an identity crisis (David 190).

Especially for Kingston and Choy, writing and memory are connected with 'haunting'-- a visitation or possession of spirits and a connection to the dead. In an interview, Paula Rabinowitz asks Kingston about the connection "between the use of memory and the function of imagination" to which Kingston replies: "[t]he artist's memory winnows out; 
it edits for what is important and significant. Memory, my own memory, shows me what is unforgettable, and helps me get to an essence that will not die and that haunts me until I can put it into a form, which is the writing (my italics, Skenazy 67). She also tells Rabinowitz that "memory is insignificant, except when it haunts you and it is a foundation for the rest of the personality." Wayson Choy too describes being haunted by his memories and views his earliest memories as 'childhood hauntings;' these are the unseen, unspeakable visions that are real to a child but to adults seem only to be a dream. In writing his memoir at the age of sixty, Choy had to consider how he perceives life and memory and so states, "I have had a haunting throughout my life... a persistent memory, therefore, is a haunting" (95). Choy uses the term, 'haunting,' as both noun and adjective: first, it is an enduring moment that connects a high awareness of the present at an intersection of a certain time and place; on another level it is the vision of a 'monster', dismissed by the adults around him as a 'childhood dream.' Kingston uses the same term but uses it as a verb: an action taken or one that takes hold of her when she states that her nameless aunt "haunts [her] as an injustice" (Skenazy 121).

Common to all three narratives are 'hauntings' of ancestral traditions and figures: ancestor worship, personal and communal memory material are interconnected in these works. The protagonists of all three works are 'haunted' by figures and images of family members, legendary cultural figures, the ancestral culture and its norms and traditions. In Kingston's The Woman Warrior, the nameless narrator is haunted by No Name Woman and the woman warrior, Mu Lan; In Choy's The Jade Peony, one of his child protagonists, Sekky, feels his family is haunted by his grandmother, Poh Poh; in Sky Lee's Disappearing Moon Cafe, Kae is haunted by her dead aunt Suzie. The importance 
of family kinship structures were given additional meaning by cultural traditions such as filial piety, the performance of duties which it is believed are naturally owed to parents and relatives. In Chinese Kinship, Paul Chao states the doctrine of filial piety constitutes "not only the nodal element of the Chinese family, but lays the corner-stone of Chinese civilization" (73). In China, filial piety was most clearly espoused by Confucius. In Confucian ethics, cultivating the 'virtues' of filial piety leads to a form of 'universal love' which spreads to other aspects of social and political life. ${ }^{8}$ The rites of ancestor worship in Chinese culture are to serve Heaven and Earth, honour ancestors, and those who had prominent roles in cultural life such as rulers and teachers (Chao 128). These ancestral rites were performed exclusively by men and the continuation of the rituals was important for both political and social reasons. The intention was to "renew and strengthen those sentiments on which the social order and stability lie" (Chao 129). The purpose was to remind living members of the ties that bind them to other members in their kinship line, as well as reinforce duties to "members of the still living, and to those who have died and to those who are not yet born" (Chao 129).

There are many ghosts in the three works and the word 'ghost' itself is multi-layered and has multiple meanings. Ghosts are something every ethnic group has in common: every culture has ghostly figures which appear in its folklore. In both American and British literature, especially works written in the gothic tradition, ghosts serve to illuminate the more shadowy aspects of characters; they serve as a representation of long repressed feelings or vehicles through which secrets can be released. In The Woman Warrior, The Jade Peony and Disappearing Moon Cafe, the inheritance of (his)stories from the past, especially with elements that are left unspoken or ignored, are often 
represented by the 'ghosts' and ghost stories. Kathleen Brogan uses the term "cultural haunting" to describe a common 'story' or theme found in ethnic minority works that is "centrally concerned with issues of communal memory, cultural transmission and group inheritance... [the stories] share the plot device and master metaphor of the ghost as gobetween, an enigmatic transitional figure moving between past and present, death and life, one culture and another" (Brogan 6).

Unlike calling on the ghost of a dead relative for guidance and protection as implied in ancestral worship, a 'haunting' is an involuntary possession - or repossession - of the past. Kingston being 'haunted' by her suicidal aunt is the spark that ignites the rest of the book. According to Brogan, in the first chapter of The Woman Warrior Kingston,

fears a possession that duplicates her aunt's terrible fate. The task she undertakes in her memoir is the transformation of haunting as a deathly possession into a haunting that enlarges self with the selective integration of family history and Chinese legend. Kingston knows that the very ghostliness of her aunt, her erasure from acknowledged family history, gives herself the imaginative room for revision (9).

The ghost is a force which represents the 'presentness' of the past and a narrator's (or character's) struggle with that past. Though there are inherent dangers in challenging a ghost, there is also an implied malleability which "provides the vehicle for both a dangerous possession by and an imaginative liberation from the past" (Brogan 11). For Kingston, the terms 'memoir' and 'ghost' "represent the same thing" (Skenazy 67). The ghosts do not need to be banished or 'exorcised;' as a writer she feels that they need to be named and recorded, for these 'visions,' as Kingston states, are "not concrete" but "they are beautiful, and powerful" (Skenazy 68). In the literature of 'cultural haunting' there 
exists a ritual commemoration of the dead that is tied to strengthening ties within a culture as well as cultural renewal. Brogan states "through the enactment of commemorative rituals, ethnicities are performed...there is an ongoing process of construction or, more precisely, enactment of cultural identity" (Brogan 22) ${ }^{9}$. By conceiving of ethnicity as a process that is not static but ever-changing, there is a rejection of cultural homogeneity. Ghosts become the vehicle through which memory can be explored when group history is not held securely in personal memory (Brogan 23).

Because they live between worlds, ghosts are consummate borderfigures. My thesis will investigate the ways in which protagonists, second generation children and other transitional, mediating figures pulled between cultures are inevitably bordercrossers. One finds protagonists and other key figures who are either inspired by and/or fearful of, other bordercrossing figures, such as ghosts, outlaws, warrior women, and sexually transgressive figures. Women especially are placed in the position of being 'borderfigures' since they are doubly marginalized. All three narratives explore notions of gender/sexual identity issues. In The Jade Peony the world of the grandmother, Poh Poh, is honoured. Her granddaughter Jook-Liang resists negative gender attitudes by looking at the example and character of Poh Poh, much like Kingston's narrator with her powerful mother and the Warrior Woman. All three child protagonists in Choy's work are associated with Poh Poh in different ways.

Borderfigures grow out of (or into) some type of borderland. Restrictive legislation was enacted to force Chinese Canadians into the most remote and poorest city areas: marginalized from mainstream society, Chinese Canadians were relegated to ghetto 
communities. Chinatowns were always in the poorest parts of Canadian cities, in close contact with prostitutes and drug addicts (Heer 21).

All three narratives contain examples of what Huntley describes as a "third space," or "location of cultural hybridity." The 'third space' is a border country where diasporic communities, minority cultures, and immigrants locate identities and a space for these to survive. For Huntley, these "border inhabitants" are "generally the younger members of immigrant families and diasporic communities, as well as members of Native American groups who are also border inhabitants, straddle two cultures, often speak two languages, two distinct varieties of English, and are frequently called upon to translate one culture into and for another"(72). Though shaped by the dominant culture, children of immigrants are often forced to negotiate between cultures, and in this way often have 'double identities:' it follows that those living at the intersection between cultures may become confused or oblivious to the nuances of the culture and so they too become a type of 'ghost.' Paradoxically, by reconstructing something that is considered part of the 'unseen' world, various narrators in each of these three works can construct their identities. Since the narrators live in two cultures, they use revisionist strategies to negotiate their way through boundaries that must be transgressed and then transformed. All three challenge notions of race and gender that are inherited from the old culture and/or imposed by the new.

In Chapter One of my thesis, I will explore the relationships between Kingston's narrator and three generations of women and noted figures from Chinese legend in The Woman Warrior. As the narrator re-tells the stories of the women who influence her life, she illustrates how the formation of an identity comes from an interplay of many voices, 
not the sole focus on the solitary 'I'. Central to the re-telling of these stories is the use of an inherited Chinese oral storytelling tradition. Through restructuring stories and the 'intrusion' of other voices into the narrative, memory and identity are shown not to be fixed, but fluid and in a process of change. Kingston also uses the ghost metaphor to reflect the complexity of memory and the process of preserving and recreating cultural inheritance and identity.

In Chapter Two, I will examine how three child protagonists define their family and environment during the war years in Vancouver in Wayson Choy's The Jade Peony. Choy's protagonists are all empowered through the relationships they have with women and the connections to a female world. All children are marginalized because they belong to a specific gender, age group or have a different sexual orientation. By allowing each child to tell the story of his/her life, Choy empowers each and illustrates interdependent identities and the process of their formation through the stories, symbolic objects and memories of others.

In Chapter Three, I will focus on Sky Lee's Disappearing Moon Cafe and the narrator's quest to uncover the truths behind four generations of her family's history. Lee's main character/narrator, Kae Ying Woo is obsessed with disentangling the past and ultimately finding what lies beneath the surface of her family stories. Through her detective-style of writing, Kae and the reader are positioned as detectives unravelling the clues to the secrets of the past. Kae's family history is also defined by the intrusion of other voices and stories interspersed throughout the narrative which rapidly shifts from 1892 to 1986 . Lee's work exposes how official anti-Asian immigration policies in 
Canada forever altered the lives of many men and women in the Chinese Canadian community. Lee outlines how these limitations compounded traditional Chinese patriarchal edicts and collectively imposed silences that impeded women's freedoms. 


\section{Chapter One}

\section{'Ghosts have no memory anyway': Ghosts, Warriors and Outlaws in Maxine Hong Kingston's The Woman Warrior}

Unlike Wayson Choy's The Jade Peony and Sky Lee's Disappearing Moon Cafe which are both fictional autobiographies, Maxine Hong Kingston's The Woman Warrior: Memoirs of a Girlhood Among Ghosts (1975) has been commonly classified as a nonfiction 'autobiography' or 'memoir.' 10 Still, it is a work that defies being neatly placed under any one literary term. Owing to the fact that The Woman Warrior is not a straightforward, linear narrative written in one voice, it is a work that has been "highly contested in Asian American literary circles" (Huntley 59) since its earliest publication. The Woman Warrior explores the lives of female characters drawn from legends, myths and stories, and from three generations of Kingston's heritage: her mother, aunts and grandmothers. Through the process of retelling their lives, the writer makes an implicit claim for the validity of other voices co-existing within, and prior to, the formation of the "I" at the centre of autobiographical narrative. In most autobiographical narratives, readers would expect to find a single voice speaking in the first person. This is not the case in The Woman Warrior. The narrator begins in the first person for most of the five sections, but tells some stories using other voices. For example, the first chapter uses direct narration by Brave Orchid, the narrator's mother, with minimal framing by the daughter. The narrator/protagonist/daughter does not look directly to herself in order to begin her quest or search for an identity; she adopts or 'tries on' the identities of five other women, some of whom are real and some mythical. In doing so the narrator reveals 
how one's identity is ultimately composed of intersecting points between oneself, other people and their stories.

Both the content, form and rhythm of the language in this work reflects the importance of oral storytelling, or 'talk story,'(19) as a means of affirming alternative interpretations to dominant narratives. Kingston not only takes possession of family history through this process of telling; it is also a means by which various Chinese myths and legends which have come to her through her mother are transformed (or rewritten) to suit American 'realities.' The work's narrative style reflects the complexity of memory in its process of preserving and recreating cultural inheritance and identity. Memory is shown not as a fixed entity but an active and on-going process of reconstruction. Kingston's re-telling and reinterpreting of the past is a means of repossession and empowerment, which comes partly from myth-adaptation. This process demonstrates that one's identity should not be defined by predetermined notions of culture or gender; instead, one should be active in the redefinition of both.

Through The Woman Warrior, Kingston also expands the notion of private memory to forge a notion of memory as collective. She does this through her recreation of the lives of various characters' whose stories (and telling of stories) often overlap as well as through the ghosts they embody and/or carry with them. Ghosts are bordercrossers between past and present and thus the facilitators of memory and identity. Through her narrative, Kingston demonstrates that storytelling, identity, and memory are tied to a collective inheritance. As Thomas Butler states, "[m]emory is not only what we personally experience, refine and retain (our 'core'), but also what we inherit from preceding generations, and pass on to the next" (13). 
Along with the work's narrative style, Kingston also uses the ghost metaphor to reflect the complexity of memory in its process of preserving and recreating cultural inheritance and identity. Ghosts cannot exist without stories about them and the continuity of the ghosts comes through the inherited stories. On one level, ghost stories in The Woman Warrior service everyday practicalities. The narrator states that "when the thermometer in our laundry reached one hundred and eleven degrees on summer afternoons, either my mother or my father would say it was time to tell another ghost story so that we could get some good chills up our backs"(87). Inevitably the ghost story takes place in China and involves this or that aunt, uncle or villager. On a much deeper level, ghosts are creations of the human imagination and act as 'midwives' in helping to define and retrieve a lost past. In this sense, ghosts are also associated with women. It is the ghosts of Chinese women such as No-Name Woman, Fa Mu Lan, Moon Orchid and Ts'ai Yen whose stories alternately horrify, enthrall and amuse, but ultimately give guidance and serve as a source of strength for the narrator. Part of recovering the past, and reinforcing the 'unheard and the unseen,' is an acknowledgement of the presence of ghosts; whether they are a real or imaginary or figurative presence makes little difference. Ghosts as the 'unseen' have long been associated with women in Chinese culture. In Shen Fu's Six Records of a Floating Life, a popular Chinese autobiography written in the latter part of the eighteenth century, the translator's note states that an "overconcentration" of 'yin' (the female principle) in a woman can result in "a propensity to see ghosts" (152). Kathleen Brogan suggests that the ghost metaphor is also a way to conceive of women's roles as 'bearers' of a given culture: 
Because female bodies are often the site of struggle for control of lineage, the shift from metaphors of blood descent to ghostly inheritances reframes cultural transmission in ways that women especially are likely to see as liberating...haunting in women's texts tends to attach to reproductive issues: the ghosts often arise from traumatic memories of rape, abortion, or miscarriage; possessed bodies are described as pregnant, or ghosts themselves may appear as pregnant; the conjuring of ghosts is sometimes represented as a form of child labor (Brogan 25).

When Brave Orchid confronts the Sitting Ghost in the dormitory of the medical school, the narrator states "she breathed shallowly, panting as in childbirth, and could not shout out" (69). No-Name Woman (the narrator's aunt), just after giving birth, becomes a ghost and her story is told to the narrator when she reaches puberty. The ghosts for which Kingston constructs a memorial through the text are not white Americans, but suicides and female babies left to die in China. In her work on gender and representation, Jean Franco writes that "death and the commemoration of the dead are central to the hero myth, for the uncommemorated are by definition unhonoured and therefore written out of the historical record. Those novelists who wish to mark their distance from official history do so by remembering the unsung dead" (129). ${ }^{11}$

There are five female characters in The Woman Warrior whose stories the narrator hears and then imaginatively transforms: the No-Name Woman (the narrator's aunt), Brave Orchid (the narrator's mother), Moon Orchid (another aunt, Brave Orchid's sister), Fa Mu Lan (a Warrior Woman from Chinese legend) and T'sai Yen (a renowned Chinese poet). Each in her own way is a woman warrior, a larger than life figure contrasted with lesser outsider figures (such as lost madwomen) who appear as more dismal alternatives. In China, there is a history of women masquerading as men and entering into battle: Fa 
$\mathrm{Mu}$ Lan is neither the first nor the only warrior woman. There is a tradition of swordswomen and practitioners of martial arts. ${ }^{12}$ Though the women do not necessarily 'make war' upon others, as in the traditional definition of a warrior, they do become experienced in fighting daily life battles and distinguish themselves in their own ways. It is clear that Brave Orchid, the narrator's mother, is a warrior woman who has a strong fighting spirit. Although Brave Orchid is a central character, the narrative does not idealize the mother-daughter relationship but instead reflects some of the anger and tensions inherent in that relationship. As well, this relationship is not the only focus since there is a larger interconnected web of women both inside and outside the family who also inform and transform the narrator. By underscoring the importance of relationships with those outside the traditional western family nucleus, The Woman Warrior foregrounds collectivity, a broader notion of what constitutes family and community, as a source of inspiration and strength. As she retells the women's stories and myths, the narrator develops a voice and agency that culminates in the transformative image of the exiled Chinese poet, Ts'ai Yen, who used words and music to "match" the sounds of a lethal weapon of war (the nock-whistle) and in this way harmonized opposing forces. Within Kingston's narrative, there are women who either create their own roles or have their function and identity ascribed to them by the men and women within their culture, or by society as a whole. Through all these women, Kingston tests different perspectives by 'trying on' various identities and personas. In this way, she is able to explore the various roles made available to women, but also to foreground other possibilities. Kingston asserts that those characters who survive, and are thereby perceived as heroic, 
are also those who are able to claim the freedom to create themselves through personal action and by way of the stories they tell. The stories presented by Kingston uncover how "the identities of the powerless are defined in such a way as to reflect the needs of the powerful...she retells them so that those who have been entirely defined by the needs of others are granted a rich, complex subjectivity" (Simmons 51).

Although the focus for this chapter will be The Woman Warrior, one should note that Kingston's intention was for The Woman Warrior to be read as a companion text to her second work, China Men (1976). Each text represents one side of the author's ancestral and immediate relations: the women who stayed in China and those who immigrated to America to meet husbands; the latter text representing the men as 'sojourners' to 'Gold Mountain' and their process of becoming American citizens. In the narrator's quest for understanding her present, telling the stories of her parents and extended relations is the only way to understand and create her identity. Kingston chose to creatively record these experiences in two separate texts because in reality the men and the women often had separate and fundamentally different experiences due to Chinese cultural traditions and American legal constraints, laws that limited Chinese immigration and prohibited Chinese women from immigrating with their husbands. Essentially, it seems that one text has been written to know and understand the mother; the other to know and understand the father. As Suzanne Juhasz notes, "taken together both China Men and The Woman Warrior compose a woman's autobiography, describing a self formed at the source of gender experience" (174). In China Men the narrator asks herself "what was it like to be my father or my grandfather or a sojourner?' In The Woman Warrior the narrator asks 'what was it like to be my mother or my aunt or Fa Mu Lan?' Although there are 
similarities between the two texts, the methods of 'telling' are fundamentally different since there are distinct psychological and linguistic differences between the ways in which a daughter relates to her father and to her mother (Juhasz 173).

In order to minimize confusion in discussions of the narrative voice in this work, most critics make the distinction between Kingston as writer and the narrative persona, and in so doing name the narrator 'Maxine.' This is an arguable practice; such an act of blurring the line between writer and narrative persona calls attention to the debatable distinctions between fiction and non-fiction, as well as the boundary between reader and writer within what Lejeune termed the autobiographical 'pact' that occurs in autobiography and memoir. Kingston herself views the writer and her personas, the child and adult narrators, as distinctly different and emphasizes the fact that her narrator remains nameless throughout the text. In response to a question an interviewer asks about the importance of names and naming, Kingston replies:

[N]aming the self is also very important. In many cultures, including Chinese culture, throughout your life you give yourself new names. You recognize new powers in yourself. You're a new person. You recognize that and you honor it by giving yourself a new name. I think that self-definition is very important. Did you notice that the narrator of The Woman Warrior doesn't have a name? Her name isn't Maxine; that's my name. I see this as a literary text that's very separate from myself. Throughout, nobody calls her anything. The point is that she is still in search of her name, she's still trying to find her powers, she's still trying to find out who she is. And by the time I got to the end of the book, I still didn't feel that I wanted to put a name to her. There would be more quests and struggles to go through (Skenazy 133). 
Nowhere in the narrative does the narrator refer to herself as Maxine; nor do other characters ever address her by her first name. She is a voice in search of an identity, but remains nameless throughout the text, much like the nameless aunt whose story appears in The Woman Warrior's opening chapter. This process of seeking a name for oneself can arise out of the pressure of external necessity or a self-imposed need. Joan Chiung-huei Chang notes that many Chinese Americans changed their names for two reasons: due to racist legal restrictions they needed to change their names in order to use a faked certificate with someone else's name in order to enter America and a Chinese name was changed to a more Anglo-sounding or Christianized name in hopes of assimilating more easily into American society (75). In this sense, one cannot depend on a name as a steady and certain aspect of identity. Still, not all immigrants change their names to assimilate into a new culture. In The Woman Warrior the narrator states that Brave Orchid, even upon entering her profession as a doctor, did not change her name and "[e]ven when she emigrated, my mother kept Brave Orchid, adding no American name nor holding one in reserve for American emergencies" (77). Though the name has its own inherent contradictions, 'brave' suggesting strength modifying a most delicate flower, it does not seem to cause any rupture in Brave Orchid's self-assuredness. Brave Orchid's daughter, however, remains nameless throughout the book and this better corresponds to her ability to fade into the background and move the stories of others into the foreground. Much like the anonymous storyteller or poet in the oral tradition, the teller "recites a poem but then 'disappears' when the recitation is over" (Slowik 249).

As in other Chinese American autobiographical works, critics suggest that there exists an aspect of 'fictiveness' in the nameless narrative voice of The Woman Warrior: 
"the autobiography may be fictive because it narrates the life of a persona who hides or disguises [or has lost or is confused about] her original identity and history" (Chang 75). This dilemma of being named or naming oneself is necessarily part of the narrator's struggle to sort out the difference between was is 'real' and what is 'made-up,' to "figure out how the invisible world the emigrants built around our childhoods fits in solid America" (5). The narrator, in representing the experiences of an American of Chinese ancestry, views the differences between America and China as a clear delineation of the differences between what is 'real' (represented by America) and what is imaginary or mythical (represented by China). This dilemma is addressed in the first few pages of Kingston's text where her narrator states, "Chinese-Americans, when you try to understand what things in you are Chinese, how do you separate what is peculiar to childhood, to poverty, insanities, one family, your mother who marked your growing up with stories from what is Chinese? What is Chinese tradition and what is the movies?" (5-6). Here the narrator directly addresses Chinese Americans, asking them to consider this aspect of their identities just after she states, "The Chinese I know hide their names; sojourners take new names when their lives change and guard their real names with silence" (5). As Chang states,

The Woman Warrior exposes a social reason for the fictiveness in autobiography, explaining why the depiction of a life lived in imaginary circumstances is as important as that of a life lived in actual circumstances...Her accommodating the fictive into her autobiography is in fact an effort to legitimize the reality of the unseen and the unheard ${ }^{13}(73-4)$. 
The 'unseen and the unheard' encapsulate those, such as 'invisible' ethnic minority men and women, in this case Chinese Americans, who are not recognized or whose contributions and stories are not given legitimacy in mainstream American culture. The 'unseen and unheard' are also the cultural secrets within families and communities that enforce silence and secrecy as an unwritten code of behaviour or as a norm.

In working to retell suppressed stories, Kingston was able to find a narrative strategy that allows her to tell many people's stories and that represents both sides of her Chinese and American cultural heritage. In his book of essays titled Imaginary Homelands, Salman Rushdie writes that finding the right technique for the telling of stories is also true for other American ethnic minority writers such as Maya Angelou, Louise Meriwether and Toni Morrison. Rushdie states, "if you want to tell the untold stories, if you want to give voice to the voiceless, you've got to find a language" (115). One of the ways Kingston is able to create events in both the actual and imagined lives of the various characters in her work is by drawing from the languages and dialects she heard as she was growing up. Kingston tried to remain true to the natural rhythms of her characters' patterns of speech. In a 1980 New York Times Book Review article she states that as a writer she is "specifically interested in how the Chinese American dialect is spoken in the California Valley...when I write dialogue for people who are speaking Chinese, I say the words to myself in Chinese and then write them in English, hoping to capture some of the sounds and rhythms and power of Say Up [a dialect of Cantonese]" (Pfaff 26). Kingston is known as the first Chinese American writer to make use of the traditional Chinese form of storytelling from the oral tradition called "talk story." She considers talk-story "to be a singularly appropriate vehicle for reimagining the past, as well as rejuvenating - and thus preserving for a new generation 
- a community's or culture's most significant narrative" (Huntley 66). There are many forms a story can take in the oral tradition: allegory, parable, legend, folktale, anecdote, myth, fable, and fairy tale, even poetry, songs, ballads, proverbs and magic chants. In an essay by Walter J. Ong entitled "Oral Culture and the Literate Mind," Ong writes that the oral mind works by proverbs, "casting its knowledge by sayings" (Fisher 135). Even while Kingston's narrator is still a young girl, she observes that "[w]henever she had to warn us about life, my mother told stories that ran like this one [of the nameless aunt] a story to grow up on. She tested our strength to establish realities" (5). Yet the oral tradition is not idealized by Kingston. Through oral sayings the narrator learns the many proverbs that enforce a fear and hatred of the female: "girls are maggots in the rice," and "it is more profitable to raise geese than daughters"(43). As in many patriarchal cultures, oral stories and proverbial sayings reinforce male privilege and reflect a fear of women. Another traditional Chinese proverb, not in Kingston's text, states "If a son is born, you hope he will be a wolf, and fear he will be a worm. If a daughter, one hopes for a mouse and fears she will become a tiger" (Clements 221).

Ong notes that "many if not most of the minority cultures in the United States are decidedly oral; for example, our Black culture, our Chicano culture and our American Indian culture...[a]lso, many of the early European immigrants coming to the country had a distinctly oral heritage (Fisher 134). Curiously, Ong, does not mention an Asian heritage of oral stories. One can see why this form was popular with early immigrant groups since the oral form of telling breaks the silence in a very different way than the act of writing. Because what is spoken is seldom fixed or static, each teller is given the freedom to reshape the story. Kingston's work illustrates how "talk story" functions as oral history in capturing 
the pleasure of telling what the written word often ignores: tales of rebellion and reparation such as the stories of outlaws, rebels and folk heroes which are passed from one generation to the next. The anonymity the oral tradition affords the teller allows the 'trying on' of various identities. Kingston's narrator claims to have learned the story of Fa Mu Lan, the woman warrior, through a chant sung to her by her mother in childhood:

At last I saw that I too had been in the presence of great power, my mother talking-story. After I grew up, I heard the chant of $\mathrm{Fa} \mathrm{Mu} \mathrm{Lan,} \mathrm{the} \mathrm{girl} \mathrm{who} \mathrm{took} \mathrm{her} \mathrm{father's}$ place in battle. Instantly I remembered that as a child I had followed my mother about the house, the two of us singing about how $\mathrm{Fa} \mathrm{Mu}$ Lan fought gloriously and returned alive from war to settle in the village. I had forgotten this chant that was once mine, given me by my mother, who may not have known its power to remind. She said I would grow up a wife and slave, but she taught me the song of the warrior woman, Fa Mu Lan. I would have to grow up a warrior woman (19-20).

Through The Woman Warrior, Kingston is able to demonstrate the actuality of 'talking story" by the "cumulative and individual re-creations of a story over time" (Winsboro 206). Kingston says "I take the old myths and play with them, show how the myths change. And when they change here in America they become American myths" (Skenazy 131). In the rewriting of these myths there is continuity: "[w]hat we learn from people who take intertextuality for granted is that stories constitute generational as well as literary continuity" (Slowik 249). ${ }^{14}$

Although both Kingston's The Woman Warrior and China Men rely on many of the forms that come from the Chinese oral tradition, The Woman Warrior also shows that the oral stories are a form of female expression, asserting the importance of a female storyteller 
and her role as transmitter of culture. ${ }^{15}$ In other words, women always emerge as the central storytellers. Vivian Hsu writes,

Chinese tradition grants men the all important role of carrying on the family line, but it is in fact the women who hold the families together, as if the men provide the form for heritage, but it is the women who provide the substance (Hsu 439).

Storytelling binds the family through time and ensures that stories will be remembered and used as a way to commemorate others. Through storytelling a "[1]ineage is established through rivers of words; the oral transmission of group history and lore itself creates the group, rather than being merely its byproduct. Families do not simply tell stories; stories create families" (Brogan 18). The "talk story" technique of transmitting stories in Chinese culture is used by Kingston to its fullest potential in the The Woman Warrior. This is the tradition that Kingston inherits from her mother, Brave Orchid. The narrative style of the book reflects the narrator's own process of receiving these stories: non-chronological, often contradictory and repetitive. As a writer Kingston is able to transform the oral stories and make them suit her own experiences and sense of space, as well as her readings of Western genres. Whereas the written words of the past may have remained static and fixed to her, paradoxically Kingston is recording them in a form of writing that reflects elements of the oral tradition. She plays with various versions and different possibilities for each myth and story. By doing so Kingston suggests these myths should be constantly changing, reworked by each new receiver. Here, the reader, like the listener, can become the co-creator of the text. 
Kingston's task as storyteller includes both the function of gap-filler and that of creator. She must fill gaps that her past leaves necessarily open because of shame or lost details. This is reinforced right at the start of the book by Brave Orchid's telling of the "no-name aunt" story. It is intended as a cautionary tale told to the young narrator as a warning against female transgression; the aunt did not act within the bounds of what was considered appropriate behavior for a woman: while waiting for her husband to return from America she became pregnant and was punished. This illustrates that oral storytelling may not be exclusively a catalyst for female liberation, but a hindrance as well because of its role in reinforcing accepted cultural norms:

Oral culture, which on one level transmits an unquestioning acceptance of women's subservience, is anything but idealized here...Kingston's motive in telling the story of the aunt, 'No Name Woman', is indeed to violate the paternal/community injunctions to silence, and beyond that, to destroy their power and authority. She not only breaks the silence but also transforms the oral story into writing and by this act denies the power of the community that maintains its cohesiveness through the oral tradition. A story that is oppressive when orally transmitted within the context of family and community is liberating when transformed into writing (Rabine 483).

The overall form of the text, the order in which Kingston's characters appear in the book, is a reflection of a Chinese method of memorialising the dead. ${ }^{16}$ This first chapter, perhaps even the entire book, is set up as a testament to the narrator's dead aunt. The aunt's story, a tale of adultery, suicide and infanticide, sets the book off to an ominous, albeit intriguing, start. Kingston has stated that she had some initial misgivings about 
beginning the book with such a 'dark' chapter. In an interview with Paul Skenazy she states,

When I wrote The Woman Warrior, I thought that the first chapter is dark, and the second chapter is happier, like sunlight. And I thought why not do the bright, happy, high chapter first, because it will bring everybody in and then I can hit them with the hard stuff later! But then I thought, 'No, no, no, that's not the way I lived it.' That's not the way I am, not the way my life is. And so I decided I would lead off with this very difficult story, and people will just have to work through it...I also saw it as like the way creation works, you know, first there was the darkness and the next day God did the light (119-120).

"White Tigers," the chapter which follows the aunt's story, retells the story of Fa Mu Lan, the Woman Warrior. Kingston terms the "White Tigers" chapter 'light' as it is an offering of relief for her reader after the darkness and difficulty of the first chapter. In Chinese tradition the dragon and tiger are token animals also associated with the dead and are often depicted on tombs. VanSpanckeren states that tigers are associated with the yin element and "eat evil spirits who could harm the dead" (46). The reader must pass through the "White Tigers" section and all subsequent chapters along with the aunt's ghost, who is all the while under the protective power represented by the tiger: "the white tigers protect the No Name Aunt within the landscape of the book. The first chapter is a marked grave; entrance to it, via understanding, is effected only by passing the white tigers as one reads the book" (VanSpanckeren 47).

With this first chapter, the narrator is not only crossing the boundary between life and death, but she also transgresses an unwritten Chinese social code regarding the dead for she claims her writing is an offering to the dead aunt. Historically, "[I]n the Chinese social 
system only male descendants could perform the ceremony of ancestor worship" (Chung 140). The narrator gives a 'voice' to her aunt, and refers to her work as an 'origamied' tribute to her aunt, a recognition of the aunt's personality and presence in the family line. Without any remembrance ceremony or offerings, the narrator worries that her aunt will forever remain a 'hungry ghost' and "would have to beg food from other ghosts, snatch and steal it from those whose living descendants give them gifts" (16). The narrator states, "I alone devote pages of paper to her, though not origamied into houses and clothes" (16). Still, the narrator has a dubious connection to her aunt, and there is some morbidity which surrounds the dead aunt's tale. The aunt as a character remains an enigma and the narrator is left with an unfinished story because of all the ambiguities inherent in her aunt's place within the family. Since she is an unsure presence, the aunt escapes to wander in the background of the text in the sense that she haunts the narrator's (and perhaps the reader's) mind. This may be because the reader is left with several versions of the aunt's story, which then concludes with the image of the voiceless ghost. This "haunting silence," King-Kok Cheung writes, is "precisely what gives wings to the niece's imagination, allowing the narrator to test her own power to talk story and to play with different identities. Not the aunt's but the narrator's subjectivity is unfurled" (Cheung 85). The narrator must feed the aunt's spirit in the hopes that it will give her "ancestral help." Though the narrator looks to her aunt for help, she also realises that the act of paying tribute to her aunt is not without repercussions as she states, "I do not think she always means me well"(16). Yet this act of "telling on her [the aunt]," as she states it in an almost child-like tone, is liberating.

The narrator/daughter's mother uncovers a family secret by telling her daughter the story of her aunt. It is a cautionary tale and is told in a most matter-of-fact way by the 
mother, Brave Orchid, who leaves out details and grants little or no sympathy to the aunt. The narrator decides to fill in the gaps of what she is not told; she explores varied reasons for the aunt's fate, giving her a personality and the subjectivity the mother's version denied the aunt. The narrator introduces the possibility that her aunt may have been a sexual rebel although this cannot be entirely confirmed. As the narrator begins to construct the various possibilities for this persona, the aunt is transformed by the narrator's imagination into a character who consciously chooses to stand out. This is demonstrated by the way in which the narrator imagines the aunt's careful attention to her appearance. Kingston writes: "On a farm near the sea, a woman who tended her appearance reaped a reputation for eccentricity. All the married women blunt-cut their hair in flaps about their ears or pulled it back in tight buns. No nonsense" (9). Hair, as an almost universal symbol of female sexuality, is what the narrator first focuses on when imagining her aunt. Although in the narrator's version of this story the aunt follows the culturally prescribed ideal of beauty in a "smooth brow", she does not come across as a typical "slave to fashion:"

At the mirror my aunt combed individuality into her bob. A bun could have been contrived to escape into black streamers blowing in the wind or quiet wisps around her face, but only the older women in our picture album wear buns (9).

The reader is also informed that "[e]ven as her hair lured her imminent lover, many other men looked at her" (10). As the narrator invents her aunt's story, there are moments when she compares her aunt to herself and to her mother. The narrator states:

I have not been able to stop my mother's screams in public libraries or over telephones. Walking erect (knees straight, toes pointed forward, not pigeon-toed, which is 
Chinese feminine) and speaking in an audible voice, I have tried to turn myself American feminine. Chinese communication was loud, public. Only sick people had to whisper... Children and lovers have no singularity here, but my aunt used a secret voice, a separate attentiveness (11).

Although the aunt is granted this individuality by the narrator, she is still not named; neither is her lover, or her baby. ${ }^{17}$ The aunt is punished for her 'transgression': the villagers raid the family home (a raid perhaps organized by her lover/rapist) all the while scolding with words like "pig" and "ghost" as the narrator's mother states "they ruined our house" (5). The aunt gives birth in a pigsty, then drowns herself and her newborn baby in the village well the next morning. In her own way, the aunt exacts revenge upon the village by 'polluting' its drinking water with her death. The narrator calls her aunt's death a "spite suicide"(16) as she 'contaminates' the water with her body and her baby, the representation of her transgression against the social norms of her community. Water is an important life-line in an isolated village and for this reason the aunt's death is a doubly-potent form of revenge against the ancestral village when she and her baby are found "plugging up the family well"(5). At the chapter's conclusion, the narrator remains unsure of where to place her aunt as she states "I am telling on her...drowning herself in the drinking water. The Chinese are always frightened of the drowned one, whose weeping ghost, wet hair hanging and skin bloated, waits silently by the water to pull down a substitute"(16). The narrator is being 'haunted' by her aunt and this is the spark that ignites the rest of the book. She is the first identity the narrator plays with as she identifies with the aunt's rebel nature and her transgressing ancestral village norms: "In the village structure, spirits shimmered among the live creatures, balanced and held in 
equilibrium by time and land. But one human being flaring up into violence could open up a black hole, a maelstrom that pulled in the sky...[t]he villagers punished her for acting as if she could have a private life, secret and apart from them" (12-3). Though the narrator looks to her aunt for some guidance as a woman who is strong and rebellious, the narrator is also unsure of where to place her aunt. She wonders if the aunt is a 'demon' (malicious) spirit who means to harm or a helpful guiding one. 'Pulling down' another woman can also be seen as an act of spirit possession. In this first chapter, the narrator "fears a possession that duplicates her aunt's terrible fate. The task she undertakes in her memoir is the transformation of haunting as a deathly possession into a haunting that enlarges the self with the selective integration of family history and Chinese legend. [The narrator] knows that the very ghostliness of her aunt, her erasure from acknowledged family history gives herself the imaginative room for revision" (Brogan 9). By being erased from family history, the aunt is silenced first by her community and then by her family: speech, storytelling, words can destroy and are powerful but the opposite, silence, is no place to retreat for comfort. The Woman Warrior undertakes a re-negotiation of speech and silence, without privileging one over the other, as speech often is privileged. Silence too can be potent and full of awesome potential: "silence before speech is a necessary and powerful interlude, a moment of infinite potentiality" (Winsboro 162). The narrator's nameless aunt remains a silent and mysterious figure and she is not the only ghost that haunts The Woman Warrior.

The many ghosts and ghostly images that haunt this text have multiple meanings and uses. Various types of ghosts in The Woman Warrior include ancestral spirits who require offerings, non-human spirits and ghosts, and "living ghosts" including the non-Chinese 
ones that surround the narrator's family (Hobo Ghosts, Police Ghosts, Meter Reader Ghosts, Social Worker Ghosts, etc.). The "living ghosts" include those born between cultures, unsure of what constitutes 'home' and belonging. 'Ghost' is not simply the Chinese term for non-Chinese; it can also represent anything that is unknown or not easily explained. The Chinese word for 'ghost' is 'kuei' and it has many connotations in Chinese, all of which depend on the context in which the word is spoken. In the final section of the book, when the narrator's mother is frustrated with her daughter's boisterous behaviour she shouts, "Get out, you Ho Chi Kuei. Get out. I knew you were going to turn out bad. Ho Chi Kuei"” (204). ${ }^{18}$

Ghosts, being ambiguous and vaporous, possess the ability to float between boundaries. By taking on the identity of a ghost, the (nameless) narrator can transgress boundaries, such as gender and race restrictions. At first, Kingston's narrator views the ghost label as having an entirely negative connotation, until she begins to see that embracing this disguise too can lead to overcoming or breaking through boundaries. She struggles with the many boundaries set before her: there are those between America and China; between herself and her mother; between the dead and the living; between the imagined and the real and between patriarchal norms of gender and her self-determined experience. In order to overcome these boundaries, the narrator conceives of them (and even herself) as ghosts: projections that are absent and yet also somehow real and very present. In this way "by locating a voice and identity that transcend the potential barrier, a common language that speaks to the inhabitants of both worlds, Kingston overcomes the power of boundaries - or of ghosts - to circumscribe or control her development as an individual" (Winsboro 155). 
Kingston's use of ghosts and her narrator's struggle with various ghostly personalities also reflects the process the immigrant often faces in terms of constructing an ongoing reality by living with the memories of his/her homeland. In order to cope with the day-to-day realities of living in a foreign culture/country, the immigrant constructs an "alternate reality" which allows "an experience of home suspended across oceans" (Rodriguez 104). In The Woman Warrior, the narrator states that the children of immigrants have to "figure out how the invisible world the emigrants build around our childhoods fits in solid America"(5). The creation of the 'invisible' in this case is also a necessity and a means of survival as it forms an identity and connections with personal and family history.

Second generation immigrants are also a type of ghost and hence bordercrossers. The narrator believes that her parents and other Chinese emigrants would not share 'secrets' within the culture "because we had been born among ghosts, were taught by ghosts, and were ourselves ghost-like. They called us a kind of ghost. Ghosts are noisy and full of air; they talk during meals. They talk about anything" (184). Vivian Hsu notes that Kingston uses the term 'emigrant' for the first generation of Chinese in America who 'emigrated' out of China but have not spiritually 'immigrated' to America. They too can be seen as ghosts since "they wander in a ghostlike existence, hanging on to a former reality" (Winsboro 105). There are many instances where even though the narrator and her parents speak in a shared language, there is confusion as the original meaning is lost. Forced by necessity to negotiate between two separate worlds (or realities), children of immigrants are often, as the narrator is at various moments in the book, forced to act as intermediaries between cultures. 
Ghosts confound logic and confuse reality. Kingston's narrator suggests new immigrants can confuse Americans since Americans (labelled as a type of 'ghost' by the mother), "have no memory anyway and poor eyesight" (184-5). The American children of immigrants as ghosts can also be thought of as blank slates since they have no direct contact with the land of their inherited cultures. This 'blankness' can be used to help redefine the past but the process of reinvention of a self's past can be dangerous. With no memory, the creator is left with having to conceive something new to replace what has been dismantled. In re-imagining her aunt (as ghost) the narrator releases herself from the burden of having to carry her dead aunt's memory and in the process frees her aunt and herself from this possession. By transforming her aunt into something free and benevolent, a force that cannot hurt her, she "simultaneously casts ghostliness as a metaphor for her own imaginative reinvention of a rich but, for women, limiting tradition. The fluid, shape-shifting spectral body offers an alternative to the anchored, all too physically defined bodies of women trapped in the role of guardians of a changeless, patriarchal culture" (Brogan 26). In The Woman Warrior, identifying ghosts, like the transformation of myths and legends is a necessary part of the process of redefinition of gender and ethnicity.

"White Tigers," the chapter which follows "No Name Woman," has often been praised by white American critics and readers as their favourite chapter of the book. In an essay titled "Cultural Mis-readings by American Reviewers" Kingston writes, "[h]ow stubbornly Americans hang on to the oriental fantasy can be seen in their picking 'The White Tigers' chapter as their favourite. Readers tell me it ought to have been the climax. But I put it at the beginning to show that the childish myth is past, not the climax we 
reach for. Also, 'The White Tigers' is not a Chinese myth but one transformed by America, a sort of kung fu movie parody" (Skandera-Trombley 97). Kingston seems to be playing the trickster with her readers by calling it a "childish myth." "White Tigers" contains many elaborate metaphors describing the process of becoming a writer and many central concepts that help provide some guidance to her readers' understanding of the remaining chapters. The chapter begins in first-person narration, but the first-person perspective shifts fluidly into the first-person persona of Fa Mu Lan as the narrator takes on this identity. Here, another boundary is transgressed. The narrator herself explains at various points in the text that she has trouble with the border that distinguishes life and fiction. The narrator's adoption of the warrior woman persona reflects this. Kingston resurrects a long-dead folk heroine and gives her narrator the ability to assume this identity. Relaxing the taut boundary between fact and fiction through the incorporation of myth into a so-called autobiographical text, "provides the narrative means for the construction of different textual realities" (Rodriguez 16) and is an accurate reflection of the multiple lived realities of The Woman Warrior's narrator. ${ }^{19}$ The version of Mu Lan's story given to the narrator by her mother is also double-sided: though her mother upholds $\mathrm{Mu}$ Lan as a brave soldier, this warrior woman also conforms to social norms of filial piety by being an ideal daughter and daughter-in-law. Kingston's narrator adopts the persona, transforms it, and uses the fantastical creation to confront the racism and sexism she faces the day-to-day realities of life in America. Kingston's recreation of the Fa Mu Lan legend comes from the recitation she was given by her mother and the movies she watched as a child. Although she reiterates the fact that she was careful not to elevate the 
"White Tigers" ${ }^{20}$ chapter to any importance and use it as the climax of the book, it in this chapter that the narrator learns many important lessons that carry her through the rest of the work. More specifically, the lessons that Fa Mu Lan learns on the mountain from the old couple "guide [the narrator's] journey from girlhood to womanhood and are clearly important enough for Kingston that she develops them thematically throughout the text" (Winsboro 172).

The important lessons the Woman Warrior learns during training include "the dragon ways," which involve "learn[ing] to make [one's] mind large, as the universe is large, so that there is room for paradoxes" (29). In Chinese culture, the metaphor for elaborate writing is "carving the dragons" (Liu) and here there is an implicit but complex connection between the writer and the warrior tale she tells. The narrator states that " $[\mathrm{t}] \mathrm{he}$ swordswoman and I are not so dissimilar. May my people understand the resemblance soon so that I can return to them" (53). The training of the s(words)woman is a quest in writing, hence, the pun on the word swordswoman. At the beginning of the chapter there are a number of images of writing that call the woman warrior to her training and her quest. These are the lessons that she requires as a writer and the $\mathrm{Fa} \mathrm{Mu} \mathrm{Lan} \mathrm{chapter} \mathrm{is}$ itself an allegory for the writer in training. ${ }^{21}$ Near the beginning of the chapter, the narrator fantasizes that the call for her training would come from a bird that looks like an "ideograph" and would arrive over the mountains "which looks like the ideograph "mountain"' (20). The clouds would be gray "like an ink wash" and would make the mountain peaks seem "as if shaded in pencil, rocks like charcoal rubbings" (20). These 
images suggest both the Chinese written character and the famous Chinese drawings in the "mountains and rivers" tradition. The old couple in the "White Tigers" chapter gives the s(words)woman her first lesson which is to "infer the whole dragon from the parts you can see and touch" (28). Dragons, the narrator tells us, are not like tigers in that one can never "see one in its entirety" (28). In literary terms, this means learning figurative language, specifically synecdoche. In practical terms, it means learning that one can never see the 'whole' person, but perhaps can learn something by piecing together and studying the 'parts' of his or her life. The narrator demonstrates that many versions, many possibilities of a person and her life exist. This is illustrated not only in the narrator's re-creations of the mythical characters she tells of, such as Fa Mu Lan and T'sai Yen, but also the characters based on women 'known' to the narrator, such as Brave Orchid and Moon Orchid. Tensions in contradiction are embraced almost from the very beginning of the text, as an attempt is made for alternate 'tellings' to comfortably co-exist alongside one another. In this way The Woman Warrior underscores the belief that one version of a life is always questionable.

Another lesson in this chapter, "embracing paradoxes," means that the narrator must learn to accept or work through contradictions: "[w]ith time [the narrator] becomes adept at stretching her mind, at understanding the Chinese people are both tyrannical and heroic, that the villagers can both sustain and stone their neighbours, and, the most difficult paradox of all, that her mother is both an exorcist of ghosts and a nightmare that threatens to suffocate her" (Winsboro 173). In this section of the writer's 'quest,' we also learn that the sword and the book have an historic co-existence in Chinese culture. The s(words)woman would always win since "Kuan Kung, the god of war and literature" rode 
before her (38).

The legend of $\mathrm{Fa} \mathrm{Mu} \mathrm{Lan} \mathrm{is} \mathrm{a} \mathrm{story} \mathrm{about} \mathrm{a} \mathrm{woman} \mathrm{who} \mathrm{belongs} \mathrm{to} \mathrm{women,} \mathrm{and}$ according to Kingston's retelling, it is a story passed on by women. In the original Chinese version of the poem, Fa Mu Lan is a weaver and the poem itself begins with the sounds of her sitting at her loom. Kingston states that there is a connection between weaving, originally a woman's art in many cultures around the world, and writing since "[i]t is important to know that the Woman Warrior did women's work; she wasn't just a military hero. Also, I love it that the word 'texture,' which has to do with weaving, comes from the same root as 'text' - 'text' in writing. So weaving and writing have a connection" (Interview with Skenazy 131). Mu Lan is significant as she is a guiding spirit: the narrator states that a medium tells her, "[t]his spirit can help me if I acknowledge her" (52). Mu Lan is a figure from Chinese literature and culture who the narrator can use to redress (even avenge) the denigrating proverbs she hears about women and girls. "The Song of Mu Lan," upon which Kingston bases her retelling of the $\mathrm{Fa} \mathrm{Mu} \mathrm{Lan} \mathrm{legend,} \mathrm{was} \mathrm{composed} \mathrm{by} \mathrm{an} \mathrm{anonymous} \mathrm{sixth-century} \mathrm{Chinese} \mathrm{writer} \mathrm{and}$ was based on a ballad from the oral tradition (Gao 10). In the section where Kingston retells the story of Fa Mu Lan, the heroine's parents carve words on her back: "“My mother washed my back as if I had left for only a day and were her baby yet. 'We are going to carve revenge on your back,' my father said. 'We'll write out oaths and names"' (34). This story dates back to twelfth century China when a general named Yue Fei fought against the Mongols. It was said that his mother "cut into his back four Chinese characters - meaning to serve one's country with adamant loyalty" (Gao 22). Gao states that this 'mutation' of the Yue Fei story "annoys many Chinese readers" so that 
Kingston's weaving together the story of Fa Mu Lan with this legend of Yue Fei is regarded by some as a "profane ignorance of Chinese culture" (23). But there is a reason for the re-vision since it serves the message Kingston wants to convey which is in keeping with a non-violent, yet activist theme: the carving of words on the body is "the revenge of the word" in motion (23). It has also been stated that the carving of Mu Lan's back relates to the oppression of women in Chinese culture (Ling 160). Either way, Kingston changed the meaning so that 'to serve' the established system with loyalty becomes to take action against it. The narrator states,

The swordswoman and I are not so dissimilar. May my people understand the resemblance soon so that I can return to them. What we have in common are the words at our backs. The idioms for revenge are 'report a crime' and 'report to five families.' The reporting is the vengeance - not the beheading, not the gutting, but the words. And I have so many words - 'chink' words and 'gook' words too - that they do not fit on my skin (53).

The narrator re-tells old stories and myths, seeking to use them as a form of revenge against ethnic and gender stereotypes. Her text amplifies the questions that surround the significance of carrying the old "stories." By doing so, the narrator examines whether they are burdens, commands, or sources of strength, much like the words of her parents' grievances which Fa Mu Lan carries carved on her back.

Chapter three, "Shaman," is about the narrator's mother, Brave Orchid's life in China as a doctor/healer: "my mother became a good doctor She could cure the most spectacular diseases" (82). There is not much exaggeration of the mother's position since in ancient China a shaman "would certainly have been trusted and would have held high and prestigious social positions" (Hsu 890). This chapter takes place in China and reflects the 
mother's successes in life. The mother was a member of the medical establishment in China and tells her daughter,

'When I stepped out of my sedan chair, the villagers said, 'Ahhh,' at my good shoes and my long gown. I always dressed well when I made calls. Some villages brought out their lion and danced ahead of me. You have no idea how much I have fallen coming to America' (76-77).

Despite the prestige that accompanied her profession, the mother is a "practical woman" (66) who "could not invent stories and told only true ones" (66). In China, a shaman was a legitimate medical practitioner. Shamans were skilled in the art of experimentation and the development of curative powers. Hsu states that "all famous early doctors in China were shamans. The establishment of medical science was mainly due to their contributions" (897). Shamans are not simply healers: they can communicate with spirits. Through her retelling and recording of stories and myths in her work as a writer, the narrator naturally shares two roles with her mother - storyteller and shaman - since both women exorcise ghosts that haunt them. The narrative of this section begins and ends in the first person, but the body of the story is in the third person focalized through the mother. The narrator's words frame the story, but she allows her mother, Brave Orchid, to exist as a character in her own right outside her role as mother. Brave Orchid's role as doctor reveals her unwillingness to accept the prescribed roles for women in her culture (at the time her husband has emigrated to the United States). As a doctor, Brave Orchid is a powerful healer who can detect death ("When a sick person was about to die, my mother read the fact of it a year ahead of time on the daughters-in-law's faces"(82)) and possesses the ability to confront and talk down ghosts, as shown in her triumph over the "sitting ghost" at the Keung School of Midwifery. 
Kingston's narrator uses her mother's own words to reflect certain events that occurred during the time of Brave Orchid's medical studies in China. During this time, Brave Orchid and the women at the medical school experience a "haunting. ${ }^{22}$ There is a haunted dormitory room at the school which none of the other students will enter since "a series of hauntings had made its inhabitants come down with ghost fear that shattered their brains for studying" (65). After the students (or 'storytellers', as the narrator states) share family ghost tales, Brave Orchid says,

'How do we know that ghosts are the continuance of dead people? Couldn't ghosts be an entirely different species of creature? Perhaps human beings just die, and that's the end. I don't think I'd mind that too much. Which would you rather be? A ghost who is constantly wanting to be fed? Or nothing?' If the other storytellers had been reassuring one another with science, then my mother would have flown stories as factual as bats into the listening night (65-6).

Brave Orchid identifies different varieties of ghosts and names the one in the dormitory a 'Sitting Ghost': "it rolled over her and landed bodily on her chest. There it sat. It breathed airlessly, pressing her, sapping her" (69). When she cannot expel it with physical force, she uses bravado, taunting it and flaunting her physical and mental superiority: "'I do not give in...[t]here is no pain you can inflict that I cannot endure. You're wrong if you think I am afraid of you...[y]ou have no power over a strong woman"” (70). After her confrontation, in order to be revived from sleep, she asks the students to pull on her earlobes and claims this is "in case I lost any of my self" (71). The students also chant the self back to the body's physical place by speaking of family and friends. Later, the narrator states that, 
[t]he students at the To Keung School of Midwifery were new women, scientists who changed the rituals. When she [Brave Orchid] got scared as a child, one of my mother's three mothers held her and chanted her descent line, reeling the frightened spirit back from the farthest deserts. A relative would know personal names and secrets about husbands, babies, renegades and decide which ones were lucky in a chant, but these outside women had to build a path from scraps. No blood bonded friend to friend (though there were things owed beggars and monks), and they had to figure out how to help my mother's spirit locate the To Keung School as 'home'. The calling out of her real descent line would have led her to the wrong place, the village. These strangers had to make her come back to them. They called out their own names, women's pretty names, haphazard names, horizontal names of one generation. They pieced together new directions, and my mother's spirit followed them instead of the old footprints. Maybe that is why she lost her home village and did not reach her husband for fifteen years (75-76).

Ultimately, Brave Orchid is successful in her confrontation of the Sitting Ghost due to her strong will and powerful sense of self. She is able to confront and then exorcise ghosts since she knows how to define herself; she does this with the help of an adopted family of women who trace the lines of descent and provide a sense of place that is seen as 'home'. After this particular exorcism, 'home' is the Midwifery school, significant in that it is a place women learn how to assist other women give birth. Kingston relates this sudden loss of a clear, 'linear' lineage to the confusion that the immigrant experiences in the process of having to find a home in a foreign land. When Brave Orchid's sister, Moon Orchid, loses her sense of self and is displaced in America her spirit also loses its way and she becomes mentally ill. Later, the narrator is aligned with the exiled poet Ts'ai Yen since both women locate an identity and a sense of home out of displacement or from a border-space. This is a common theme in The Woman Warrior: a time of feeling lost is an almost necessary prelude to 
forging new paths.

Moon Orchid is the focus of the fourth chapter "At the Western Palace," a chapter that warns of the perils of immigrating and the process of altering or exchanging traditional roles in favour of new roles and traditions. Moon Orchid is portrayed as a woman who conforms to the norms of femininity within traditional Chinese culture. The narrator views her as gentle and attractive, but almost useless when it comes to doing what she considers 'real' work. At the parents' laundry Moon Orchid "was wearing stockings and dress shoes and a suit. The buttons on the presses seemed too complicated for her to push" (136). She laughs "softly in delight" and brings the children gifts of jade and gold earrings and "paper dolls" with "blue feathers" (120). Unlike her sister Brave Orchid, whom Kingston identifies as one of those "powerful peasant types" (Skenazy 132), Moon Orchid is a woman who represents the "feminine powers" that trouble Kingston's narrator. According to Kingston herself, this aunt is beautiful to look at but "she doesn't know how to do anything" (Skenazy 132).

As she anxiously awaits her sister's arrival at the airport, Brave Orchid fails to identify her from a series of other women she sees. And even later, she still almost does not believe what she sees of her sister. She cannot accept the fact that her sister has aged, her sister's weaknesses or any of the differences between them:

Brave Orchid looked at this delicate sister. She was such a little old lady. She had long fingers and then, soft hands. And she had a high-class accent from living in Hong Kong. Not a trace of village accent remained; she had been away from the village for that long. But Brave Orchid would not relent; her dainty sister would just have to toughen up (127). 
The narrator's observations of Brave Orchid's thoughts illustrates how an immigrant's memories of people and the places they come from often remain frozen in the state in which they left them: those they leave behind, like the places, are often fixed in that time and not subject to change. But it is also Brave Orchid's own stubborn nature and powerful sense of self that prevents her from accepting her sister as she is. Though her strong personality is a necessary resource in times of crisis, there are disastrous results when she forcefully imposes her views on those around her.

Brave Orchid ultimately distorts her sister's sense of self by viewing it through her own lens. Her intentions are to help her sister either reclaim or take revenge against her husband for 'abandoning' his first wife. Moon Orchid's husband has a new life: he has remarried and is working in the United States while also providing for Moon Orchid and their daughter who live comfortably in Hong Kong. The mode of agency Brave Orchid proposes for her sister is entirely unrealistic and unsuited to the person Moon Orchid has become. Moon Orchid's story is embedded in the retelling of a traditional Chinese parable about two empresses, the eastern one good and the western one evil, and the Earth's Emperor being imprisoned by the Empress of the West. Kingston uses this tale to title the fourth chapter, "At the Western Palace." According to the narrator, Brave Orchid attempts to use her retelling of the story to incite her sister to action. Brave Orchid forcefully maintains,

[y]our husband is going to have to see you. We'll make him recognize you. Ha. Won't it be fun to see his face? You'll go to his house. And when his second wife answers the door, you say, 'I want to speak to my husband,' and you name his personal name... Walk past her as if she were a servant...you yell at him too (124-5). 
It becomes clear that Moon Orchid's own objective is only to visit with her sister, brother-in-law, nieces and nephews. Her only reply to Brave Orchid's instructions is that she is "scared" and wishes "to go back to Hong Kong" (125). Perhaps to find a more gentle and indirect way to motivate her sister, Brave Orchid then uses a parable to incite her sister to take some action:

'A long time ago,' began Brave Orchid, 'the emperors had four wives, one at each point of the compass, and they lived in four palaces. The Empress of the West would connive for power, but the Empress of the East was good and kind and full of light. You are the Empress of the East, and the Empress of the West has imprisoned the Earth's Emperor in the Western Palace. And you, the good Empress of the East, come out of the dawn to invade her land and free the Emperor. You must break the strong spell she has cast on him that has lost him the East' (143).

From the very beginning of the novel, the narrator maintains it is important to seek personal meaning from these stories. As the final outcome of Moon Orchid's story indicates, there is always some danger that comes from translating and re-interpreting stories. The task is perilous since it involves using another's directives (presented through a traditional story) as a mode of agency. Moon Orchid is unable to conform to her sister's fairytale analogy and it permanently affects her mental health. She cannot follow her sister's advice, nor can she begin a new life with a new role. The lack of a 'realistic' perspective on Moon Orchid's situation makes the moment she is forced to confront her husband tragic. The parable only distorts the entire situation and, as Rabine states, carries a "double message," that "legends cannot be interpreted as analogies for experience" (485). It is a similar "double-bind" that the narrator gets into when she examines, and then puts to the test, some of her mother's stories. Brave Orchid fails her sister miserably as she tries to make an exact map for action 
from a fable; she attaches a very literal meaning to this story, not a new or imaginative one, and not one that can be used to make sense of such a new and ultimately traumatic experience. The narrator realizes she must seek her own meaning through the stories she hears; she can empower herself through re-telling and re-shaping the stories in a way her aunt cannot. Moon Orchid is suddenly and forcefully torn from her traditional role and given an alternative she cannot use to situate herself. After the confrontation with her husband, madness consumes Moon Orchid and the mind's fragility is again related to narrative, the ability to tell and re-shape stories. Brave Orchid teaches her children that stories have the power to shape (or distort) the self:

Brave Orchid saw that all variety had gone from her sister. She was indeed mad. 'The differences between mad people and sane people,' Brave Orchid explained to the children, 'is that sane people have variety when they talk-story. Mad people have only one story that they talk over and over' (159).

Like her mother, the narrator also believes that "talking and not talking made the difference between sanity and insanity. Insane people were the ones who couldn't explain themselves. There were many crazy girls and women"(186).

Moon Orchid is not the only 'mad' woman in the text: The Woman Warrior contains other female characters who exist outside mainstream culture as marginal figures. These are the mad women and outlaws who transgress boundaries: "the woman next door who was chatty one moment - inviting us children to our first 'sky movie' - and shut up the next" (186); "Crazy Mary" was forgotten for twenty years when her parents emigrated from China to the United States; "Pee-A-Nah" was a "witchwoman...[o]f all the crazy ladies, she was the one who was the village idiot, the public woman" (188). These women usually annoy or 
scare children, then like ghosts are forgotten when they disappear and it is assumed that they have, as the narrator states, "been locked up in the crazy house" (189). These instances of mad women in the text serve to highlight, according to Cheung, "the connection between social norms and the construction of insanity" (93). The Woman Warrior illustrates that just as patriarchal dictates attempt to silence women or keep them from speech, another tactic is to label them 'crazy' or 'insane' whenever they step out of so-called normative or socially acceptable roles or even dare to speak and voice their perspective. In their article "Women, Power, and Mental Health" Weber, Hancock and Higginbotham suggest that it is in the struggle for self-definition that "the relationship between oppression and mental health is most clearly seen" (383). Through even the most subtle means, more privileged members of a society have the power to deny others the right to full participation and self-determination. In mainstream North American culture, it works through the dominant culture's representation of members of minority groups:

Negative stereotyped images of women, members of different racial and ethnic groups, gays and lesbians, and other subordinate groups pervade the media and institutions such as education and the law. The objective of a stereotype is not to reflect or represent a reality but to function as a disguise or mystification of actual social relations. Stereotypes are invoked to make racism, sexism, and other forms of oppression appear to be natural, normal, and inevitable parts of everyday life. Because of the pervasiveness of group stereotypes, members of oppressed groups routinely face difficulties when people in positions of power act to limit their life options based on stereotypes of them as less competent, less capable, less worthy - in short, as less than fully human (Weber 383).

Kingston's narrator faces double obstacles since she is not only battling what mainstream American culture conceives her to be, but also some of the long-held misogynistic beliefs 
found in Chinese culture. The narrator fears that she is not so different from the other 'mad' women that inhabit the outskirts of her childhood world: she suspects that she too may be insane when she feels unable to conform to her parental or societal expectations of what she should be: "I thought every house had to have its crazy woman or crazy girl, every village its idiot. Who would be it at our house? Probably me" (189). The narrator begins to see herself as "anomalous" and this explains her interest in the stories of Chinese deviants (Cheung 93). It is through these 'deviants,' the women that do not conform to the norms of their respective cultures - the madwomen, the outlaws, the warriors and the poets - that the narrator locates role models and her own ideological space. These women, like the narrator herself, are border-figures. Through these women the narrator sees many possibilities for women who do not conform to the norms of patriarchal culture. Although there are the tragic cases of women who become lost, voiceless and disappear, there are also those who manage to exist and thrive within the boundaries.

In the last chapter of the book "A Song for a Barbarian Reed Pipe," the narrator is actively trying to reconcile many opposing forces: speaking and silence, memory and forgetting, herself and her mother. Here the narrator finally confronts the "champion talker" and storyteller: her mother. The narrator speaks out to express the two main grievances she has against her mother. The first is that the narrator believes her mother cut her frenum to cause her to talk less. This act inspires the narrator to feel both awe and fear towards her mother. The second act she feels her mother commits against her is that she secretly conspires to have her married and thus become "a wife and slave." By American standards, the narrator believes her mother cut her frenum to disempower her. 
However, when the narrator finally confronts her mother, Brave Orchid states, "'I cut it so you wouldn't be tongue-tied. Your tongue would be able to move in any language"" (164). Playing the 'devil's advocate' role, the narrator throws back a Chinese proverb at her mother and says, "But isn't 'a ready tongue an evil?"'to which her mother replies "things are different in this ghost country" (164). Considering the definition of the word, 'frenum,' Brave Orchid's version of this story is the truer one. 'Frenum' is defined as "a connecting fold of membrane serving to support or restrain" (Barber 334). 'Frena' (the plural form) means 'brake' in Greek; cutting the frena releases something for uncontrolled movement. $^{23}$

Whether her frenum was cut or not has little relevance. Like other stories in The Woman Warrior there is no one confirmed truth. Instead there is an acknowledgement of multiplicity and, in the final chapter of The Woman Warrior, hope and reconciliation. It is in this last chapter that "Kingston celebrates the realization that she possesses a distinctive voice that allows her at last to communicate candidly with her mother. The book concludes with the rewritten and starkly beautiful story of Ts'ai Yen (Cai Yan), who recovers her voice as she listen to the music of barbarian flutes, and is inspired to write poetry that distills into words her sadness and anger at her long separation from her beloved China" (Huntley 77). At the end of the work there is an attempt for unity or at least an ending that promotes some harmony between peoples. The final identity that the narrator tries on is that of the poet Ts'ai Yen, who is known as the "first great woman poet in Chinese history" (Chung 134). The daughter of a writer, she was captured by the Huns during a raid around 195 A.D. and taken to the north of China. According to Kingston's narrator, she was kept away from her family and home for twelve years. The 
narrator begins this last chapter with the image of the "outlaw knot-maker" to whom she likens herself:

Long ago in China, knot-makers tied string into buttons and frogs, and rope into bell pulls. There was one knot so complicated that it blinded the knot-maker. Finally an emperor outlawed this cruel knot, and the nobles could not order it anymore. If I had lived in China, I would have been an outlaw knot-maker (163).

Again, here is the reinforced motif of the danger inherent in telling and re-telling stories. The narrator claims the re-shaping of stories as her right; she acknowledges that the story of Moon Orchid cannot be told in the same way her brother originally told it since hers is "twisted into designs. The hearer can carry it tucked away without it taking up much room" (163). The knot-maker, the poet and Kingston as writer share a belief in the power of imaginative transformation; the knot-maker's work can, in fact, be seen as a metaphor for the way Kingston 'weaves' together her own stories. An example of this is the way in which the story of the narrator's grandmother is begun by her mother and ends in the daughter's telling. In this telling the narrator/daughter imagines her grandmother's familiarity with the tale of Ts'ai Yen's capture by the "barbarians" (207-9). Like the narrator, the poet converts feelings of joy, sorrow and anger into song and both come to discover they have found a voice, the voice of an artist. Ts'ai Yen could also stand for Brave Orchid: just as Brave Orchid's children laugh at some of her beliefs and traditions, so the poet's children "imitated [their mother] with 
senseless singsong words and laughed" (208). The daughter sees that her mother is somewhat distanced from her children, especially when it comes to what she feels is the appropriate custom or action to take for certain situations as Brave Orchid feels "her American children had no feelings and no memory" (115). The poet Ts'ai Yen can also represent Maxine Hong Kingston's role as writer, translating old "stories" to her readers. This means some mutual likeness occurs in both mother and daughter, since they share the power of storytelling.

Because she is an exiled poet, the Ts'ai Yen persona represents a need to search for a place that is home, whether it be physical or emotional. In China Men the narrative structure is "based, like much traditional male narrative, on a linear and circular quest to return to a lost paradise; [i]n The Woman Warrior...there is no lost paradise, not in China the mythical homeland, or in childhood, or in her [the narrator's] relationship to her mother; and its absence structures the text" (Rabine 477). Like other feminist critics, Rabine is right to say women's texts often lack a sense of 'home' as a paradise that is lost and then regained at the end of the story. Still, this noticeable absence takes the form not of a single-minded drive to return home as in Greek narratives such as Homer's the Iliad and The Odyssey, but as a constant seeking and yearning.

At the end of The Woman Warrior, the poetess Ts'ai Yen yearns for her homeland and a place of belonging, as shown in this translation of her "Eighteen Verses Sung to a Tartar Reed Whistle." In the eleventh stanza Ts'ai Yen writes: 
I have no desire to live, but I am afraid of death.

I cannot kill my body, for my heart still has hope

That I can live long enough

To obtain my one and only desire -

That someday I can see again

The mulberry and catalpa trees of home (Chung 5).

The narrator, like her mother, is a gifted storyteller; however, unlike the daughter, Brave Orchid can "only transport - not translate - her stories into a different context" (Gao 40). This is best illustrated with the East and West Empresses myth that Brave Orchid tells her sister. The final sentence of The Woman Warrior is "[i]t translated well" (209) referring to the story of Tsai'Yen, the story of the exiled Chinese poet that survives in the daughter's translation or revision of the tale. The story "translates well" not because there is a process of near-perfect direct translation; the poet's song is about what is common to all peoples: love, loss, family, a sense of home. The words, the formulation of language is secondary and all that matters is that the poet transmits her feelings with intensity and authenticity: "[h]er words seemed to be Chinese, the barbarians understood their sadness and anger" (209). The narrator seems to favour the Tsai'Yen story since it claims the ultimate transformation: it illustrates how the main character can take an instrument of death (the 'nock-whistles' that shoot arrows) and turn them into an instrument that transmits elements of harmony and peace (the reed pipe which plays the music to her poetry). When Ts'ai Yen hears the 'barbarians' play their flutes she sings of her original home and family and her voice "matched the flutes" (209). Like Tsai'Yen who sings Chinese to barbarian music, Kingston tells Chinese and Chinese-American stories in English: a tongue not of her ancestral origins yet her song, like Tsai'Yen's, 'translated well.' 


\section{Chapter Two}

\section{The Power of the 'Dark Storyteller': Family and Connected Identity in Wayson Choy's The Jade Peony}

Wayson Choy, a professor of English at Toronto's Humber College, was raised in Vancouver as the son of two working parents and, "was cared for in a variety of Chinese households" (author biography, The Jade Peony). Though his stories have appeared in various anthologies, The Jade Peony is his first novel. It began as a short story that was published almost eighteen years before the completed novel and it "provides a literary space for a semi-autobiographical project based on the author's own childhood"(Lee 19). Many reviewers have commented on the novel's semi-autobiographical nature and that "with its episodic forward movement and rich period detail, its delightful set pieces and flashback interpolations, The Jade Peony resembles a memoir in texture" (Gambone 15).

The Jade Peony tells the story of a Chinese Canadian family living in Vancouver's Chinatown during the 1930s and 1940s. The narrative is split into three sections, written from three distinctly different viewpoints belonging to each of the family's three Canadianborn children: Jook Liang, Only Sister; Jung-Sum, Second Brother; and Sek-Lung, Third Brother. The family also includes the Father, Kiam, First Brother born in China, Stepmother and the septegenarian grandmother, Poh-Poh. Kiam appears throughout the novel, but his viewpoint is absent, though of the four children he appears to be closest to the 'Old China' ways of Poh-Poh. He can still argue politics with his father and converse in his grandmother's many dialects, although he also wants to blend into the new culture. Choy clearly chose to focus on the Canadian-born voices. This generation represents the "border crossers': those struggling at an early age to make sense of an identity that stems from elements that are both Chinese and Canadian. Caught between these forces of old and new, 
the children represented within this novel are the first large generation of Chinese Canadians (Mason 37).

The position of the child as narrator figures significantly in The Jade Peony. In a note to his article "Engaging Chineseness in Wayson Choy's The Jade Peony," Christopher Lee suggests that Choy believes "he has been spared much criticism from the Chinese community because his use of child narrators has protected him from accusations of 'airing dirty laundry' and that his sequel to the novel, which will probably include the grown-up versions of these characters, may not fare as well'(33). Each of the children in Choy's novel experiences a 'wounding' or loss that signals a realization which leads to understanding of the outside world. The children learn to see not only their own separate identities, but also a hybridized view of identity that is not solely based on individuation but on connection with others. Further, only those characters who are closely associated with the women, Stepmother and Poh-Poh, are given the narrative 'space' to tell their stories. All three children are connected to an empowering and liberating female world which often transmits secret knowledge or transgressive behaviours to them. Choy subverts the traditional Confucian construction of gendered identity by privileging the female point of view and the spaces women inhabit throughout their lives. Through the narrative structure of the novel, Choy inverts Confucian birth order which gives more weight to male kinship structures and paternal authority in order to privilege the voices of those who have been marginalized because they belong to a specific ethnicity, gender, age-group or have a different sexual orientation. Choy demonstrates not only how these categories shape the identities of individual characters, but also how these identities can be transformed through the process of making the necessary connections through the stories and memories of others. 
In The Jade Peony, Choy organizes the chapters of the novel in three parts under the headings that complement each child's birth order: "Jook-Liang, Only Sister," "Jun-Sum, Second Brother" and "Sek-Lung, Third Brother." Choy subverts the 'natural' order presented in an ancient Chinese text, the I Ching, by placing Jook-Liang, the only daughter's narrative, first (i.e. it is not the First Son but the First/Only Daughter who speaks first). This reflects what could be a main focus of the novel itself: privileging the voices of those who have been previously marginalized. In addition to giving voice to those whose stories have not been heard, Choy's narrative also reflects his premise of storytelling as an act of making connections between people and events as well as between past and present. As a way of building a strong sense of connection and unity through memory into the narrative sequence Choy gives his characters various symbolic objects (or symbolic stories) that connect them to others and to the past. In his interview with Choy, Glenn Deer notes how "certain objects from the past resonate in an almost immanent way with their overlaid history" (39). These objects include ribbons, the mythical Monkey King, a turtle, Johnson's old fox coat, Jung's gold watch, the jade peony amulet, Sekky's wind chimes, and even ghosts. Choy almost seamlessly weaves these specific objects into the narrative and these symbols act as a key to various shades of character, memory and identity. The objects represented and their connections with various characters form a central motif in the novel: each object connects to a strong sense of not just personal, but collective or communal memory.

The central symbol/object of the novel is the peony flower. According to Choy,

the peony flower has a symbolic structure and meaning to the grandmother...for me it's a matter of seeing in human life what object is always important to people when they remember others who enriched their lives... an object that someone gives us, will now have 
the meaning, will now carry the weight of memory as a kind of triggering point. This object, like the Chinese reverence for jade, will emanate, even if only in our own eyes, as something that connects deeply with something both outside and inside ourselves (Deer 39).

In Chinese culture, the peony flower itself adds significance to the emphasis on the socalled 'feminine' aspects of a male/female duality. Traditional Chinese art would often depict items such as the peony, the peach, plum and chrysanthemum as domestic items associated with the home since traditionally "the softer, more yielding character of plant life and its obviously close dependence on the earth gives it especially strong yin [female] associations" (Sacred Symbols 45). Though these symbols are problematic because they ascribe to strict gender norms, the objective in these depictions is to evoke a balanced combination of symbolic male (yang) and female (yin) qualities. The heirloom jade peony in Choy's novel belongs to Poh-Poh and is passed on to her grandchildren. As SekLung, her youngest grandchild, states, the jade piece is "her [Poh-Poh's] most lucky possession" and represents "the colour of her spirit" (149) and "h[olds] the unravelling strands of her memory" (149). The significance of the jade peony is summarized by JungSum at the end of his section:

Grandmother told that story, and then another, each story brief and sad and marvelous. There were seven pieces of jade, carved in the shape of ancient symbols. The one she held most dear, we knew, was a coin-sized one, an exquisitely carved peony of translucent white and pinkish jade; its petals were outlined in a simple, carved relief against a perfect round of stone. Its underside was smooth and flawless (124).

Being equated to the necessity of storytelling, this central object illustrates how stories are attached to every individual life. Poh-Poh goes on to say that " "half the jade in 
Chinatown is made from bits of bone and flesh...the other half...is made of blood"'(124). Both in Choy's memoir, Paper Shadows, and Sky Lee's Disappearing Moon Cafe, bones carry memories: bones represent culture, history and ancestral ties. The jade amulets Poh-Poh proudly displays for her grandchildren, and which they will one day inherit, reinforce the bonds with her grandchildren. They still belong to PohPoh's world despite what Father tells her: "'Your old ways are not the new ways. Your grandchildren have to live the new ways"'(124). Though a change may come for the children in the future (i.e. they may come to distance themselves from their Chinese heritage) for the time being the children retain a strong connection to their grandmother. Jung-Sum states “...I still belonged with Poh-Poh, belonged to her stories and her ghosts, just as Liang and Sekky did" (125). Poh-Poh is associated with another central symbol of connectedness and storytelling: she is skilled in the art of tying intricate knots and attempts, unsuccessfully, to teach this skill to her granddaughter. Jook-Liang laments the fact her grandmother hesitates in teaching her this traditional art:

It was a ribbon-tying trick only Poh-Poh knew, taught to her long ago in Old China when she had served as a 'housedaughter' to a refugee Shanghai family. The First Concubine threatened to break her fingers if she did not learn fast enough how to knot pom-pom flowers and how to handweave sun-dried, skin-cutting grass stalks into flat 'eternal love' patterns so seamless that each design revealed neither a beginning nor an end...Finally, she could tie even thinnest silk strands in the most subtle patterns (34).

As with Kingston's narrator, the act of knot-making requires the ability to 'weave' together disparate strands (i.e. voices) into a cohesive unit or whole.

Wayson Choy often speaks and writes of the necessity of story-telling as a tool against monolithic and exclusionary notions of history, as it is "the best defense that 
individuals have against despair" (Bemrose 64). More specifically, it is oral storytelling that Choy views as being particularly important as he recalls, "We didn't have television, and it wasn't a literate generation, but oral history was the way we discovered meaning. All of us who grew up in Chinatown absorbed those mythologies without thinking" (Bemrose 64). In a talk Choy gave in 1998 entitled "The Importance of Story: The Hunger for Personal Narrative" he states: "We need to know that story-telling is powerful: many of us discover through narrative the meaning of our own lives. Narrative is how one joins events together, like joining dots to discover the larger picture, the greater meaning" (93). Story-telling, specifically oral telling, is a process of connections -- from one individual to another, from past to present. Choy adds that in "telling our stories to each other, we create and become community" (103). The 'hunger' for telling stories is clearly present in The Jade Peony. All the central characters are engaged in telling their stories and relating them to others who have had an impact on their lives. The child narrators all anxiously listen to their grandmother's stories.

At the same time, there are the unofficial and hidden stories which simultaneously present both narrative problems and possibilities for these protagonists. At the start of each of their narratives, the child protagonists initially yearn for a clear, linear official story which they soon realize does not exist. Jook-Liang finds this frustrating and states "every brick in Chinatown's three and five storey clan buildings lay like the Great Wall against anyone knowing everything"(50). In Disappearing Moon Cafe, Sky Lee's narrator Kae also notes "the great wall of silence and invisibility we have built around us" (180).

These protagonists learn that histories, through the process of engaging all possibilities, have to be pieced together. In Oral Histories and Cultural Memory, Roxanne 
Rimstead writes that critics have analysed how "oral histories contest dominant cultural constructions by recovering oppositional subjectivities and cultural memory from the standpoint of the silenced and oppressed whether the other is colonial, gendered, classed, racial, ethnic, or whatever" (143). In his article titled "Engaging Chineseness," Christopher Lee reads Choy's novel as a re-reading (or re-writing) of Chinese Canadian history by "suggesting ways to rethink the World War II period through a focus on marginalized voices and experiences." Further, Choy "interrogates the process of becoming Chinese, linking ethnic identity formation with various power structures such as the family and the Chinese community-at-large"(Lee 19). As Jook-Liang sees it, the 'Old timers hid their actual life [his/stories] within these fortress walls...only paper histories remaining, histories blended with talk-story" (50). But the secrecy is not limited to the "clan buildings" or "fortress walls." Jook-Liang realizes other houses in the neighbourhood, immigrant homes, harbour their own untold, suppressed or hidden stories:

I wondered if all the clapboard houses along the street harboured as many whispers as our house did...Some nights I would hear in my dreams our neighbours' whisperings rising towards the ceiling, Jewish voices, Polish and Italian voices, all jostling for survival, each as desperate as Chinese voices (51).

Chinatown itself can be viewed as a site where residents were marginalized both symbolically and spatially. According to Kay Anderson, ${ }^{24}$ who has written extensively about Canadian and Australian Chinatowns, this 'space' or construct speaks more about its 'host' societies than about the ethnic Chinese population: 
Perceptions like race are not ideal speculations or forms of belief that operate only at the level of ideas...state practices institutionalized the concept of a Chinese race, but it was in space that the concept became materially cemented and naturalized in everyday life...the nexus of race and space operated in two senses: physical and cognitive (28-9).

Part of Anderson's thesis is to illustrate that 'Chinatown' is a mythical, mental construction: the name itself began as an evaluative term ascribed by Europeans negating the right of the residents within that community to name themselves, and thereby authentically claim both an immediate and an historical space -- so residents were marginalized both symbolically and spatially. Choy's epigraph from Wing Tek Lum's “Translations" interrogates this problem:

Tohng Yahn Gaai was what we once called where we lived: "China-People-Street." Later, we mimicked Demon talk and wrote down only Wah Fauh- "China-Town."

The difference is obvious: the people disappeared.

Yet, the prevailing linguistic diversity alone [over thirty distinguishable Chinese dialects exist] suggests that there can be no homogeneous conception of 'Chineseness.' While immigrants from China brought over cultural traditions which were a strong unifying force in building a localized community, the prevailing sense of being closed-in and isolated on the part of Chinese Canadians in these communities may have been a strategy for distancing themselves from white (Anglo) Canadians. However, this self and other forms of imposed community isolation left those who may have wanted to assimilate with little choice (Anderson 29-30). This marginalization certainly proves problematic for the child narrators 
who struggle in this community 'space'.

Alongside community, the family is another 'space' a child struggles within. In North America's dominant culture, the term 'family' is often used to refer to the 'traditional' nucleus of two heterosexual parents raising children. Anything diverging from this model is termed an 'alternative' lifestyle. Yet, historically the term 'family' is not universal and has always been a concept in continuous flux. In "The Myth of the Traditional Family" Linda Nicholson points out that our current notion of what constitutes family in the West today is really a post-World War II conception with ties to an institution that is only slightly older:

What we mean by the 'traditional family' is an institution that began to emerge for the upper classes during the eighteenth century. It is typified by a strong sense of the separation of the unit of parents and children from both a more extended kinship network and from such non-kin related people as servants. It is marked by a norm of partnership between husband and wife and by the special role of the mother in shaping the character of her children. In brief, it represents an institution less organized around relationships of authority and more geared toward relationships of affection as the household became a unit less focused on production and more on sexuality, affection, and consumption (83).

Nicholson further reminds us that the "traditional family" as a category is in itself treacherous as she states "the 'traditional' family possesses no more claims to 'naturality' or historical universality than do 'alternative' families... what constitutes 'traditionality' itself keeps changing" (78). English speakers today use the term 'family' in two ways: to refer to a small unit composed of two people joined by marriage, blood, or adoption or they could mean 'all of the people with whom one is related.' This second notion makes "family" synonymous with "kin" and kinship exists in many societies. Although societies differ in their arrangements of kinship, it is 'kinship' not 'family' that is considered more universal 
and more traditional than 'family.' This "common-sense view" of family as being simply an extension of the nuclear family is a myth and instead underscores the high degree of variability among kinship systems.

Though Nicholson uses early modern Europe and post-war United States as a place of reference to illustrate the divergent meanings of family, one's relations even within the core unit of parents and children have almost always been determined by factors such as class and gender. In The Jade Peony there are contradictions between Poh-Poh's negative gender messages and her empowerment as family matriarch. In Chinese culture, age has long been venerated for its inherent wisdom and by this standard Poh-Poh holds a position of respect within the family. Poh-Poh's role parallels those played by Brave Orchid in The Woman Warrior and Mu Lan and Fong Mei, the latter of whom goes from subservient daughter-in-law to prosperous family matriarch, in Disappearing Moon Cafe. In the first section of The Jade Peony, the past and present lives of the women (Grandmother, mother and daughter) are almost seamlessly woven into Jook-Liang's narrative. More specifically, Choy makes connections across time and space by contrasting two girlhoods: Jook-Liang's (Canada) and her Poh Poh's (Old China). At the start of the novel, the five-year old narrator has already internalised many of her grandmother's personal stories and Chinese legends. The granddaughter pays careful attention to Poh-Poh's status: she notices how her grandmother lives and behaves, instead of what she says. Jook-Liang states that her grandmother, "Poh-Poh, being one of the few elder women left in Vancouver, took pleasure in her status and became the arbitrator of the old ways" (14). Poh-Poh also has the ability (and hence power) to choose the appropriate language to suit each moment: "The Old One had a wealth of dialects which thirty-five years of survival in China had taught her, and each 
dialect hinted at mixed shades of status and power, or the lack of both" (16). For JookLiang, Poh-Poh has the ability through language (both standard and non-standard forms) to speak "secrets" (25). Jook-Liang mimicks her grandmother's stories when she claims, "I need a girl-baby to be my slave"(15), recalling her grandmother's 'bad memory' of the past and her early years as a child servant in a rich household in China; Jook-Liang has heard the stories of her grandmother being "too ugly" and a "useless girl-child." We realize the differences between the two are not so great but the relationship between grandmother and her only granddaughter is not idealised by Choy. It is most often depicted as being quite tense: “There's no war in Canada', I said. 'This is Canada'. Poh-Poh sighed deeply, gave me a condescending look. 'You not Canada, Liang,' she said, majestically, 'you China. Always war in China." Jook-Liang claims to hate 'the Old One' and she proclaims "Grandmother never let me get on with my movie-star daydreams" (37). Jook-Liang, like most children, seeks belonging and acceptance through imaginative play by which she seeks to define her 'place.' When her grandmother tells her that she is "spoiled" and that "'In China, they tie up your feet," Jook-Liang says:

I also play acted for myself, imagining a world where I belonged, dressed perfectly, behaved beyond reproach, and was loved, always loved, and was not, no, not at all, mo yung (40).

Though Jook-Liang is told by her grandmother that "a girl child is mo yung - useless" she ignores the remark since "after all, she was a girl, too, even if she was, as my father respectfully called her, the Old One" (32). Through Poh-Poh's respective roles as wife, then mother and most importantly a grandmother and elder, she has status and power within the family and local community. 
The Jade Peony's first narrative section belongs to the granddaughter of Poh-Poh, Jook-Liang. Jook-Liang briefly outlines her own family's history and the existence of the mysterious, secret and hidden aspects of this history: "there were, besides false immigration stories to hide, secrets to be kept" (14). The lao wah-kiu or "Chinatown oldtimers" encourage all to believe that 'simple is best,' which would include reconfiguring the complex kinship structure of the Chinese family:

Poh-Poh insisted we simplify our kinship in Canada, so my mother became 'Stepmother.' That is what the two boys always called her, for Kiam was the First Son of Father's First Wife who had died mysteriously in China; and Jung, the Second Son, had been adopted into our family. What the sons called my mother, my mother became. The name 'Stepmother' kept things simple, orderly, as Poh-Poh determined (14).

Older kinship structures cannot be eliminated, but neither can they remain unchanged: the process of displacement through immigration forces old relations to be reformed to suit the needs of the present. The importance of family kinship structures is given additional meaning by cultural traditions such as filial piety, the performance of duties which it is believed are naturally owed to parents and relatives. Confucius' followers were instructed that propriety and/ or piety towards parents and later towards all superiors should supersede all other obligations. The following forms Confucius's doctrine of filial piety:

Filial piety is the root of moral power in man. His trunk and limbs, his hair and skin are received from his father and mother, and the beginning of filial piety consists in his not daring to injure them. To establish his moral character, to walk in the right way and to extend his good name to later generations, thereby satisfying his father and mother, this is the final accomplishment of filial piety (Chao 79). 
The Confucian school of thinking puts emphasis on vertical relationships in such a way that "the meaning of life is to be found in the existential quest for wisdom or moral perfection, and this, in turn, is especially discovered in those social virtues that govern family relationships (between parents and children, between husbands and wives, between ruler and ministers, and between friends)" (Ching 68).

Confucian ethics dictate gender roles; the father bears the responsibility of disciplining and educating the children, while the mother is responsible for providing "loving care" (Chao 54). However, the mother's main role or 'function' is "to perpetuate the family name by bearing male children. Unless this goal is attained, her position in the family is precarious, irrespective of what virtue she may possess, for barrenness is one of the seven groups leading to her repudiation" (Chao 55). The focus of Confucianism with its emphasis on 'action' and the 'yang' force does not give much emphasis to any of the traditional feminine qualities or the 'yin' force. Taoism, on the other hand, both as philosophy and religion, gives a higher place to women than Confucianism (Ching 68). Lao-Tzu's writings refer to the Tao as "the mother of the world" and shows preference for images associated with the feminine such as water, valleys, emptiness"(Ching 95). The Tao or 'Way' is reflected in the image of mother and child and the interconnected cycle of movement between the two. ${ }^{25}$

Further, Taoism itself is intricately connected to a well-known Chinese classic which needs to be examined when exploring any family structures since it forms the basis of Chinese social thought. "Taoism," states Tom Riseman, "is inseparable from the philosophy of the I Ching" or Book of Changes (8). The book contains a collection of linear symbols that are to be used as oracles. The symbols are eight trigrams that reflect 
or represent "all that happens in heaven and on earth" (Wilhelm 1). Each trigram represents certain forces in nature (i.e. thunder, water, wind, fire, etc) and a family consisting of father, mother, three sons and three daughters, "not in the mythological sense in which the Greek gods peopled Olympus, but in what might be called an abstract sense, that is, they represent not objective entities but functions" (Wilhelm 1). Again there are set gender assumptions made in the $I$ Ching. For example, the Father is attributed with being strong and connected to the image of heaven, while the mother is associated with the earth and the attributes of being "devoted" and "yielding." In the key for identifying these hexagrams, the importance and proximity of relations between family members can be noted by observing the symbols which are placed in the following order: Ch'ien (Father), Chen (First Son), K'an (Second Son), Ken (Third Son), K'un (Mother), Sun (First Daughter), Li (Second Daughter), Tui (Third Daughter).

In Jook-Liang's section, Poh-Poh is clearly the 'key' to the past and Jook-Liang soon realizes that "there is no other way to learn" (35) but through following her grandmother. This can be illustrated through her grandmother's refusal to teach Jook-Liang how to create her infamous, exquisite knots:

The First Concubine threatened to break her fingers if she did not learn fast enough how to knot pom-pom flowers and how to hand-weave sun-dried, skin-cutting grass stalks into flat 'eternal love' patterns so seamless that each design revealed neither a beginning nor an end. Poh-Poh told me her fingers bled while, as a young girl not yet ten, she frantically practised tying rough kelp filaments together, tying them endlessly until she perfected each design (34).

When Old Wong Suk, her grandmother's oldest friend, buys Jook-Liang satin ribbon 
laces for her hair and tap-shoes, Jook-Liang watches as "the satin strips danced between her [grandmother's] bony fingers"(32). But when Jook-Liang clumsily applies her grandmother's instructions and fails in the art of making knots, her grandmother raises her hand "ready to slap" and then freezes as she calls out, "No more teach!" (35). Jook-Liang states "all her womanly skills she would keep away from me, keep to herself until she died: 'Job too good for mo yung girl!"' (35). Poh-Poh, in being reminded of her own painful memories from the past, refuses to pass on this particular skill to her granddaughter.

Though Poh-Poh refuses to 'pass on' the expert knot-maker's skills to her granddaughter, she does share stories that transform and shape Jook-Liang's reality since Poh-Poh is a masterful storyteller:

There were in Grandmother's stories, always, wild storms and parting clouds, thunder, and after much labour, mountains that split apart, giving birth to demons who were out to kill you or to spirits who ached to test your courage. Until the last moment, you could never know for sure whether you were dealing with a demon or a spirit (21).

In traditional Chinese folk narratives, thunder signals power and heralds the appearance of an ominous or benevolent figure or event (as the above quote demonstrates, "you could never know for sure"). Wong Suk, Poh-Poh's oldest friend who becomes a focalpoint in Jook-Liang's childhood world, appears with thunder midway through Poh-Poh's telling of the Monkey King story (21). Jook-Liang immediately sees Wong Bak as the embodiment of the Monkey King and she experiences the disintegration of the line separating myth from reality; paradoxically, the world for Jook-Liang seems "more real than it had ever been for me" (23). With this event, Jook- Liang begins to more fully realize the 'not-so-obvious' way to interpret life and the power in what is 'unseen'. 
Through Wong Bak, whom Jook sees as the living Monkey King, Poh-Poh's stories literally come to life:

I thought of all the stories Poh-Poh had told me since I was two: Monkey King, in all kinds of disguises, adventuring through the world of ordinary people... My eyes were in pain from so much staring. I could not help myself: here beside me, the Monkey King sat, playing at being an old man as ancient as Poh-Poh, yet wielding chopsticks with youthful ease (27).

In classic Chinese folk literature, Monkey is the most popular hero of all the animal myths and legends. His countless exploits are recounted in the famous sixteenth century classic Chinese folk epic, Journey to the West. Though the story originally existed as oral legend, it came to be written down by Wu Cheng'en during the Tan Dynasty (618-907). The story tells of the Buddhist monk Triptaka and his three disciples, Monkey, Pig and Friar Sand, as they travel west in search of the Buddhist Sutras [holy scripts] which they then bring back to China. In Journey to the West, Monkey King or Sun Wukong is blessed with qualities that also made Odysseus a hero in Greek folk tradition: keen insight, wit, strength and taking pleasure in the mischief he causes by fooling those around him, especially his most powerful enemies. Mostly described as 'handsome' and 'powerful,' Monkey is playful, curious and has an insatiable desire for prestige and power; as such, Monkey is often punished by Buddha in many tales since he thirsts for these vices. It is also possible to view Monkey as a Trickster (or 'ShapeShifter') figure. ${ }^{26}$ In one of his many adventures (the epic consists of one-hundred chapters), Monkey acquires the ability to gain "an immortal body, and there was no magic transformation of which he was not capable. Since he had followed the 'Way' [the 
Tao] he could metamorphose each of the eighty-four thousand hairs on his body into anything he wanted"(Wu 37). ${ }^{27}$ Like all great oral stories or legends, the story of Monkey King is highly adaptable; what began as a story that explained how Buddhism entered China has been transformed into an allegory of human ingenuity. There are even modern Chinese re-workings of the tale: "in present-day China, a different interpretation is put upon the still universally popular story of Monkey, which, it is now suggested, represents the people's ability to subdue the forces of nature and the triumph of their struggle against the old ruling class" (Hayward Scott 94). The tale has also been said to dramatize the conflict of the child with parental authority (more than likely the father's). Monkey not only symbolizes human ingenuity but closely parallels a child's experience. In Childhood in Contemporary Cultures, the following interpretation of the tales is offered: "The child, in so far as he resembles Monkey, believes that his own aggressiveness entitles him to a high place in his social world. Only after he has suffered severe frustration does he learn that in order to merit the acknowledgement of his elders, he must modify his aggressiveness in such a way that can be utilized for the benefit of the family" (Mead 248). In Popular Chinese Literature and the Child, Dorothea Hayward Scott writes that the key to Monkey's exploits, as with all other enduring stories, is in the elasticity and the ability for the story to be re-shaped by each successive generation in or outside China since the story itself contains allegorical elements and is based on universals such as respect, love and truth.

The versatility of this popular figure is reflected in The Jade Peony in that there is no conflict with Monkey finding his place in Western popular culture. In one instance, Poh- 
Poh uses the Monkey King legend to transform what her grandchildren see on a 1940s Vancouver movie screen. Poh-Poh announces that "Cheetah was another one of the Monkey King's disguises" (27). This is how Poh-Poh shows her grandchildren other possibilities; by virtue of the imagination, one gains the ability to transform stories, recreate events and subsequently create another way of viewing 'reality'. Jook-Liang sees her grandmother as having "educated" her in this way:

...here, too, right beside me in his patched-up shirt, with his soft eyes, like liquid - sat the marvelous Cheetah of the matinee movies; Cheetah, Tarzan's friend. Poh-Poh had educated me about this...Cheetah was another one of the Monkey King's disguises. It was a way for the Monkey King to be with his Monkey tribe and still keep in touch with Buddha's commands, for Monkey could not do without human company, black or white or yellow. After all, people were closest to Buddha, PohPoh told me (27-8).

When Wong Suk first appears in the story he is seen as "a dark figure with an enormous hump." Jook-Liang sees him as an "obscure figure" who is "old and angular, someone bent over, his haggard weight bearing down on two sticks" (22). The 'obscure' and ‘dark' figure makes a significant impact on Jook-Liang. Wong Suk represents aspects of the 'unseen' and a link between the past and present; much like Jook's grandmother, he opens the door to the imaginative/mythic world, bringing Old China into the present. For example, Wong Suk's physical appearance is perceived as being grotesque and this causes him to be viewed as an outcast ${ }^{28}$ among those in the community, but Jook-Liang learns to see beyond externals and accept difference as a source of strength: 
I took care to set a perfect make-believe world before Wong Suk, my old guardian, my adopted uncle; Wong Suk, my one and only true friend since I was five. Others said he was ugly, old, with squashed lips that gave him a hapless monkey-face. True, Wong Suk was doubled-up and cruelly crippled, but to me, Wong Suk ambling along on his pair of thick bamboo canes seemed only different, unusual. I, his Shirley Temple princess, always saw only a bandit-prince in disguise (38).

Jook-Liang sees Wong Suk not only as the folk hero Monkey, but as her alternate Robin Hood or "bandit prince in disguise" (38) who can rescue her; Wong Suk shares qualities "so much like the heroes of Old China"(39). Wong Suk too has an object associated with his past. A cloak, given to him by railroad foreman Johnson when Wong Suk saves his life. This becomes a 'costume' which enables Jook Liang to view him as her "bandit prince:" Jook Liang loves the story of the cloak as she states, "I thought his cloak was even more lucky. I always leaned against its thick warmth and begged Wong Suk to let me drape it over my shoulders, to let me fly about, become Robin Hood's bandit-princes, turning rapidly around and around in the imaginary forest of our back yard, the cape lifting, like wings, lifting above the earth" (55).

Initially, these two figures, the young Chinese Canadian girl and the elderly Chinese man, are very different. However, Jook- Liang and Wong Bak share a common bond in their position as outsiders, as those who are 'othered' by family, community and society. The connection between the 'unwanted' bachelor man and the 'useless' girl child is made explicit by Jook-Liang herself:

I was happy. I knew our adopted relationship was a true one: Wong Suk would otherwise have been only one of the many discarded bachelor-men of Chinatown - and I, 
barely tolerated by Poh-Poh, would merely be a useless girl-child (39).

The early Chinese male immigrants, or 'bachelor men', were often seen as outcasts since one form of validation in Chinese culture for men is granted by becoming a patriarch, the head of a family. Early Chinese American men experienced confusion, discomfort, and even humiliation in North America. In some sense, they were often relegated to subservient positions (so-called 'women's work') in laundries, restaurants and diners. Conversely, in China, historically most men enjoyed a more prestigious social position thanks to the Confucian hierarchy, while women assumed subservient positions. For centuries, upon marriage a woman had to leave her family behind, thereby entering the unfamiliar (her husband's house) just as these early sojourners were venturing onto unfamiliar land on this continent.

In The Jade Peony, the only one who encourages Jook-Liang in her fantasy-play and role-playing is her grandmother's oldest friend. For Jook-Liang, Wong Suk is "my old guardian, my adopted uncle...my one and only true friend since I was five" (38). Unlike her brothers, Jook-Liang does not withdraw from him as Wong Suk tells her family that "this child not afraid of me." Through Wong Suk, Jook-Liang is free to explore other possibilities through play. She "set[s] a perfect make-believe world" for her adopted uncle as she "mimicked the Chinese Opera heroines: the woman warrior, a deserted wife, the helpless princess" (38). Yet when Jook-Liang looks in the mirror she does not see "Shirley Temple with her dimpled smile and perfect white-skin features," but,

A broad sallow moon with slit dark eyes, topped by a helmet of black hair. I looked down. Jutting out from a too-large taffeta dress were two spindly legs matched by a pair of bony arms. Something cold clutched by 
stomach, made me swallow...I looked down: masses of red [ribbons given by WS] clustered at my feet. I thought of old Wong Suk learning on his two canes. And I danced (43).

Despite being slightly obsessed with looking like Shirley Temple, Jook-Liang realizes she can never look like her idol, and, in part, comes to embrace difference because of Wong Suk. For Wong Suk, she is not a "useless girl-child" but "tiger-willed." The tiger is a powerful symbol in Chinese culture as it is known for its fierceness and strength. There is resonance with Kingston's work here, as her legendary warrior woman is also associated with tigers. In The Jade Peony, Jook-Liang has a guide, just as Kingston's warrior-in-training is guided by the elderly couple. Through Wong Suk, Jook-Liang has her own nature affirmed as she is shown the skill to look beyond physical appearances and embrace a vitality of spirit.

Jung-Sum, Jook-Liang's adopted brother, also learns to look beyond the exteriors or the obvious. Jung-Sum's section introduces the concept of family in the community at large, and perhaps even a re-conception of what 'family' and family/ancestral lineage means. Jung-Sum is the adopted son who is brought into the family at four years old. His sense of where he 'belongs' is initially dictated by others (i.e. Mr. Chang who arranges his adoption, Poh-Poh who brings him home): "Mr. Chang said that I must be well-behaved. I now belonged in this house, belonged with these people" (85). In this section of the novel, Jung too is in the process of redefining his world. He is often told "this is the way things are" (87) and then thinks "this is the way the world is" (90). The bachelor men introduced in Jung's section, such as Dai Kew and his turtle which JungSum inherits and Gee Sook, the tailor/dry cleaner, represent figures, like Wong Suk, who stand outside the standard notions of family and the role of patriarch within the Chinese 
Canadian community. Jung notes that "Gee Sook seemed neither bitter nor jealous of anyone with children, as some bachelor-men were. He gave generously of his cleaning and tailoring services, and at the lowest fees, to those poorer families like ours who were always making over old clothes" (95). Gee Sook re-stitches an old coat for Jung-Sum and it transforms him, making him feel like a "young warrior"(101). Gee Sook then 'grandly' announces, "[t]his is a man's coat...All of you women stand back"”(101). This old-to-new or "reincarnated" coat incites both collective and individual histories. PohPoh is reminded of early Chinese immigrants coming to Canada and then of Jung-Sum's own journey to Canada: "Poh-Poh told everyone, once again, the story of how I was already in my First Mother's tummy when she set sail to join my First Father in Victoria. 'Jung-Sum born in B.C. town. Family move to Kamloops. Aaaiiiyah, too many years ago!"” (102). Then when Jung-Sum sees himself in the mirror after the coat alterations are completed he feels "reborn" (103). As with most 'uniforms,' the coat gives Jung-Sum a sense of pride, identity and belonging.

Jung-Sum's search for the truth about his birth parents and history is contrasted with the experience of Frank Yuen and his parents. For Jung-Sum there was "no history to be told" (107) about his own parents, whereas Frank Yuen's family has a definite, albeit nefarious, history within the community. Jung Sum inherits Frank Yuen's gold watch when Frank leaves to serve as a soldier overseas. This watch is almost as significant as the jade peony in terms of its symbolism and reflects the relationship between Jung-Sum and Frank: "The old watch had a cut-out, upside-down crescent under the numbers, and in the semi-circle the face of an antique sun rose and fell, and then the moon took its turn" (122). Poh-Poh insightfully links Jung-Sum to the moon even though she and Mrs. 
Lim "knew the moon was the yin principle, the female" (82).

After Jung-Sum receives the watch from Frank, Poh-Poh tells Jung "what else the moon was besides the yin force": "She [Poh-Poh] said the moon was the sign of the dark storyteller. In Old China, this was the one who told of hidden things not seen in the glare of daylight. Moon people felt things, as she did, things that others did not name" (123). Poh-Poh offers Jung-Sum an alternate and instinctive way of viewing what he senses as his gender and sexual 'difference' from Kiam and Frank. Jung-Sum's homoerotic sexual awakening occurs during the physical confrontation he has with Frank in the temple hall, and he describes this as his moment of "clarity." Frank challenges Jung-Sum to fight him in the temple and Jung's initiation into boxing reflects the cult of hyper-masculinity and homoerotic bonding that exists in male-dominated sports. During this 'fight scene' Frank alternately metamorphoses into various imposing forms in the boy's eyes: friend, mentor, brother, father and warrior. This kick-boxing scene between the two brings to the fore repressed feelings and emotions for Jung-Sum. He believes he must 'prove himself' by working to be worthy of whatever he earns, just as he had to do when he first came into the family as an adopted son. In one instance during this scene Jung-Sum states "a memory came to me" (116) in which he confuses Frank with his abusive biological father. Though Frank holds him "like a child being cradled, back and forth" (117), he realizes "Frank Yuen could not comfort me forever" (117). It is in this scene that JungSum experiences desire for another man: "a strange yearning awoke in me, a vivid longing rose, relentlessly from the centre of my groin, sensuous and craving, rising until my hands unclenched, throwing me forward, soundlessly, until my fingers tingled and stretched to grope the raw tactile air" (117). Jung-Sum experiences a moment of clarity, 
just as his sister did through her grandmother's stories, and again it is as dramatic as a flash of light. He finally views his realization in this way: "Sometimes a lightning bolt strikes the darkness, making visible for miles a frieze of housetops, trees and mountains carved against the sky, and you see at the same time your smallness against the immensity of the world" (121). He begins to see himself as complementing Frank and not necessarily being in opposition. Here too, the aforementioned coat fixes part of Jung's identity: "Frank Yuen is the sun...Yes, I said to myself as I finished putting on my coat, my armour, I am the moon...the Old One's words followed me"(118).

Though Jung-Sum's relationship with his grandmother is highly significant since she assists him in embracing his difference, of the three grandchildren, the youngest, SekLung, seems to have the most intimate connection with his grandmother. Poh-Poh is SekLung's first teacher ("Grandmama taught me most" (148)). Sek-Lung often uses the word "magical" to describe his grandmother: her hands, her skills, the objects she creates, the stories she tells of the past. Sekky describes Poh-Poh's wind-chimes and is everfascinated, as are her other grandchildren, with the jade pieces she keeps. Poh-Poh has strong memories attached to these objects and skills. During her youth in China she meets a juggler/magician/acrobat with whom she falls in love and who teaches her some of these skills that she in turn demonstrates to her grandchildren. Sek-Lung states:

Most marvellous for me was the quick-witted skill her hands revealed in making windchimes for our birthdays: windchimes in the likeness of her lost friend's parting present to her, made of bits of string and the precious jade peony, a carved stone the size of a large coin, knotted with red silk to hang like a pendant from the centre, like the clapper of a sacred bell. This wondrous gift to her had broken apart years ago, in China but Grandmama kept the jade pendant in a tiny silk 
envelope, and kept it always in her pocket, until death (145).

Yet Sek-Lung also notes her ability to make others feel uneasy, to de-stabilize their realities: "They all loved Grandmama, but she was inconvenient, unsettling" (145). Even after her death, Sek-Lung's talk of her return and of ghosts upsets the entire family. Perhaps to shield the child, but also to quiet their own fears, Sek-Lung's family avoids discussing death and instead insists on a sanitized, official version. Due to noticeable discomfort in confronting the unseen the youngest grandson notes "no one in the family really wanted to talk about ghosts, not when they were speaking around me. On the contrary, they insisted only on the facts of life and death" (164). Because of his intense connection to Poh-Poh, Sek-Lung cannot find a way to release his memory of her. After Sek-Lung notices Poh-Poh's ghost wandering about their home, a geomancer and a Buddhist monk are called in to perform a traditional funerary ceremony. Third Uncle states “"[pay] your respects properly to your dead mother. You must bai sen, you must bow. Pay your respects! All this political talk you talk, one world, one citizenship! You forget you Chinese!?!"” (164). It is only after the ritual of ancestral veneration is performed by the entire family that Sek-Lung concludes, "the Old One no longer haunted us" (169).

Sek-Lung's narrative, the last section of the novel, has proven particularly problematic for many critics. His is the longest chapter of the novel, over one-hundred pages, double the pages given to the narratives of Jook-Liang and Jung-Sum. One critic states "Sekky's tale is longer and more complicated than the others, and seems to meander a bit as Choy delineates the boy's relationship with his grandmother, his battle for health, his early difficult days at school, and ultimately his role as witness to a 
forbidden relationship" (Quill and Quire 32). Paradoxically he is not "mo no" ("no brain") as he thinks others view him: Sek-Lung is the grandchild who spends the most time with the grandmother and is the most open to absorbing her 'ways.' The section may 'meander' somewhat, which works to reinforce Sekky's own confused state of mind. The writing may also be more characteristic of the non-linearity, necessary digression and repetition of an older talk-story tradition yet to be 'reformed' by standard schooling. ${ }^{29}$ Sek-Lung's first-person narrative ' $I$ ' is one that interweaves the personal with the communal. The characteristics of oral histories that are evident in Sek-Lung's section shows how they seek to contest dominant cultural constructions by "recovering oppositional subjectivities and cultural memory from the standpoint of the silenced and oppressed other" (Rimstead 143).

Sek-Lung's section seems to be the most significant of the three 'tellings' of personal and family history because "it seems to represent the vulnerable and innocent child who is in the process of being formed by (among other things) the discourse of ethnicity" (Lee Canadian Literature 19). ${ }^{30}$ The final section of the novel illustrates the process by which Sek-Lung enters various symbolic orders: the family, ethnicity and identity. A sense of 'Chineseness' is constructed through family, fantasy, community and history and then used to maintain various hierarchical relationships. Choy challenges essentialist notions of history and ethnicity by illustrating how historical 'truths' can be contradicted and how ethnicity, as part of identity, is equally valid in a hybridized form and dependent on meaningful interconnections with others.

Sek-Lung's section begins with a key motif and underscores his main obsession: that 
he is dismissed as "mo no" or "no brain." Sek-Lung is the youngest and seemingly weakest of the children, in terms of his physical well-being. His narrative begins, "In 1939, when I was six years old, the whole family, my brothers and my sister, and all our relatives considered me brainless" (129). For Sek-Lung the official rankings are confusing. He states, "I stumbled over calling my adopted Gim San gons (Gold Mountain uncles) their proper titles. I would say "Third Uncle" instead of "Great Uncle" (129) and later "Every Chinese person, it seemed to me, had an enigmatic status, an order of power and respect, mysteriously attached to him or her" (131). But Sek-Lung also understands that the 'mystery' came out of specific socio-political necessities, a necessary reaction to exclusionary racist laws:

These persons were also tied to us by false papers to obtain immigration visas, the became 'paper sons,' or 'paper uncles', heirs to a web of illegal subterfuge brought on by laws that stipulated only relatives of official 'merchant-residents' or 'scholars' could immigrate from China to Canada. Paper money could buy paper relatives. But whose papers were connected to whose relatives? My head pounded (132).

So despite his confessed confusion, Sek-Lung guides the reader through the most complex aspects of family and community life. His distance via his birth order complicates matters for him but paradoxically he makes the perfect guide as he tries to make 'sense' of the complexities of his inherited culture. Family rankings and the mystery of titles, and the various dialects used within his own family and the Chinese Canadian community at large all confuse yet obsess Sek-Lung. Though Father often instructs the family to "keep it simple," Sek-Lung realizes that nothing is simple: "All the Chinatown adults were worried over those of us recently born in Canada, born 'neither 
this nor that,' neither Chinese nor Canadian, born without understanding the boundaries, born mo no - no brain" (135). Though the older family members tell him there is a need to 'keep things simple,' Sek-Lung soon realizes that nothing about his situation is simple and the rankings are complex, interrelated constructs.

The dichotomy that Sek-Lung and the other children are caught between is the official and non-official versions of family relations and family history. These are not only reflected in the 'face' the family presents to the Chinese Canadian community and the white community, but also in the many alternate 'versions' of family history. Within Sek-Lung's family there are many stories, not only those told by his grandmother but also those of Stepmother:

Sometimes I found Stepmother sitting in Father's large wicker chair. She looked far away, and I knew she was thinking again of her girlhood in China and the family she had left behind, and the history that was hers, her ghost-whispering history. Balanced on her lap there were two precious things: the old bamboo-framed photograph of two women standing by a moon gate, and a large, delicately carved sandalwood box. Within its sweet, mysterious scent, Stepmother kept her own family photos and all the letters and the few photos sent by Suling. Once Stepmother said to me, as if she were stranded on an island, 'Suling is my only friend who knows my family stories. Not the stories Poh-Poh tells you' (136).

Stepmother's history is a "ghost-whispering history:" hers is an unofficial story as she is a second-wife and as such she is an unrecognized and 'unofficial' member of this family. Suling is the close friend she left in China, who knows her and her "family stories." Stepmother remembers Suling as being a Christian teacher who is studious and fluent in English. She hopes that when they one day meet again, Suling will come and give her son 
Sek-Lung "a brain" (129). Stepmother too has her symbolic objects loaded with memories of her past: old family photos, the framed photograph of Suling, Suling's letters, the protective sandalwood box she keeps these things in, and a silk scarf given to her by Suling. Stepmother's story is one that remains private and mysterious for her children.

Sek-Lung is introduced to secret, hidden and unknown things by women: by his grandmother, his mother and later by Meiying, Mrs. Lim's tall, elegant and intelligent seventeen year old adopted daughter. Mrs. Lim, according to Sek-Lung, "habitually wore black, as if she still lived in the peasant world of Old China" (189), and so he is overjoyed when instead of Mrs. Lim, Meiying becomes his babysitter. She is attractive, intelligent and popular in her community; as Sek-Lung states, "Meiying was not like most girls...everyone liked Meiying" (206). Sek-Lung is impressed with her ability to easily pronounce the names of his 'war toys' and with the fact that she soon trusts him with her 'secret.' Meiying shows Sek-Lung another side of town by taking him, as he says, "away from familiar territory, away from the boundaries of Chinatown" (208) to Little Tokyo to meet Kazuo, her Japanese Canadian boyfriend. Like the No Name Woman in Kingston's The Woman Warrior, who has an adulterous affair during a time when there is a famine and her husband is overseas, Meiying hides her relationship because in the eyes of her community she commits a 'crime' in the eyes of her community by becoming romantically involved with a Japanese Canadian boy at a time when Japan and China are enemies at war. Sek-Lung knows that "If Chinatown found out, Meiying would be cursed and shamed publicly as a traitor" (220). In the heightened atmosphere of Chinese war propaganda, he imagines she will be "beaten up, perhaps branded with a red-hot iron until her flesh smoked and flamed" (220). Since their story takes place during World War II when the Chinese are living under Japanese 
aggression, Sek-Lung sees Little Tokyo as "enemy territory." The wartime propaganda that proved to be one of the few aspects of his life that demonstrated coherence for Sek-Lung has now also become confusing and problematic. He says "my head was filled with mixed thoughts" (212) and "We had crossed a line. No one would have minded if Kazuo had kept his distance and we, ours; if this girl and this boy had remained onlookers and not trespassers" (213). But instead of being afraid, Sek-Lung takes some pleasure in the thrill he experiences after coming face to face with 'the enemy:' "I knew of course, Meiying was involved in something shameful, something treasonable...Yet I felt oddly relieved. Uplifted even. Powerful" (214). Sek-Lung feels he is part of a secret conspiracy and feels a special connectedness to Meiying in the ability to keep her secret.

It is assumed that no one other than Sek-Lung knows Meiying's secret. However, Sek-Lung notices that there is a good deal of "whispering" that goes on behind closed doors between Meiying and Stepmother. We can only assume that Meiying trusts her and she knows her secret too. The two women seem to have a close relationship: as Sek-Lung states, "I knew Stepmother liked her; sometimes, they spent time chatting together while trying out hairstyles or make-up" (206). Another connection between the two women is the belief that they had little choice in terms of their present situation. Meiying was abandoned by her parents to be raised by the elderly Mrs. Lim. Stepmother also feels her choices in life have been limited by her gender and class. Sek-Lung states, "When Third uncle told me that 'Stepmother' was a ranking much more respectable than 'family servant,' more honourable than 'concubine,' but never equal in honour or respect to the title of First Wife or Mother, Stepmother remained silent" (131). There is one moment in the novel when Stepmother voices her feelings: during an argument with her husband about the availability of property 
in China after the war, which leads to a confrontation. It is the only time in the novel that she releases so much emotion: “'I chose? I was bought!' Stepmother said, for all at once she could not stop herself. She stood up, as if pulled against her will. 'Even Jook-Liang and SekLung-my own two children-call me Stepmother!" (235). Unlike Poh-Poh, the other women in The Jade Peony appear to have few moments in which they can exercise free will. It seems they have had little choice in terms of the lives they have and have survived by adapting to their present circumstances.

Towards the end of Sek-Lung's section and the novel, the tension builds for all the characters, as the events of the outside world impact ordinary family life. Keeping her pregnancy a secret, Meiying suddenly dies after a failed self-induced abortion. It is only after her death that Sek-Lung begins to see his mother outside of her official role and title within the family and claims what she means to him by affirming she is his 'mother':

I thought of Meiying and her [his mother] whispering together in that room, sitting before the dresser mirror, sharing Three Flowers perfume, easily chatting away, fluttering voices, like butterflies of palest amber, gossiping... She was looking in the dresser mirror, with an old silk shawl around her shoulders. It was the one with gold flowers that her girlhood friend in Old China had given her when she herself was just a girl, a shawl Meiying had once admired, as girls will. I thought, as Meiying must have often thought, how lovely she looked. Her eyes were wet.

\section{'Mother,' I said, 'I'm here.'}

She reached out to me. I took her hand and pressed into her palm the carved pendant Grandmama had left to me (238). 
The three characters who are marginalized by their families or community, Sek-Lung, Stepmother and Meiying, are connected in the final section of the novel. Although, unlike Meiying, Stepmother's survival tactic has been to either be silent or make compromises (Lee Canadian Literature 30). Lee also writes "Choy seems to privilege [the mother-child relationship] as liberating against the patriarchal culture of Chinatown. Juxtaposing this moment of enlightenment with Meiying's tragic death, Choy ends the novel on a provocatively disturbing yet hopeful note" (30). Taking this a step further, Choy seems to be privileging the female connection as liberating in terms of all his narrators. Another reviewer ( $T$. Matson) views the final act as a kind of catharsis or healing. With only one word Sek-Lung “corrects the confused alliances in his own family, passing along Poh-Poh's jade peony to his mother, calling her 'Mother' for the first time" (141). This act can be viewed as a reconciliation or the beginning of a bridge between the old and new ways. One reviewer of Choy's novel notes the child narrators are "bound to the complex and delicately balanced Old World of their grandmother and parents...[and] at the same time, leaving it" (Mason 38). But there is more to this balance than being caught between the Old World vs. New World. Sek-Lung's narrative is about crossing boundaries, both those which are external or physical, such as Chinatown vs. Little Tokyo, and those which are internal or emotional, such as transgressing titles and distances between people. The adults of the novel - Poh-Poh, Father, Stepmother, Mrs. Lim, the uncles and various aunts of the first generation of Chinese Canadians - represent the old ways. The children and the teen-aged Kiam and Meiying represent the tensions not only between the old and new, but between other opposing forces presented throughout the novel: dark and light, war and peace, male and female, young and old, family and strangers and, finally, official versions and unofficial 
stories and truths. The conclusion helps to show how a fusion of the two is possible and how harmony and newness can grow out of seeming opposites and discord. Yet at the same time the novel's ending with Meiying's death highlights the danger of keeping secrets and living with lies. Her story represents how the unofficial or hidden stories that are interwoven into the fabric of the three narratives can also be problematic and potentially tragic.

The three child protagonists struggle within spaces such as family and community to form their own stories and identities. Being marginal for different reasons (i.e. gender, sexual preference and "mo no"), the children are outcasts and, as such, gravitate to other border figures. Through the various female characters in the novel, the children are connected to an empowering and liberating world of secret knowledge. Poh-Poh is the keyfigure in terms of acknowledging aspects of life that are not always obvious. All the children gravitate to their grandmother as they are empowered by learning from her 'secrets' and wisdom. When Jung-Sum notes that his grandmother has the ability to see what is not obvious to others, he notes how she uses the image of the moon (associated with the feminine principle) and the dark storyteller. "In Old China, [the dark storyteller] was the one who told of hidden things not seen in the glare of daylight" (123). This is the most important way Poh-Poh transmits her knowledge. Telling stories, a key theme in the novel, is proven to be as necessary to maintaining family history as breathing is to life. The children in the novel ask their grandmother to tell the stories related to each piece of jade she keeps. The title and central symbol of the novel reinforces the idea that each object has its story, just as each person presents layers of both the obvious stories and the hidden ones that lurk underneath: 
Grandmother told that story, and then another, each story brief and sad and marvellous. There were seven pieces of jade, carved in the shape of ancient symbols. The one she held most dear, we knew was a coin-sized one, an exquisitely carved peony of translucent white and pinkish jade; its petals were outlined in a simple, carved relief against a perfect round of stone. Its underside was smooth and flawless (123-4). 


\section{Chapter Three}

\section{A Chinese Canadian Saga: Family 'History as Mystery' in Sky Lee's Disappearing Moon Cafe}

\section{Like Wayson Choy's The Jade Peony, Sky Lee's Disappearing Moon Cafe is a} 'collective (fictional) autobiography.' Lee's narrator, Kae, is the only anchor within a commotion of other voices. Her narrative is woven mainly from anecdotal evidence, presented in a series of rapid flashbacks that cover four generations of her family. Like her ancestor, Wong Gwei Chang, who is sent on an expedition to recover the bones of dead railway workers, Kae too is engaged in the process of recovering or piecing together what has been lost. As a writer she depends on language as she attempts to 'straighten out' the past and searches for a pattern. At the same time, she also realizes that language has an "unpredictable" power (184). But this power is not exclusive to the written word; like that of the narrator in The Woman Warrior, Kae's identity is shaped by oral storytelling. In order for Kae to reinvent the narrative of her family history, she must use everything at her disposal and not necessarily rely on official documents and newspaper articles. Disappearing Moon Cafe uses letters, talk-stories, a telegram, phone calls, and the narrator's own creative re-constructions, such as a ghostly gathering (or séance) in the novel's concluding pages, to understand her family history. Like the narrator in Kingston's The Woman Warrior, Lee's narrator is obsessed with what lies beneath the surface of family stories, the unspoken and hidden elements of the past. Both narrators are made aware that the past contains unspeakable secrets about select family members. Lee's work offers all the intrigue of a detective novel as Kae, the narrator/writer, and the reader are constructed as detectives unraveling the clues in the mystery. Kae is often having an on-going dialogue with herself, and many of her both dead and living family members, as she attempts to untangle a history of 
silence and oppression. Often 'official,' especially written, versions of past events appear to be unalterable and impenetrable. Bulgarian-born writer Elias Canetti writes "History portrays everything as if it could not have come otherwise. History is on the side of what happened" (Speake 66). One way 'the other side' of history is uncovered in Lee's work is her use of the ghost motif. When the narrator is given the power to resurrect the dead, the ghosts of her dead relatives are freed from the conventions and social mores of their past lives and given the freedom to explain their past actions (or in-action). Lee's work explores the connection between cultural and gender silences by giving voice and presence to women whose choices were limited by patriarchal traditions and masked under the concept of performing their 'duty.' Disappearing Moon Cafe, even more so than The Jade Peony, illustrates how the lives of both Chinese Canadian men and women were drastically altered by anti-Asian immigration policies in Canada during the 1920s and 1930s. Women's isolation and the lack of understanding for their struggles is connected to their exclusion from mainstream Canadian history. In part, Lee's novel sets out to illuminate forces such as sexism, racism, collectively imposed silences, family edicts that impede the character's freedom of choice. The alternative is to stake a claim for women as subjects who are responsible for their own actions.

Like The Woman Warrior, Lee's Disappearing Moon Cafe is a 'border project' that traverses differences between fiction and non-fiction, genders, and cultures. Disappearing Moon Cafe questions the boundaries between men and women, Chinese and Canadian, mothers and daughters, the dead and the living; all of these separations are blurred and called into question. To illustrate this, Lee introduces various characters who act as 'border inhabitants:' Mui Lan, Fong Mei, Gwei Chang, Ting An, Morgan, Kae, Suzie, and the ghosts. These border inhabitants live with, and somehow negotiate within themselves, two or more different cultures. Ghosts, also 
border inhabitants, are used to show the 'presentness' of the past and act as a vehicle for reenvisioning the historical past as well as the present.

Lee's narrator uses mainly anecdotal evidence of the past through the women who 'talkstory' around her, the same narrative technique originated by Maxine Hong Kingston. Talkstory is an appropriate vehicle for re-imagining the past, which is one of the main tasks of this novel. Disappearing Moon Cafe is often interrupted to reflect the ways in which the past (private memory) is constantly intersecting with the present in a seemingly endless cycle of beginnings and endings. The unpredictable narrative shifts also "protect [Lee's novel] against any temptation she may have had, or her readers may have, to tie up loose-ends with a totality - a pressure toward closure that few narratives can resist" (Chalykoff 158).

In the Prologue titled "Search for Bones," the young Wong Gwei Chang is sent on a mission in 1892 "to search out the bones of those who have died on the iron road, so they can be sent back home" (2). Wong Gwei Chang is sent on this journey as a young man and the narrator states that the men of the Chinese Benevolent Association had probably chosen him for the mission because "the old men had liked his face and its look of kind innocence. This youth has a tender face, but he has the look of an old soul"(2). Wong Gwei Chang is engaged in the same act that later preoccupies his granddaughter, Kae. Like Kae who must also re-awaken the dead for their stories, Wong Gwei Chang is told he must believe in his mission. An old member of the Association (like a ghost from the past who is only 'old eyes') says "To believe is to make it live! You must make your mission live, or else you will not succeed" (2). However, at that time of his life Wong Gwei Chang is lost, and searching for meaning and direction. When he finally completes his mission and delivers 'the bones' the narrator states that "like them [the Chinese Canadian workers], he would piece himself together again from scattered, shattered bone and 
then endure" (13). The 'search for bones' is a most appropriate place for Sky Lee to begin her novel. Most Chinese Canadian historical texts make little mention of this search; both Lee and Choy's novels do as it is a powerful signifier taken directly from Chinese Canadian history. Lien Chao suggests that 'searching for the bones' is a trope widely used by contemporary Chinese Canadian writers and that this search represents "the task of recovering family genealogy, Chinese Canadian women's herstory, community history" (27). In his memoir Paper Shadows, Wayson Choy remembers when he was told about the unburied bones of many of the early Chinese immigrant workers by one of his aunts:

By the onset of the Second World War, the bones of the dead Chinese who never made it back to China - who died of old age, of despair, of ill-health- languished by the ton in the Bone House in Victoria at Foul Point (Harling Bay), or were tagged and wrapped in gunny sacks piled up in damp warehouses in Nanaimo and in Vancouver.

'Spirits,' Fifth Aunty called them. 'Spirits wait for the war to end. Wait to go back to family'. Chinatown residents were never sojourners by choice. ${ }^{31}$ If they were buried in Gold Mountain, their coffins were packed into Victoria's segregated grounds at Ross Bay or tripleburied in the rocky headland at Foul Point. In Vancouver, the dead were interred in poorly drained land reserved 'For Chinese Only.'

'Yes, yes, many go back,' Fifth Aunty told me, thinking perhaps of her own father and mother's bones. 'Why?' I asked. 'They're dead.'

Fifth Aunty gave me a puzzled look. Tears welled up in her eyes. When she spoke, at last, I could barely hear her words. 'Bones long for respect,' she said (75).

In Disappearing Moon Cafe, the young Wong Gwei Chang must come to realize who the bones belonged to and why they 'long for respect.' The "macabre" (12) work of the bones search changes when he meets the "old overseas chinese" who "never wasted anything" and 
"worked unceasingly" (11). When he finally "touched the bones" of the "wilderness uncles," (12) the ghosts of the railroad workers take shape before him and he connects their experiences to his own: "they followed him about wherever he roamed, whispered to him, until he knew each one to be a hero, with yearnings from the same secret places in his own heart" (12). After meeting these men, some in the flesh and some in 'spirit,' Wong Gwei Chang experiences a change:

he had met them all - uncles who had climbed mountain heights then fallen from them, uncles who had drowned in deep surging waters, uncles who had clawed to their depths in the dirt of caved-in mines. By then, he wasn't afraid and they weren't alien any more...The next time Gwei Chang walked into a work camp, he was ready to share with them instead of taking from them. He took their surliness and learned to talk tough and blunt, a chiselled edge to his words to express the backbreaking task of survival that all of them shared day after day. They talked like comrades-in-arms after the battle, still grateful to feel the ache of so many work-worn years, to fill their lungs with mountain mist, to see their shadows walk ahead of them, homesick (13).

The title 'uncles' is used for all these men by Gwei Chang. In Kingston's China Men the narrator uses the term the 'grandfathers' for the men who were the "founding ancestors" of America. These terms reflect a broad notion of who is included as 'family' and the degree of privileging collectivity over individual feats of heroism. ${ }^{32}$ In China Men, the narrator's description of Chinese railway workers reinforces the need to see the immediacy of this history and proclaims a direct connection to those men:

[o]nce in a while an adult said, 'Your grandfather built the railroad.'

(Or 'Your grandfathers built the railroad.' Plural and 
singular are by context). We children believed that it was that very railroad, those trains, those tracks running past our house; our own giant grandfather had set those very logs into the ground, poured the iron for those very spikes with the big heads and pounded them until the heads spread like that, mere nails to him (126).

The men here are depicted as having almost super-human strength as the narrator witnesses some of the feats they accomplish. In Lee's Disappearing Moon Cafe, Gwei Chang is both physically and spiritually marked, changed forever, after he witnesses the collective experiences of the men in the Canadian work camps.

Wong Gwei Chang is at first hesitant about this mission. Like all the other main characters in this novel, he is faced with difficult choices. The first hard choice Wong Gwei Chang is faced with is whether to give up the expedition to work as a servant in one of the rich houses in Victoria (6). In other words, he must decide to give up a spiritually meaningful endeavour for a more lucrative one. The second choice Wong Gwei Chang must make is whether to stay with Kelora Chen, a woman he meets in the mountainous woods of British Columbia's interior. At first, Wong Gwei Chang thinks she is "another spirit here to guide him over to the other side" (2). He eventually marries Kelora, whose mother is Native and whose father is Chinese, and they have a son: Ting An. Though he does complete his public 'mission' with the help of Kelora and her elderly father, he decides to leave Kelora, mainly out of fear of poverty and instability, and return to China for a traditional arranged marriage with Mui Lan. The origins of the 'trouble' in Kae's family history actually begin with the 'founding father' of the Canadian family-line, her great-grandfather, Wong Gwei Chang.

Kae's voice first appears in the first chapter after her great-grandfather's 'Search for Bones,' titled 'Waiting for Enlightenment.' Like him, she is on a quest to retrieve the past, 
but when she comes to the point in her life where questions about the past resurface with greater urgency, she has no map to follow and, initially, no one to offer guidance. Like the narrator in The Woman Warrior, Kae seeks "ancestral help." Here, in her mid-thirties, she has achieved many of the external markers of success: a successful career, a partner, a child. She appears to be a feminist free-thinking individual and yet she waits, as she did when she was a child, with an ominous sense of foreboding for something to happen. Now disappointed in adulthood, she states,

I've been brought up to believe in kinship, or those with whom we share. I thought that by applying attention to all the important events such as the births and the deaths, the intricate complexities of a family with chinese roots could be massaged into a suant, digestible unit. Like a herbal pill - I thought I could swallow it and my mind would become enlightened (19).

But Kae will have to do much digging and disentangling of these 'chinese roots' before attaining any form of enlightenment. She feels that her choices in life have been deeply affected by her parents withholding certain truths about the family's past and pretending that everything was uncomplicated: "I get tricked because I want to be so damned perfect all the time. Now I've found that nobody has told me the whole messy truth about anything!" (20). Kae is given the core of the 'whole story' in the hospital after she gives birth to her son, Robert, and after her mother loosens "a little of her iron grip on her emotions in order to reveal a little of her past that she thought so shameful - the same past that has shaped so much of my own life, with evil tentacles that could have even wormed into the innocent, tender parts of my baby" (23).

After the birth, Kae's mother begins to 'whisper,' the truth by saying "'but there has 
been much trouble in our family. It's best that what I tell you does not go beyond these four walls"' (23). Kae comes to see 'not telling' as a culturally transmitted trait:

Maybe this is a chinese-in-Canada trait, a part of the great wall of silence and invisibility we have built around us. I have a misgiving that the telling of our history is forbidden. I have violated a secret code. There is power in silence, as this is the way we have always maintained strict control against the more disturbing aspects in our human nature. But what about speaking out for a change, despite its unpredictable impact! The power of language is that it can be manipulated beyond our control, towards misunderstanding. But then again, the power of language is also in its simple honesty (180).

The narrator acknowledges that there is a power in silence, but it is to manipulate and withhold information. In this instance, silence is damaging; at least frustrating, but at most, potentially fatal. Kae blames her family's silences for allowing a series of unhappy and/or disastrous relationships to continue, and for the eventual suicide of her aunt Suzanne. The forbidden, the secrets her family cannot speak of are the outgrowth of various nontraditional relationships: falling in love or having a relationship with someone from a different social class, race or culture (Kelora Chen and Wong Gwei Chang; Beatrice and Keeman; Choy Fuk and Song An) and engaging in an adulterous affair (Fong Mei and Ting An) lead to 'complications' and the unspeakable. Finally, with the possibilities of selecting a mate becoming drastically limited by racist exclusion laws in Canada, Lee illustrates how Vancouver's Chinatown becomes 'ripe and ready' for the ultimate taboo: incest.

Disappearing Moon Cafe is about confronting taboo aspects of culture and breaking the silence and forbidden nature of secrets. Kae must unravel the layers of lies and realizes that her mother, aunt and grandmother are tied together; grandmother Fong Mei cannot save either daughter from the "entanglement" that continues by her disapproval of her daughters' 
relationships (163). The truth of the family past is finally unravelled by Kae when she is made aware of her aunt Suzie and the disturbing death of her son, the last Wong male who dies at birth. Kae realizes the destructive power of these family secrets: "[t]heir insular little world - an ivory sphere, protected by layer upon layer of filigreed lies, all revolving independently of each other, finally collapsed like a decomposing melon. Those who would cling to the wreckage clung; those who didn't spun into oblivion" (163).

Like the talk-stories shared by the men and women in her family, Kae is in the process of 'transforming' silence by the hearing, telling, re-telling and recording the stories she hears. In this way, Kae is finding her way through varied and often contradictory stories. The abstract process is concretized by Kae when she states, "In writing, I feel like a drunk weaving all over the road. The air can be made wavy and warped, hot with tension, full of mirages. Or details can be made to distract extravagantly, cling possessively. Information can cringe from pain, or reply in a cold detached manner. How many ways are there to tell stories?"(185) Kae is in the process of discovering that there is no one 'master' narrative but many voices which in the end can speak as one. As Lee is playing with melodrama's conventions, Kae comes up with several parodic titles for her stories: 'House Hexed by Woe' or 'Temple of Wonged Women.' These titles reflect how family stories, like sagas, can be romanticized. Kae tells her nanny $\mathrm{Chi}$, “in the end, entire lives are nothing but stories" (209). Yet this does not necessarily mean that the stories are false. Kae, like the narrator in The Woman Warrior realizes that there are multiple lived realities that can coexist and all be equally 'true.' Lee reinforces the fact that life stories are left open to several interpretations as opposed to one 'official' version. Disappearing Moon Cafe is revisionist and seeks to reframe the historical past by reflecting other possibilities. Chao states: "the 
historical silence of Chinese women in Canada can be broken by breaking through the silent archival documents and rewriting the existing history. Breaking through the silence means constituting minority women as agents" (338).

Like The Woman Warrior and The Jade Peony, Disappearing Moon Cafe is a work that exhibits an interplay of various literary forms. Lee's work can be considered a border project between fiction and non-fiction as fictional autobiography and "like many diaspora narratives...a loosely autobiographical rendering of family and ghetto history" (Peepre 14). Lee also parodies and revises the romance genre, a hybrid form which allows writers to combine elements of reality and fantasy. The term 'romance' has two distinct uses:

In common usage [romance] refers to works with extravagant characters, remote and exotic places, highly exciting and heroic events, passionate love, or mysterious or supernatural experiences. In another and more sophisticated sense, 'romance' refers to works relatively free of the more restrictive aspects of realistic verisimilitude (Holmon and Harmon 413).

Northrop Frye viewed romance as occupying a space between myth (or fable) and mimesis (Holmon and Harmon 413). According to Frye's assessment, this middle zone allows a writer the freedom to create characters that are god-like in their passions and powers, but demonstrate the same weaknesses and confusion experienced by human beings.

In Disappearing Moon Cafe, Kae cannot help but marvel at, but also criticize, the women in her family for partially contributing to their own or another woman's misery and destruction. Kae cannot promote these women as typical heroes of the family saga; this tradition rejects women as heroes. The truths she learns about the women do not diminish her sympathy for them as she gains an understanding for the circumstances in which they lived: 
In the telling of their stories, I get sucked into criticizing their actions, but how can I allow my grandmother and great-grandmother to stay maligned? Perhaps, as Hermia suggested, they were ungrounded women, living with displaced chinamen, and everyone trapped by circumstances. I prefer to romanticize them as a lineage of women with passion and fierceness in their veins. In each of their woman-hating worlds, each did what she could. If there is simple truth beneath their survival stories, then it must be that women's lives, being what they are, are linked together. Mother to daughter, sister to sister. Sooner or later, we get lost or separated from each other; then we have a bigger chance of falling into the same holes over and over again. Then again, we may find each other, and together, we may be able to form a bridge over the abyss $(145-6)$.

In remembering her grandmother, Kae is struck by the fact that she had a somewhat idealistic view of her grandmother. She states, "I do know of her [grandmother, Fong Mei] indirectly through my mother, who used to hug me all the tighter whenever she talked stories about her own mother to me. Everything about her seemed so good and beautiful, like a fairy godmother. When I was young, I used to get her mixed up with my mother all the time" (37). Kae believes that "the two lives [of mother and grandmother] flowed together, one into the other, so perfectly" (37). Though relations between the women are in no way 'perfect,' Kae, like Kingston's narrator, is able to see how women's lives 'branch into' each other.

Graham Huggan situates Lee's novel within the tradition of "genealogical romance...a tradition in which romantic (mis)adventures are assimilated to identitary fable, and the generational conflicts of an extended family are contained within a redemptive structure of collective - 'group' - endeavour" (39-40). Though Lee reflects elements of the romance tradition in her work, she also subverts it, "using the disruptive potential of the romance form to cut across its own idealistic pretensions" (Huggan 40). 
Huggan notes Lee's use of "the discontinuous structure romance to dispute the patriarchal law of genealogical descent"(40), much like Wayson Choy in The Jade Peony. It is no coincidence that Kae uses the phrase "a lineage of women" since "the phrase envisions a female romantic saga which is based on women's collectivity" (Chao 101).

Kae's friend Hermia offers her some direction in terms of how she views her female relatives. Hermia asks Kae:

'Do you mean that individuals must gather their identity from all the generations that touch them - past and future, no matter how slightly? Do you mean that an individual is not an individual at all, but a series of individuals - some of whom come before her, some after her? Do you mean that this story isn't a story of several generations, but of one individual thinking collectively?' (189).

One reason for this common connection among women could be that one woman acts as witness for another. In Betrayal and Other Acts of Subversion, Leslie Bow finds commonality within plot structures of various Chinese American and Chinese Canadian works. These include Lee and Kingston's which "place the female protagonist in a position of witnessing women's oppression, either that of the previous generation or of contemporaries associated within an ethnically distinct home-space" (72). In narratives where there exists what Bow terms this "genealogical transmission" there can also be found the underlying belief that women have the ability to be able to make better choices in life. In Disappearing Moon Cafe, it is neither marriage, nor economic freedom, nor immigrating to Canada (which is perceived as being "ultramodern"(42)) that gives women a sense of individual or collective agency. It takes several generations for the women to realize that although they seem alone, there is interdependence based on shared experiences between 
them.

Lee rejects the solitary perspective of a first-person linear narrative in relating family history, even history itself. The distant past, the more recent past and the present are constantly intersecting within the various chapters as the narrator relates and also comments on the stories of several other characters. These disruptions are an attempt to undermine the uninterrupted line of patriarchal descent reflected in the family saga. Though Wong Gwei Chang, the 'founding father,' begins and ends the narrative, the women of the family (greatgrandmother, grandmothers, mothers and daughters) consistently 'disrupt' the family line by telling their views of the past. Huggan claims that unlike the linearity of realist narrative, "romance patterns itself on the discontinuous" (44). Through 'romance patterns,' Lee can tell the women's stories and at the same time undercut some of the patriarchal mandates that limited their lives. Completeness, authenticity and reliability are all questioned in Lee's work since none of the narratives in Disappearing Moon Cafe are complete or entirely reliable.

Lee's novel also playfully ridicules the 'cult' surrounding romantic love. Chinese women were often trapped by arranged marriages but the traditional Western illusions surrounding romantic love do not afford much more freedom. Kae's great-grandfather, great-grandmother and grandmother all base their choice of partners on maintaining class status and upholding tradition. Though Kae views them as 'cowards' for giving up true love, the ideal of romantic love is treated with irony. For instance, during one of Ting An's early passionate encounters with Fong Mei, the two lovers come up against a contrived image of Western heterosexual love and the newest symbols of middle-class comfort: 
Ting An was too overwhelmed to move, but Fong Mei sprang to her feet and pulled him into the Wong's kitchen with surprising strength. She backed him up against the wall and held him hostage, eagerly pressing against him. His head still reeling from the shock of this welcome, he fell back onto a calendar tacked to the wall with a nail. Everybody had apparently been too busy to tear off the previous month, already long passed. It still decorated the household with a maudlin image of a ghost-boy beneath a huge, resplendent umbrella, mooning in total adoration of his ghost-girl love. On top, fat winged cherubs danced, floating in the air, cheekily testing for raindrops. The curly, golden-haired girl looked out at the prosperous kitchen with its ultramodern refrigerator, and half-smiled knowingly (119).

In terms of their marriage partners, women like Mui Lan and Fong Mei base their choice on economic security and social status, not passion or love. A choice based on economics is shown to be just as delusional as one based on romantic illusion. In this instance economic status and popular images of romantic love are contrasted with Fong Mei and Ting An's melodramatic, physical encounter. Images of romantic love and its illusionary nature are also linked to Fong Mei and Mui Lan:

The waitress married the gambler. Mui Lan got deposed. And Choy Fuk kept his mouth shut. So, one could say that life marched on. But what about other hidden entanglements - the corrosive mess underneath, which eventually would make the bottom fall out? Well, except for one little story that happened right after my grandmother had my mother, the rest may be just embellished speculation... This story was told to me by Morgan Wong. How he came to know it, and why this particular incident endured, I don't know. But I believe it is true, because my mother still has the teak chest-not very good quality - decorated with plum blossoms and phoenixes, a romantic scene of a scholar with his maiden-love carved in relief, except the maiden's face is a bit lopsided (136). 
Here, as elsewhere in the novel, Lee pokes fun at romantic love by juxtaposing fantasy with reality. The story that surrounds the chest is about Fong Mei threatening Mui Lan with a pair of scissors. When Fong Mei refuses to store her baby's clothes in the chest, Mui Lan curses her for "contributing to the ruin of the Wong clan" by being lazy, having "unlucky eyebrows" and for not producing a male heir (136-8). This story of Kae's grandmother and great-grandmother comes to her 'second-hand' from Morgan. Though Kae might be able to prove there is some truth to it, she cannot be sure of whether it has been embellished or how her source came by it. None of the stories she hears can be taken as wholly reliable. Kae realizes that appearances cloud reality and that family history is deceptive.

Kae's work is the process of untying the knots surrounding the 'truth' about her family. To reflect the complexities of this task, Lee makes reference to the family saga but parodies its seriousness in the process. The term 'saga' was originally applied to medieval Icelandic and Norse stories which contained accounts of heroes and their adventures. Family sagas focus on a collective cultural inheritance of a specific group of individuals, telling the stories of those who shape a culture's history and traditions. Yet these narratives also contain mythological elements. Situated between fiction and non-fiction, 'saga' itself is a hybrid, a representation of a constantly shifting duality and an interplay of two forces: fantasy and reality. The saga represents the fluidity of the past and the process by which mythology can turn into history: "[t]he term came to be used for a historical legend till it was accepted as true - a form lying between authentic history and intentional fiction" (Holmon and Harmon 422). ${ }^{33}$

Disappearing Moon Cafe is about confronting taboo aspects of culture and the forbidden nature of secrets. Kae must unravel the layers of lies and realizes that her mother, 
aunt, and grandmother are tied together. Grandmother Fong Mei cannot save either Suzie or Beatrice from the "entanglements" that are her daughters' relationships (163): the sisters are both involved in 'incestuous' relationships though one is real and the other is only assumed by the family (Suzie with Morgan and Beatrice with Keeman). The birth and death of Suzie's son is the symbolic outcome of keeping secrets; but the novel begins with another birth (Kae's son) that signals the start of uncovering this interconnected web of secrets and lies.

In contrast to Kingston's narrator who invokes the intricacies of tying ornate knots, Kae uses untying knots as a metaphor for her quest of finding truths behind her family's wall of silence and secrecy: "My private life is what I find confusing. At home, I must work at unraveling knots- knots in my hair, knots in my stomach. Knots of guilt; knots of indecision. Knots in our dainty gold chains. Figurative knots in our children's shoelaces. Do not panic lest we get more tangled! We must pick, trace, coax and cajole each knot out. One at a time, even when we know there are hundreds more (123). Further, when Kae imagines a meeting between her dead and living family members and friends, her dead aunt Suzie is shown to have had the same feelings of desperation : 'knot after knot after knot!' Sue cries. 'All this bondage we volunteer ourselves! Untie them! Untie me! Don't tie any more!' Kae is an unraveller of narrative knots. As she undertakes this journey, there are three characters who help her fray the 'tapestry' of her family past and who act as guides by giving her clues that help her piece together some of the mystery about the past. These characters are her childhood nanny Seto Chi, her one-time boyfriend (and great uncle) Morgan Wong and her close friend Hermia.

Chi is especially important in Kae's life since she was one of her primary care-givers 
and the one who later gives her the most information about Kae's dead aunt, Suzie. Kae realizes that she cannot rely solely on Morgan's tainted memories of her aunt. Like the narrator of The Woman Warrior, Kae is obsessed, and at times possessed, by the ghost of a dead female relative. Kae claims she has an "unwholesome curiosity surrounding [Suzie's] demise" (191) as though finding out the truth about her aunt's life and death is forbidden. Kae is connected to her dead aunt in many ways. She is born the same year her aunt dies (192). In one instance, Morgan's troubled mind confuses Kae with her aunt Suzie, his former girlfriend. During the last few days she spends with Morgan, Kae realizes that "His [Morgan's] bedroom was filled with the heaviness of her ghost. She possessed us like the heat wave pressing down on us, shimmering off the cars and pavement" (165). Kae seems to enter Suzie's body and the two women are collapsed into one during the scene where Suzie/Kae is giving birth: "Suzie is on the verge of death again; her labour long and hard. Suzie is worn out, gasping for air; I got slurped in. 'I can't take any more,' my dark, clammy moan" (206). One is reminded of what Kae states in the beginning of the novel: the 'mystery,' "the story - the well-kept secret" (23) of the past finally ends with the birth of her son. It is not just the "sentimental occasion" (23) of birth that frees Kae's mother to reveal the truth. On a subconscious level, Kae's unraveling is reinforced in the way that her life shadows her aunt Suzie's. Kae clearly states, "I could find my way in my own stories about Suzie" (174) and she does so with the assistance of Chi. Chi tells Kae that Suzie "was desperate to break out" (175) of the role that her family's status and tradition imposed upon her.

Chi's family history is just as complicated as Kae's or Hermia's. Chi tells Kae "...both your father and I come from rather dubious parentage" (132). Kae notes their 
connectedness: "[o]ne was born out of infidelity, the other of mercenary intrigue, as for myself, I was tainted with incest" (132). Chi was born in Malaysia to a Chinese family whose fortunes had fallen. Her mother sold her to a Hindu couple shortly after she was born and she was raised with their other children. But she lost this family after the Japanese invasion and she escaped to Vancouver, Canada with one brother. Beatrice, Kae's mother, meets Chi at school and the narrator describes her as follows: "her features seemed unmistakably chinese, but she had a long, well-oiled single braid down her back, she smelled of curry, and she barely spoke english at all except with a thick tamil ${ }^{34}$ accent. Her toes stuck out of a pair of torn sandals although it was October, albeit a warm October" (129). Seto Chi, much like Mui Lan, Fong Mei and other characters in this novel, assumes an identity out of an instinct for survival: "Chi was a rare oddity and seemed profoundly happy to stay umbilically attached to my mother. Like a hatchling, Chi must have had to imprint immediately lest she get misplaced again - maybe permanently. Following an instinct for survival in a hostile situation, she had to assume an identity, preferably one which would nurture her back" (130).

Chi's identity is comprised of more than just her role as nanny. Kae states that Chi is “my mother's housekeeper, also dreamkeeper and protectress; my mother's barker. When Chi stands behind me, I am confident someone is always there to hold out a hand in case I falter" (127). An important bond exists between the two women. There is an acceptance by Kae of her mother's friend and her care-giver as "other mother" (Chao 101) and Kae refers to Chi as a "(trans)parent." Chi's relationship with Kae is part of the extensive network of family that extends beyond blood-lines and closed parent-child family nucleus. When Kae needs help in her household after the birth of her son, it is Chi and her mother who bring 
order, comfort and stability: "Peace and serenity descend. A feminine order takes charge; a hearthlike warmth alights. Magic" (127). Kae states, "Chi, my old nanny, was the only one who could finally chase me into bed, relying on her folksy, peasant image to cut through the nonessentials. As a (trans)parent, she established an intractable reference point for power between the two of us right from the start. She had all, and I had none. Simple and also quite elegant, if you think about it" (127).

The person that Kae has the most difficulty with and cannot relinquish power to is Morgan Wong, another one of the guides for Kae's quest who is always giving her "yet another version of another story" (163). When Morgan tells the adolescent Kae point-blank, "your grandmother had a lover - my father. Your mother and I are half-brother and sister," Kae becomes enraged. As Morgan reveals the truth to Kae, Lee uses their confrontation to de-sentimentalize the way Kae views the past. Kae can now begin to look beyond the illusion of a "divine memory"(84) of her ancestors. Initially feeling that Morgan 'soils' the nature of her family origins, her words also reveal that the Wongs used money and power within the community to construct an image of legitimacy. Kae states, "[s]uddenly, I felt so ashamed for lusting after this incredible creep, this blasphemer who was assaulting the integrity, the sacred legitimacy, of my family origins. The honour of ancestors and descendants was at stake! And the more money, the more righteous!" (85). Though Kae calls him a "rotten-egg bastard" (86), Morgan tells Kae the truth she later longs for: like Hermia, his life and words complicate Kae's notions of family origins and the legitimacy and clear directness of lineage.

After Morgan places doubts in her head, the teen-aged Kae begins to imagine all sorts of possibilities for her relatives: 
Compared to my prim Poh Poh, she [Ngen Ngen] was casual, too easy and sloppy, although I just could not picture her with a secret lover no matter how hard I stretched my imagination. Yet, come to think of it, she did have this sleazy way of walking. It must have been worse in her prime - perm-burnt frizzy hair, rouged lips, bedroom eyes glazed over with indolence. A swaybacked shuffle from booth to booth, slowly swinging her voluptuous hips from side to side. It must have driven those Chinatown bachelors wild with lust...Suddenly it occurred to me I was allowing him [Morgan] to soil my Ngen Ngen's divine memory too. She was a wonderful woman, kind and giving (86).

Though the alternatives Kae supposes may be equally untrue, they still lead her to question the version of family history she had previously believed. Kae remains 'deaf' to Morgan's story as the 'revelation' episode ends with a car accident on a stormy winter night. She hears Morgan yell “'Duck, Sue!” as in that moment he collapses the memory of Suzie with Kae. After the accident, Kae realizes that all Morgan had told her was true when she sees Morgan and her mother confront each other in the hospital as "longtime, mortal enemies" (89). Initially, Kae does not trust Morgan's version of her/their family history:

Was his [Morgan's] story the same as my story? Or should I have said, is history the same as mystery? ...Too bad for my family that money couldn't buy long life (prosperity couldn't buy posterity either); too bad for me, I could have simply asked. Instead of dead, silent ancestors who kept me hanging by a million possible threads, someone would have told me - I'm sure. Instead of Morgan busy fraying the tapestry, I could have claimed my righteous inheritance to a pure bloodline. I wouldn't have fallen in love/hate with his/my truth and wasted all these years trying to answer him (66).

Kae believes the truth Morgan reveals about being her uncle is an act of destruction against the stability and order her family has attempted to maintain. This act of 'destruction' is 
represented, as in a 'romance' novel, by a dramatic external event: Kae and Morgan's car accident. Years later, after she gives birth to her son, Kae states "[a] close scrape with death always makes us want to rethink our lives or, to be more candid, rewrite it wherever possible" (21). Morgan echoes her friend Hermia's affirmation of collectivity, as he tells Kae, "No matter where you turn, we're all related in the end" (69), but his words do not offer comfort. Kae sees Morgan "busy fraying the tapestry" (66) but blames her ancestors who leave her 'hanging' by their silence.

Morgan begins calling into question the uniformity of family history by telling Kae about Chinatown and the community's reaction to the Janet Smith trial. Morgan tells Kae about the community 'banding together' over the Janet Smith trial in 1924 explaining that the story "told a lot about Vancouver then" (68). The trial is an example of how "throughout the 1920 s Chinatowns, especially the one in Vancouver, continued to excite the imagination of white society" (Con 177). ${ }^{35}$ A white female domestic worker was killed in a prosperous Vancouver district and the main murder suspect was a Chinese male domestic worker. The male worker was eventually acquitted "with much consequent fund-raising in the Chinese community in support of the legal expenses of the accused" (Con 178). Morgan tells Kae “'It [the trial] was a historical landmark in British Columbia's usual pattern of interracial relations... Chinatown fought back the rising tide of virulent hatred headed their way, and for a change, they won!" (68). Morgan retells the story of the trial to Kae and the role of their great-grandfather ("the old patriarch') in the events of "those bizarre times" (67). The feelings of those in the community must have reached a fevered pitch as Morgan says "[l]et me tell you, the whole town went nuts! The Chinese Exclusion Act - the Day of 
Humiliation - and then this killing"(67). Early in Choy's The Jade Peony, the narrator explains the Exclusion Act and its outcomes:

'Go to Gold Mountain,' they told one another, promising to send wages home, to return rich or die. Thousands came in the decades before 1923 , when on July $1^{\text {st }}$ the Dominion of Canada passed the Chinese Exclusion Act and shut down all ordinary bachelor-man traffic between Canada, shut off any women from arriving, and divided families. Poverty-stricken bachelor-men were left alone in Gold Mountain, with only a few dollars left to send back to China every month, and never enough dollars to buy passage home. Dozens went mad; many killed themselves. The Chinatown Chinese call July $1^{\text {st }}$, the day celebrating the birth of Canada, the Day of Shame (17).

The effects of the Chinese Exclusion Act are far-reaching, affecting several generations. When her children are grown, Fong Mei also has fears that the discriminatory exclusion laws against the Chinese had all but eliminated immigration: "there was such a meagre number of young people - no new immigrant blood. What few there were, were native-born. Since 1923 the Chinese Exclusion Act had taken its heavy toll. The rapidly diminishing chinese canadian community had withdrawn into itself, ripe for incest" (147). Fong Mei is aware of this long before 'entanglements' ensue between her daughters, Keeman and Morgan: "the truth was that Fong Mei had always been ten-parts nervous about the smallness and intimacy of Tang People's Street. Her plan was to eventually transplant Beatrice, John and Suzanne back into China" (140). By "[a]nalyzing the impact of racism, patriarchy and class-striving on the lives of her ancestors, Kae uncovers and begins to interrogate the ideological structures that systematically reduce the lives of individuals" (Bow 105). Only after this process is complete can Kae free herself so that she may be able 
to choose a new life, which includes writing and a relationship with Hermia. ${ }^{36}$

Kae marvels at how aspects of Hermia's identity could be so unproblematic for her: "I used to marvel at how carefree she was and wondered how anyone chinese could be that lighthearted" (39). It is disappointing that Kae never directly confronts Hermia by asking her how she feels about her parents, family and 'illegitimacy.' Kae only thinks "I wondered what it was like to be the misplaced bastard daughter of a gangster and his moll - no matter how moneyed. I would be afraid of an identity like that" (41). For her part, Hermia seems to view her 'family' situation in a realistic way: she demonstrates light-hearted humour and takes full-advantage of her class situation and her father's money. Opposite Hermia, Kae states, "What a coward I was! I was afraid of risks, and I had to cling to the ground, pebbly and jagged. I wallowed in petty detail and ignored the essence. Legitimate, traditional and conventional were the adjectives to wear in those days, especially when I suspected my own identity might be as defective" (41). For Hermia, legitimacy is rejected from the start. Nothing about Hermia's family is conventional and so she 'complicates' the standard view of family and origins for Kae. She also re-directs Kae's energies by forcing her to confront the way she views women and writing about women's collective experiences: “'I don't have to tell you this. Kae, your chinamen stories are about, how shall I say - trying to fit in any way we can...Sweetie, why don't you write about women trying to fit in any how they can do it?"'(138).

The women that Hermia tells Kae to write about live an experience that includes a double discrimination for their race and gender; this leads to women such as Mui Lan and Fong Mei having shared experiences of exile, alienation and isolation. The narrator sees the 
commonalities connection between these women, but she is astute enough to simultaneously distinguish the nuances of difference in their experience:

[o]ne generation between mother and daughter, and already how far apart their goals and sentiments. They shared a common experience, but while Fong Mei hated this country, which had done nothing but disqualify her, Beatrice had grown up thoroughly small-town canadian. While Beatrice hardly knew anywhere beyond the quiet streets of Vancouver, Beatrice's mother hated this pious town, which kept her bored and labouring like a poor woman. After Ting An had finally ejected her from the last bleeding shreds of his heart, she hated him too. She hated her marriage, and her mother-in-law especially. She longed to leave them all and go back home (164).

Fong Mei understands she had few opportunities to make life choices, just as she also sees her children's futures are limited. On the one hand, the Chinese community is small and offers few choices; on the other, the first generation of the family born in Canada is also barred from full participation outside Chinatown. Even before her children are fully grown, Fong Mei plans to send them back to China. Fong Mei's daughter Beatrice (Kae's mother) is denied entrance into a music school since "they said that her english marks were not good enough" (202). However, her sister Suzie notes "I could see that stinking old man who was supposed to be the head of the department couldn't even look at Bea without hate oozing from every pore. Pure envy and jealousy that a mere girl, and chinese to boot, should be so gifted"(202).

Life within one of Canada's earliest 'ethnic ghettos' was far from ideal and the government regulations and racist lobbyists that led to Chinatown's inception and poor conditions were based on irrational fears of Chinese 'propagation' and racial 'contamination'. The Jade Peony and Disappearing Moon Cafe both use Vancouver's 
Chinatown as a main setting, presenting Chinatown as a lived reality for their characters, as neither writer either idealizes or entirely denigrates this space. In The Jade Peony, Choy describes the poor conditions in an area of flats where 'forgotten' men live and the name of the place itself suggests the irony of what was awaiting many of the men who thought they were coming to the 'Gold Mountain':

In the city dump on False Creek Flats, living in makeshift huts, thirty-two Old China bachelor-men tried to shelter themselves; dozens more were dying of neglect in the overcrowded rooms of Pender Street. There were no Depression jobs for such men. They had been deserted by the railroad companies and betrayed by the many labour contractors who had gone back to China, wealthy and forgetful. There was a local Vancouver by-law against begging for food, a federal law against stealing food, but no law in any court against starving to death for lack of food. The few churches that served the Chinatown area were running out of funds. Soup kitchens could no longer safely manage the numbers lining up for nourishment, fighting each other. China men were shoved aside, threatened, forgotten (17$18)$.

In Disappearing Moon Cafe, Ting An recognizes the claustrophobia and tensions of this space: "this dead town was full of vicious ghosts" (107). In some sense, Chinatown was viewed as a 'ghost-town,' a borderland on the fringes of society, by non-Chinese Canadians. In "Representing Chinatown: Dr. Fu-Manchu at the Disappearing Moon Cafe," Maria Noelle $\mathrm{Ng}$ suggests that in the early twentieth century, the white community viewed Vancouver's Chinatown as a lawless ghetto with opium dens housing gangsters and prostitutes, and that "the area was condemned as morally pestilential" (158). $\mathrm{Ng}$ examines the stereotypes surrounding fictional representations of Chinatown and reads Lee's work as "proof of the lingering power of stereotyping in ethnic characterization and setting" (163). 
There is an ongoing dialogue among critics of Chinese Canadian literature in terms of whether it is right to depict Chinatowns, laundries, and restaurants as the necessary backdrop for stories about Chinese Canadians. Critics like $\mathrm{Ng}$ reject these "easily recognizable locations and plotlines"(173), yet these were very real locations where many Chinese Canadians lived and worked. $\mathrm{Ng}$ is right to point out the danger of allowing these settings and plots to dominate and that Lee's work alone is "not sufficient" to teach anyone about Chinese immigrant culture. To paraphrase Kingston, these are writers and not anthropologists or sociologists. However, it is often the case that the ethnic minority writer is put in the position of having to be either a community activist and /or an archivist (Chao 27). $\mathrm{Ng}$ warns that one must "locate the Chinese immigrant experiences featured in Sky Lee's novel historically, in order to avoid wallowing in nostalgic recapitulation of what the white community has done to the Chinese, instead of actively accepting the Chinese now living in Canada" (164). Focusing solely on the victimization of the Chinese in Canada does not achieve very much; it would be wrong to homogenize all Chinese immigrants with few distinctions. $\mathrm{Ng}$ warns that certain images Lee uses of the early Chinese immigrant community, the gambling and 'secretive' meetings, may reawaken images of "illegal activities and gang warfare" (165). Historical texts that focus on Chinese Canadian history indicate that whites were equally attracted to and frequented Chinese gambling places (Con 178). Further, with Lee's depiction of the men meeting during the Janet Smith trial, $\mathrm{Ng}$ fears readers may misinterpret the positive aspects in the 'brotherhood' of the Chinese Benevolent Association and see only negative images that are "patriarchal, paranoid, potentially violent, illegal...deeply misogynistic" (165). But Lee does illustrate the positive aspects of the Association and the need for its existence for her readers. Although the writing of the men's 
dialogue does reflect patriarchal and misogynistic notions, this inclusion illustrates the fact that Chinese Canadian women had to confront racism in the dominant culture and sexism in their core culture.

Chinatown exists as a representation of segregation and exclusion since this space was originally a site where early Chinese immigrants had to live because they were barred from living and working in Caucasian areas. In The Enigma of Ethnicity, Wilbur Zelinsky considers Chinatown as a "sort of faux ethnic façade" (73). Many Chinese immigrants could not own property and the buildings were designed by white architects and developers. Zelinsky quotes Dell Upton who states 'these 'Chinese' buildings were designed by people who had never seen the originals themselves" (73). The buildings themselves were often cited as being non-authentic and historians have labeled the building designs as "invented tradition" (Zelinsky 238). The historical focus of Chinatown often fixes this space as an ethnic ghetto and later a revenue-generating tourist attraction which promotes a distilled version of Chinese culture. Both Disappearing Moon Cafe and The Jade Peony tear down the building's 'exotic' facades to reveal a real community of substance beyond exteriors, a place Chinese Canadians lived their everyday lives. In Disappearing Moon Cafe, Chinatown at one time was a "tight watchful community" (94) that stepped in to aid the waitress, Song An. But at the time Wong Gwei Chang is one of its elders, Chinatown is in a process of transition and changes in attitudes brought by new immigrants of another generation:

He [Wong Gwei Chang] realized that the old ways in Chinatown were fast disappearing. He played a so-called prominent role in the associations now, because the oldtimers had agreed to give him big face. In the old days, they'd had to band together to survive. Share a little more during good times, share a little less during bad. Years ago, the game had been deadlier; protection was 
sought. Everybody need to play by the rules, abide the leader. But Chinatown had grown. He had no real say in this motley social order anymore. More and more, the patriarch came face to face with young, hostile loners like Wong Foon Sing, who'd just as soon tell you to go die! Fart in your face! They had no respect. Why should they follow you. As soon as they get off the boat, they were all out for a good time and easy money. Like wild beasts, they'd eat their own kind for it too. However, if they found themselves in trouble, they'd surely come back then, trailing police-devils behind to ransack Chinatown. They didn't care that the devils would gladly wipe out the whole fellowship for the folly of one individual (80).

Wong Gwei Chang sees that isolation has forced those in the community to develop their own resources for survival. In From China to Canada: A History of the Chinese Communities in Canada, historians, sociologists and anthropologists explain how the physical setting and construction of Chinatown doomed it to isolation and other unhealthy living conditions from the start:

Vancouver's Chinatown was comprised only of wooden buildings, many of which were shoddily built. Furthermore, its location at the marshy extremity of False Creek did not lend itself to sold construction, and many shacks were raised on piles over ground too wet for foundations. Some of the shacks were 'dilapidated and filthy,' and the surrounding land was saturated with 'manurial refuse and garbage,' for the houses on Dupont street were not on the sewer. Many Chinese suffered serious overcrowding which further exacerbated the unhealthy living conditions...overcrowding in the boarding houses caused some concern among nonChinese, although usually this issue was raised by the anti-Chinese racists rather than by those seeking to improve conditions (Con 64-5).

The economic conditions and racist fears of 'contamination' that led to its creation contribute to the claustrophobic feelings of the inhabitants. The 'tightness' and wall of 
secrecy around the community may be stifling but this allows elders, like Wong Gwei Chang, some measure of control. Fong Mei is perceptive and forward-thinking enough to see that selective immigration would eventually have disastrous results on the Chinese community. Legislation enacted within Canada's Immigration Act, such as the Chinese Immigration Bill in 1923, "would virtually terminate further Chinese immigration" (Con 141). Lee connects the community's claustrophobic atmosphere, inclinations to secrecy and limited job opportunities (for both men and women) with the crime of murder (the Janet Smith trial) and the taboo of incest. The male Chinese worker accused of the crime is portrayed as being trapped within this community:

What boy wouldn't have dreams to sustain him while he toiled in the filth and stench of a laundry? Wonderful dreams of adventure and prosperity in a big land...He had meant to learn proper english right away, but when he arrived he found everything too overwhelming. He spent months staring into space, at the same time able to wander about only in 'safe for chinamen' areas. Beyond his grinding work routine, the most he could do was loiter on the outer reaches of Chinatown and stare at caucasian pedestrians. Sometimes, he felt flattened like an insect on the limited horizons of Chinatown (222).

When Morgan describes the atmosphere of Chinatown at the time, the teenaged Kae recalls,

I smiled ever so sweetly and chose not to tell him that I didn't ever go down to Chinatown except for the very occasional family banquet...those little old men were everywhere in Chinatown, leaning in doorways, sitting at bus stops, squatting on sidewalks. The very thought gave me the creeps (67).

Prohibitive immigration laws kept the "bachelors" of early Chinatown away from their families, women and children. Historically, the opportunities for Chinese women to 
immigrate to Canada were limited by political, economic and social factors. In 1903, a new Chinese Immigration Act included a head tax of $\$ 500$ on each Chinese immigrant and only six classes of persons were exempt, one of which included the families of established merchants (Con 82-3). In Disappearing Moon Cafe, Mui Lan represents those women who were among the earliest Chinese women to immigrate to Canada, mainly wives of merchants and government officials. She enters Canada under the identity of 'merchant's wife' with her son, Choy Fuk. Like the daughter-in-law who comes after her, Mui Lan experiences loss and disillusionment in this 'new' land and her worst fear, loneliness. Once in Canada, Mui Lan "missed the daily sweep of woman-talk from morning till night, about who received a letter and who didn't get money...all of them desperately weaving tenuous, invisible threads over the ocean, to cling cobweblike to their men and sons in the Gold Mountains"(25-6). Through Mui Lan's memories, China is portrayed as a land that offers comfort, companionship and sustenance to women: there she has a "society of women" (26) which she loses when coming to Canada. In Canada, the narrator states that Mui Lan becomes lost: "Gold Mountain men were like stone. She looked around for women to tell her what was happening, but there were none... Without her society of women, Mui Lan lost substance. Over the years she became bodiless, or was it soulless, and the only way she could come back was by being noisy and demanding-because if nothing else, she was still the boss's wife, wasn't she?" (26). As she takes over the operations of the restaurant, Mui Lan adopts a man's role and becomes a 'new world' business woman. Even in China, the fact that Mui Lan works outside the home would not have been considered unusual: pioneer Chinese women who settled in Canada came from regions in Southern China that encouraged women to demonstrate "self-reliance by sowing and harvesting while the men 
were away" (Go 18). But in China, there was a strong sense of community for women, despite the absence of men. In Canada, appearing older than her true age of forty-four years old, Mui Lan sees that financial success alone does not offer fulfillment. The reception most people greet her with does not match her role as "proprietress of the busiest, largest restaurant in Chinatown, and as the wife of the most admired and likable businessman in Chinatown." She realizes "people had a simpler reason for not liking her. Perhaps it was because she had done very well for an ignorant village woman...it must have chafed them to see the chronic pain on her face, as if to suggest that she suffered more than they did. After all, they'd all known the same bare-boned poverty" (24). Later, the narrator states Mui Lan's hard work is the main reason for the business's success for which she takes credit :

Managing a large restaurant such as Disappearing Moon called for a hard nose and a sharp tongue...[h]er husband could not be relied on. Left to his own devices, Wong Gwei Chang would let his business be eroded in no time into bankruptcy by petty thievery and laziness. Mui Lan often wondered how he'd got along before she came. He was too easygoing (27).

All Mui Lan can do is commit much of her time and energy to the successful family business.

In Jin Guo: Voices of Chinese Canadian Women, the editors state that there were also Chinese cultural factors that influenced the immigration experience of men and women:

The men went abroad to try to make a better life. But this path of escape was not open to Chinese women. The male-dominated family clan put a lot of pressure on women to remain in China, instead of trying to follow the men. Some villages were supported entirely by the remittances sent by the family wage earners in North America. Thus, most women and children stayed behind 
to make sure that the men would continue to send money home (17).

Jin Guo includes a chapter written by Sky Lee about her family and experiences in Port Alberni, a mill town in northern British Columbia. Even years later, Lee recognizes how difficult life was for her mother who immigrated to Canada in 1951. Her mother's experiences provide a biographical context for Lee's character Mui Lan:

Life in Canada was very isolating and alienating for my mother. Of course, when she came over here, she had baby after baby, and she was an older woman with failing health. Having to face the impersonal Western doctors with whom she couldn't communicate must have been very difficult for her...Giving birth here was so different from her days in China, when her babies were delivered in her own bed with just a midwife beside her. She would have had lots of support from the community of women (91).

In less isolated communities, such as those in Vancouver, the number of women within the community would rise and social groups would form closer to the years before the Second World War. This is illustrated in Wayson Choy's The Jade Peony where the women gather to play mahjong and gossip. Jook-Liang, the family's young daughter, watches as her mother and other women engage in "curious talk" which includes matters they would never discuss in front of men:

The women's mahjong gaming tables were a cozy haven, like a club gathering, a sorority. With their men often away on seasonal work, the women got to swear as hard as any man, said the outrageous without hesitation and with much delight, traded shopping tips and imparted gossip before anything bad festered into reality. Gossip was a way everyone warned everyone else about what was known...or warned you about what was to be discovered (The Jade Peony 59). 
No such gatherings exist for Mui Lan. Kae comes to understand how these circumstances solidified her great-grandmother's character. When Kae comes into the narrative to comment on Mui Lan's life, she states,

My dumb great-granny! I don't know why she wasn't asking more relevant questions, like where does one go for comfort and relief from such a barren life? But there probably were no halfway houses for women, no places to hide out from a rocky marriage. Ejected from a cloister of women into the stony society of Gold Mountain men must have been a bit like being smashed against a brick wall...It wasn't just that my greatgrandmother was pathetic - she became a tyrant (31).

Mui Lan instead takes comfort in the status and power she has as a wealthy man's wife and uses her power to manipulate others in order to secure what she believes is best for the Wong family name. In "Ties Overseas - A Ticket In" Mui Lan is shown torturing her daughter-in-law over not providing a grandson. Now that she has attained some status as a wife and mother, Mui Lan uses money and her position to secure a role as grandmother. Mui Lan "wanted a grandson to fulfill the most fundamental purpose to her life. A baby with a brow as clear and as promising as his future. A little boy who came from her son, who came from her husband, who also came lineally from that golden chain of male to male. The daughters-in-law who bore them were unidentified receptacles" (31). It matters little to Mui Lan if Fong Mei is the one to carry her grandchild; when Fong Mei fails to become pregnant, Mui Lan uses her money and influence to try to secure a male heir. For Fong Mei, the marriage and family are the 'ticket in' but she sees no 'ticket out' of her situation.

The limitations and unhappiness of her own life cause Mui Lan to abuse those who are closest to her and weaker than herself. In the scene in which Mui Lan informs Fong Mei that another woman will soon be chosen to produce an heir for the family, she unleashes a 
"tirade of raging obscenities" and reduces Fong Mei to one who has "lost her standing as a human being" (58):

Mui Lan had escalated to such a brain-bursting pitch so quickly that she had to pause to regather her corporeal forces...Taking great gulps of air, she started again. 'For five years, five years, we've housed, fed and clothed her. And for what end? So that she could disgrace our ancestors' good name and bring bad luck into this family, and ultimately risk our future descendants? Where am I to find peace in such a situation? Who do I go to for justice? Damned stinky-she bag!' Having no face left at all, having lost her standing as a human being, Fong Mei's colour drained away, her neck limp and weak as if broken...this tirade of raging obscenities left her flaccid with fear. Snot driveled out of her nose; tears trickled after each blink. Sobs, chokes and mucous muffled into her sleeves...Ha! Mui Lan thought to herself, looking over the results of her exertions, satisfied with the slumped remains of her daughter-inlaw before her. That despicable pig-bitch wouldn't dare wrangle with her...She might as well die! (58)

Lee's melodramatic language creates an awareness of both the tragedy and absurdity present in the confrontation between the two women. Kae wonders how her great-grandmother could denigrate another woman and what would have happened had her grandmother had the strength to confront her great-grandmother: "how willingly we fuel the white fire with which to scar other women. What choices did she have? Like so many hordes of women, didn't my grandmother consent to give away her own destiny? Who but women would do that?" (63). What the two women, Mui Lan and Fong Mei, do not see is how alike they are due to their shared circumstances.

Fong Mei proves to be just as alone and isolated as her mother-in-law was when she arrived years before. One of the ways Fong Mei eases her loneliness is through letters to her sister in China. Years later these letters are crucial to Kae's understanding of her 
grandmother's reality and her feelings of isolation and loneliness. Kae is moved by the letters and states "they made me wish many times that I too had a sister as my grandmother did." (41). In the very first letter, Fong Mei is careful not to reveal her sorrow over her new home: "My new life here in the Gold Mountains has been very exciting... everything here is so 'ultramodern.' You don't know what that means, but everyone here likes that ghost word. It means the best and the newest" (42). She notes that the other women, especially older ones, are very protective during the time she and many other women are detained by "white-devil immigration officers" who ask "their absurd, senseless questions." Fong Mei realizes that "here in this hostile environment, we are all like family" (43). But her arrival and subsequent marriage fill Fong Mei with sorrow and the narrator notes that "one letter is unmistakably tearstained" (44). The first 'shock' Fong Mei experiences is the clash between her cultural traditions and those of North America. Like most new immigrants, Fong Mei seeks refuge in the safety tradition affords. About her wedding day she writes, "I couldn't hide my face [behind the "flimsy veil"], so now I know the embarrassment of being a 'barefaced bride.' In that way, the old-fashioned red silk veil had more compassion for us. I tried to be modern" (45). Though Fong Mei's sister is dazzled by the extravagance depicted in the photographs of her sister's wedding, she wonders why her sister hardly writes about it. As a daughter-in-law within the Wong family Fong Mei is soon declared to be an entirely dispensable entity. During the early years of her marriage, Ting An sees Fong Mei "in the dusty back recesses of the storeroom where the discarded things of the Wong family were shelved" (56).

Her sister assures Fong Mei that a woman has to break ties with her 'childhood past' and enter her new married life: "This is the way of women... our lives belong to strangers. 
Eventually, we must all learn to accept our fates. For instance, you and I who are loving sisters, must accept that we may never meet face to face in this life again. Women who don't, their souls will be pulled apart; they will meet their end at the bottom of a well, mark my words!" (45). These words are echoed by Hermia who tells Kae "“Grown women are orphan children, are we not? We have been broken from our mother's arms too soon and made to cling to a man's world - which refuses to accept us - as best we can, any how we can. And of course, let me tell you, many of us are just barely hanging on by the skin of our teeth"” (138).

These letters, as well as the deeds and words of women like Mui Lan, reinforce the patriarchal edict that a woman's body is the battleground upon which her struggle for legitimacy is fought. Fong Mei's sister assures her that once she becomes a mother, her status will be secure: "If it is a boy, your status in this great family will be assured" (48). In the early phase of her marriage Fong Mei is made aware that marriage is one of the consequences a woman must suffer to have children: "a perfect baby had been her [Fong Mei's] one desire - something for which one's body had to be bartered away in marriage" (49). Fong Mei's emotions turn from the self-pity of the daughter-in-law at the mother-inlaw's mercy to misery and finally to rage. One encounter with Mui Lan awakens a new feeling for Fong Mei; she "realized that there was rage as well. So, it was rage, pushing her body beyond its limits! Rage that made her body shudder with icy fear"(60). After these clashes with her 'tyrannical' mother-in-law, Fong Mei believes, "the idea of a baby swelling her stomach had seemed grotesque, a symbol of her enslavement. She had nightmares of a baby with Mui Lan's face leeched onto her breasts, draining her dry"(49). Kae sees that the seeds for defeating women's agency and self-assuredness are found in the limitations 
imposed by various roles, divergent backgrounds, even the very language they speak. ${ }^{37}$

When motherhood finally comes for Fong Mei, it brings her the confidence to assert herself and gain some new freedom. Though her first child is a girl, Fong Mei becomes more confident, more determined and more vocal, attaining the new prized status her culture affords motherhood:

Fong Mei produced only a girl, who tiny as she was, gave her mother enough armnipotence to vie for power and launch a full-fledged mutiny (as one can do only from deep within the ranks). First, Fong Mei learned to drive a car; next, she took her share in the family business and turned it into the most lucrative one of all real estate (134).

None of the 'legal' and culturally sanctioned marriages in the novel are born out of love.

Fong Mei stayed in the family she was miserable with but became financially prosperous:

Fong Mei and real estate didn't do too badly in the postwar years either. There was a cheap-housing boom happening, and the lure of easy money was too tempting. That was why Fong Mei hung on for four more years, when she should have refugeed out of the Wong household long before disaster caved it in. Her intuition surely must have told her to flee with her money and children right after the waitress's story collapsed one side of the crumbling walls. True, she did try to make plans to wrap up her business ventures, but she was too greedy, wasting more time trying to keep as much as the family holdings out of Mui Lan's grasp as possible (167).

With her role within the family finally secured, Fong Mei releases years of anger, "chastising her mother-in-law to her husband, with a mouth as bitter as bitter melon" (135). Though for some time it is unclear whether the child Mui Lan arranges for her son to have 
with the waitress is actually his, Fong Mei forbids Mui Lan to bring Choy Fuk's supposed son into her home: "she would tear her [Mui Lan] to bits if she ever dared to bring that baby home"(135). Fong Mei's new self-confidence places her in an endless cycle: it gives the power to oppress the one who had oppressed her. The clash between mother and daughterin-law is representative of how the two women have contributed to their own miseries. As Bow writes "Mui Lan and Fong Mei are both victims of and participants in women's 'common debasement"'(104). Though Fong Mei and Mui Lan come from different generations, they are both strong-willed women who survive. As women, they are outsiders within the families they marry into, and outsiders in the countries they immigrate to. Both are border figures orphaned by sexism and a lack of family and community.

There are also three generations of 'orphan' men in this work: Wong Gwei Chang, Ting An and Morgan Wong. Ting An is the son of Wong Gwei Chang and Kelora Chen, the family Wong Gwei Chang abandons when he returns to China to marry Mui Lan. Near the end of the novel the narrator states, "[m]aybe Ting An knew Gwei Chang was his father, but for sure Ting An refused to be Gwei Chang's son. That realization was what finally broke Gwei Chang in the end" (220). The narrator in no way absolves Wong Gwei Chang of his responsibility in how he affects other lives although he is shown trying to maintain the appearance/illusion of legitimacy and propriety within his family and community. He is never able to directly say "you are my son," but instead tries to buy Ting An by throwing "a pile of guilt money after him, just so he could die with some face left" (220).

Ting An's position within the family and the community means he lives both within and without borders: "People remarked he spoke english like a native speaker; he behaved much like a ghost too, never very visible...He dealt with most of the business outside of 
Chinatown too. There were lots of others who could get by in english, but Ting An got along really well with the devils" (113). As in The Woman Warrior, Lee's use of the word 'ghost' has multiple meanings. Ting An is able to successfully negotiate his way within the white community as if he were a non-Chinese person, a 'kuei' (ghost). He also lives within both the Chinese and white communities but is never fully visible since he is not entirely accepted by either community. Lastly, ghost figures are border inhabitants; not part of the living and yet not quite fully dead, they wander in a zone between worlds. Just as Ting An is outside community, he also lives outside the family. The narrator states that "Ting An hardly knew a closeness to kin" (114). His life is tainted by the fact that Wong Gwei Chang never really 'legitimizes' him by formally acknowledging that he is his son. Abandoned once by the father who leaves for China to re-marry, he is again left behind by Fong Mei who also abandons him when she refuses to separate from her husband, Choy Fuk, and thereby lose her social and economic status. The narrator states,

[u]nfortunately, Tin An being an orphan didn't have a secure enough framework to cordially absorb rejection, filing it away under the you-can't-win'em-all category of his memoirs. He suffered disproportionately...No protection whatsoever, except for the true grit Ting An rubbed on like exterior paint, year after year. Only the two people who knew him intimately later on in life his wife and his son - knew that his house was built on sand. He died in 1942 - of drink, or so the rumour went (184).

Ting An marries a nameless French Canadian woman and has a son, Morgan Wong. Kae views Morgan as "wounded" and "quite simply a haunted man" (64). Twelve years her senior, Morgan already seemed to be a "dinosaur" (64). He is 'haunted' by the ghosts of the past that he carries with him: he is the former boyfriend of Kae's aunt Suzie; he has stories 
about Kae's great-grandmother, grandmother and their great-grandfather; he has details of Chinatown's troubled history. Both Morgan and Ting An are of mixed race: relegated to the margins, they never entirely fit into the white community or the Chinese community. Yet their positioning gives them a unique perspective on community, history and personal relationships.

The adolescent Kae is initially fascinated by Morgan because he is a handsome, older man who carries an air of mystery and a sense that he is 'haunted' by an other-worldly presence. She is also drawn to him because he is the physical representation of a social taboo: "Morgan was eurasian, which totally occupied my mind. After all, I had understood that kind of thing just wasn't done in nice families" (84). Morgan's 'double identity' at first fascinates and attracts Kae. He is crucial to Kae's 'awakening' to her family's secrets and because of his relationship with her deceased aunt Suzie, Morgan is Kae's most intense connection to the spirit world and the dead. His presence is permeated with Suzie's memories, so Kae is reminded of death and her aunt when she is with Morgan:

Those weary eyes, staring relentlessly at me, haunted by Sue. I wanted to put my hands over them and gently close them like a dead man's. I wanted to tell him that I recognized him in spite of his camouflage. We were looking for the same answers. Given half a chance, I could communicate with him and his ghosts, but he'd only be offended. And with the tension already built up, we would both end up screaming at each other, neither one listening (162).

Since directly communicating with Morgan about his relationship with Suzie is fraught with confrontation, Kae must commune with the dead spirit and so envisions her dead aunt communicating with her in the least likely way. Trapped between different worlds 
(family/community/society) in death as she was in life, Kae imagines Suzie assumes her mother's choices were motivated by fear and greed:

I could begin with Suzanne...Vancouver street for the six o'clock news? Black-and- white TV. Nineteen-fifties dress. The most beautiful asian woman you've ever laid eyes on, especially knowing how invisible asians are in terms of the media.) saying: 'Money.'

'What can I say? She sold out to a whole generation of vipers.'

She might add, referring to Fong Mei, 'Women who are never satisfied, who throw away happiness with both hands... She turned her back on the wrong guy. She got scared of being with an orphan. She got scared of being another waitress (185).

These words open the second-last chapter's section, "Feeding the Dead," as Kae begins to commune with her dead relatives and imagine how some of them would respond to the way all the lives have unfolded within their family. As in Kingston's The Woman Warrior and The Jade Peony, ghosts have the power to harm and/or to heal and protect those who encounter them. Lee, Kingston and Choy's works are infused with elements attuned to the Chinese practice of ancestor worship: Kingston's work is set up as an extended elegy to the dead, while Choy and Lee's works contain scenes of resurrecting spirits and conducting ceremonies to appease the dead.

According to Paul Chao's work on Chinese ancestral worship, there are two levels of belief in this area: one intellectual/academic and the other of "illiterate" or popular opinion: "the belief that the ancestors, if deprived of money and food, will become demons and afflict the living with illness does not appeal to Chinese intellectuals...At the other extreme are the masses of peasants who believe in occasional retribution for neglect; they stress that a man 
who has died is not entirely finished" (106). The oldest Chinese documents mention an after-life, but there is little mention of "purgatory or enduring punishment" (Chao106). The worst punishment for the dead in Buddhist thought would be for the deceased to become a preta, or hungry ghost. A preta suffers in the after-life for past deeds: "pretas are beings whose karma is too good for rebirth in the hells, but too bad for rebirth...Greed, envy, and jealousy can, according to the traditional view, lead to rebirth as a preta" (Kohn 173). Pretas are subject to various tortures, such as suffering from an intense hunger which they can never satiate. Kae's ancestors cannot be thought of as 'hungry ghosts' in the traditional sense of the word 'preta' since these women are not grasping at anything they can to appease their souls. The women resurrected here are angry and exhibit frustration over their past lives. It would be more accurate to apply another Buddhist term to this type of spirit: Dakini. Dakinis are female 'demons' in whom "the inspiring power of consciousness" is depicted (Kohn 50). Buddhist iconography usually depicts them as "treading on the demon of ignorance" (Khon 51). They are usually wrathful (or semi-wrathful) deities of the feminine gender who move on the highest level of reality and represent truth and consciousness.

Though they are somewhat angry and embittered, the women, specifically Mui Lan and Fong Mei, seem to view their pasts in a realistic way. For example, Fong Mei states,

'Even after this list of my crimes, I still have not told you of the worst of my cowardice. The worst was when I willingly gave up the love of my woman's body to the poisonous oppression of woman-haters. I can see clearly now that I was put into this life to be tested. At every turn, I failed miserably. I can see now that it didn't matter that the ignorant, brutal men around me leered and had a dozen different ways to threaten and beat down women. In the end, their impotent violence was 
nothing in the face of love.'(Silence follows, As the ghost recedes, she seems to want to say that she wouldn't love any of us less if we lost the same fight and went with her) (190).

The chain of continuity, especially among the women, the "one individual thinking collectively" concept that Lee carries throughout the novel is suited to the nature of conducting a dialogue with the dead. The ritual of ancestral worship exists to reinforce continuity between the living and the dead. The relationship with the deceased ancestors is on going and the living members are reminded of this when various rituals are enacted, whether they be through playing music, offering food, chanting or reciting prayers. Death does not break the cycle of continuity. One source that Chao uses in his work states "the Chinese hold that ancestor worship is not merely commemorative, but a pretended real intercourse with the spirit world, supposing that happiness of the dead depends on sacrifice by their descendants" (126). The relationship between the dead and the living has not ended but only changed.

In this section of Lee's novel, the otherwise impenetrable border between the dead and the living, and between insiders and outsiders, is broken: Suzanne, Fong Mei, Beatrice, Chi, Morgan, Hermia and Mui Lan gather to discuss the choices they made and the circumstances that drove them to those choices. The opportunity to speak with the dead is a fantasy for anyone who traces family history and yet when Kae resurrects the dead for confrontation she finds conflicting stories and unhelpful relatives. Yet, this ghostly gathering reinforces Disappearing Moon Cafe's disruption of the official and/or patriarchal line of inheritance, where women's names and identities are often erased, by depicting a lineage of women gathering to share experiences. 
In the séance scene, Fong Mei stands apart from the other women, such as Mui Lan, perhaps because Kae envisions she has come to realize what motivated her. Fong Mei is the "dark, shrouded lady who has been lurking in the corner of a twilit room for years" (187). Fong Mei herself asks,

What is this Wong male lineage that had to be upheld at such a human toll? I once thought it was funny that I could take my revenge on the old bitch and her turtle son. Another man's children to inherit the precious Wong name, all their money and power. I forgot that they were my children! I forgot that I didn't need to align them with male authority, as if they would be lesser human beings without it (189).

In her speech beyond the grave, Kae imagines that Fong Mei could have escaped the family and her mother-in-law's control; after all, Mui Lan states, "[t]his was a land of fresh starts" (188), but she says "I was a coward and wasn't willing to give up their money and position...I went around blind, deaf, senseless, unable to touch or feel. That was how the old lady got the better of me" (188). Kae imagines that her great-grandmother too would admit some of her responsibility in the outcome of events: "I was too inexperienced when these deeds were done, and I wouldn't have been able to explain them then because I didn't understand them myself. But I am speaking to you from beyond the grave. And I have had plenty of time to dwell on these matters since"" (187).

This ghost-scene illustrates the 'timeless' continuum where women are connected to one another. Instead of an exorcism to banish these ghosts, there is integration; Kae states "My mother, myself, Chi, Sue, Hermia, my other grandmother, my two great-grandmothers - all the women wailing around a timeless circular table; we sense her [Fong Mei's] presence long before she deigns to speak. She is resentful that her worldly deeds have been 
misunderstood. But Grandmother, aren't we all misunderstood in this life?"(187). Kae desires 'a classic scenario of wailing women huddled together to 'feed the dead.' Lots of eerie mist. I want to make them weep for their own time periods and, at the same time, in harmony with each other" (188). Lee revisions the traditional (patriarchal) commemoration of the dead. Traditionally the Chinese ceremony involves setting up ancestral tablets, usually made of wood; one table for the mother and another for the father. The names on the tablets are arranged in chronological order, the family founder at the top (Chao 115). The living must tend to the tablets and make offerings as a form of paying respect to dead relatives. Prayers are spoken during the traditional ceremony; in other words, the living speak and not the dead.

In Lee's "Feeding the Dead" section, there is no 'wailing' but the women do chant and Suzie, the youngest and most vulnerable, is the only one who "breaks down into tears" (189). The women then come together to soothe Suzie and give personal testimonies. As they speak, they stand as individuals, no longer as nameless bearers of male heirs and the all-powerful family name. Kae attempts to solidify their presence in the present, in history and memory. Just as Kae's great-grandfather saw "the ghosts on the rail-road ties" so that his mission became more real to him, Kae too uses ghosts to come to terms with the 'unspeakable,' the secrets of her family's past and her quest to piece together a "story full of holes." The ghost-scene is the way Kae can call on her ancestors to help her re-envision the past. Brogan, who examines the ghost-metaphor in contemporary literature, states "the work of mourning requires the integration of, rather than the banishing of, the dead. Through the incorporation of the always revised past, new ethnicities emerge"(22). Brogan makes the connection between women, their role as mothers and their lack of control over lineage, in 
the way women writers use the ghost metaphor in their writings to envision new possibilities: "Because female bodies are often the site of a struggle for control over lineage, the shift from metaphors of blood descent to ghostly inheritances reframes cultural transmission in ways that women especially are likely to see as liberating" (25). Like Choy's technique of associating all his protagonists with women, Lee uses the ghost metaphor to disrupt a long-standing Chinese patriarchal practice by recasting it in a way that foregrounds the influence and connections between women.

In addition to reimagining the past by using the dead, another main theme of this novel is the resistance towards tying up 'loose ends.' In presenting many versions of one life, Lee's work resists neatly bound endings. For this reason, readers might wonder if Disappearing Moon Cafe's ending provides any real closure. But Lee's work ends much as it begins: with the patriarch Wong Gwei Chang lost in his ghostly remembrances and returning to his life with Kelora and his beginnings in Canada. In the final pages, Gwei Chang's mind is "circling and circling with endless thoughts - thoughts to the end" (231). Both Gwei Chang and his great-granddaughter, Kae, seem to have to become 'lost' before they can find some direction to their lives. And both these characters are changed after receiving 'ancestral help' from the dead. The séance Kae creates is another way of breaking the silence between the dead and the living, and of disrupting the linearity between past and present in order to find ways that the two intersect. 


\begin{abstract}
Afterword
My interest in these works and the decision to study ethnic minority writing began while I was taking an undergraduate course called "Major Women Writers" at the University of Toronto. Through this course I was introduced to the works of Maxine Hong Kingston and Sky Lee. I learned how the writers' experiences within their own families and communities influenced their writing. My choice of topic was influenced by my upbringing between borders. I was born in one place (Athens, Greece) and raised in another (Toronto, Canada). I went to school to learn English in the day-time and Greek in night-school. Through these works, for the first time I was able to see some of my own experiences as a Greek Canadian reflected by characters trying to forge identities within cultural and national borders, multiple histories and through the complexities of multi-layered stories. Bordercrossing, or transgressing boundaries, my chosen theme, challenges absolutes on many levels. The idea of homogeneity, ethnic purity and independence in any culture is no longer valid.

As the eldest daughter of Greek immigrant parents, I could understand all the edicts, secrets, and tensions between the protagonist of The Woman Warrior and her mother. Other immigrant children I went to school with were aware of how our parents, as Kingston's narrator states, built an "invisible world" that reflected the values and beliefs of their ancestral villages. For this reason, I see the concept of memory being linked to absence and mystery in works that observe the histories of immigrant communities. In such works, the writers must fill in gaps by exercising memory in more imaginative ways. Of the three writers examined in this thesis, Sky
\end{abstract}


Lee's work is the one most explicitly engaged in reconstructing a family history while at the same time paralleling the fortunes of the Wong family with the history of the Chinese community in Canada. When 'history is a mystery,' uncovering memory has much to do with uncovering secrets. This is also true for both Kingston and Choy who use the concept of 'haunting' as a metaphor for the 'unspoken' secrets or taboos that can persist for generations in a kind of "transgenerational haunting" (King 15). Continuity, or the process of making 'connections' between people, is reinforced through the act of storytelling. Through their works, Kingston, Lee and Choy show how important it is to use storytelling as a tool against exclusionary notions of history. Storytelling becomes a process of making connections with the past. This connection to a cultural past is further emphasized by the use of Chinese oral tradition and classical literature. 'Talk story,' used by Kingston and Lee, is a means of imaginatively renegotiating the past and then transforming it to create new possibilities. By using Chinese folk heroes from an older tradition, such as Monkey King in The Jade Peony and Fa Mu Lan in The Woman Warrior, Choy and Kingston illustrate how writers use old stories from traditional tellings to suit new realities. The oral tradition exhibits features such as an anonymous teller, subversive themes, openendings, and multiple versions of a tale. Multiple versions of one story initially cause some confusion for narrators such as Kae in Disappearing Moon Cafe and Sek-Lung in The Jade Peony. In the process of searching, the narrators overcome the desire to reconcile disparity or 'gaps' in the narrative and find one truth. Problems become possibilities, and the ability to embrace the absence of a 'neatly closed ending' is especially true of Lee's Disappearing Moon Cafe, where one character is constantly 
interrupting the narrative trajectory to insert his/her version of the past. This adaptability is an inheritance from an older, oral storytelling tradition that infuses all these works.

All three works activate the conventions of autobiography as the border between fiction and non-fiction is frequently ambiguous. Lee parodies the seriousness of the 'family saga' genre to prove no category is entirely stable. The sole focus of the narrative is not the independent life; Kingston, Choy and Lee are writing fictional autobiographies about the lives of others. Incorporating autobiographical elements into fiction does not need to be problematic. For women especially, autobiographical accounts challenge notions of ethnic minority women as passive victims of their cultures and traditions. In Transforming Chinese American Literature, Joan Chiunghuei Chang states "The Woman Warrior explains that an autobiography is not a static description of an integrated and lucid self, but a dynamic presentation of constant deconstruction and construction of a forever undecidable self' (72). In this sense, the multiple tellings and versions of stories reflect the changeability or fluidity of identity itself. Each of these works also share the use of child protagonists or narrators who reflect on childhood as a means of trying to sort out the complexities involved in forging a new identity when one is caught between different cultural values. The narrators are engaged in a process of negotiating between the culture they were born into and an older inherited culture. The children in these works struggle in spaces like community and family for a voice and presence. For children growing up in an immigrant culture, questions of social, personal and family identity are critical.

All narrators, especially Kingston's, identify with outlaws and transgressive 
figures who do not fit in. Writers/protagonists such as Kingston and Lee's 'try on' different personas to tell their stories. The narrators themselves also transform their voices into those of other characters: mothers, aunts, ghosts, legendary poets and warriors. Protagonists, as bordercrossers, are also both inspired by, and fearful of, other bordercorssing figures: ghosts, outlaws, warriors and sexually transgressive figures.

The narrators of these works are engaged in transgressive acts such as 'narrative revision' which involves translating the past in terms of the present. Kingston's nameless narrator, Lee's Kae and Choy's Sek-Lung, are 'haunted' by ghostly presences that possess them until they somehow (by a formal ritual and/or by 'telling') exorcise the ghost by retelling their stories and reframing the past. The . narrators transform this 'ghostly absence' into something real: a tangible and empowering identity through a connection to dead relatives who, since they too are not fully present and able to participate in this realm, are also borderfigures.

All three writers show how their narrators are 'haunted' by an ancestral culture, norms and traditions. Ancestral worship is tied with community memory. Each writer is engaged in the preservation of cultural memory and of renewing ancestral traditions by honoring them in a new context. The acts of recovering family genealogy and community history, especially Chinese Canadian and American women's history, are important goals associated with these works. In Disappearing Moon Cafe Kae seeks for voices to offer guidance and reanimate 'dead silent ancestors' as does Kingston's narrator in The Woman Warrior. The notion of one sole omniscient (all knowing, all seeing narrator) is challenged by these works. The 'disruption' of the narrative by 
interjecting disparate voices as with Lee's use of the séance scene in 'Feeding the Dead' is a way of breaking the linear flow of the past to the present.

Works such as Disappearing Moon Cafe and The Jade Peony also illustrate how there are various levels of oppression and struggles that transcend uniformity within any one culture. These two narratives are complicated by more than just gender and ethnicity as some characters are shown to be struggling with gay identity and with the boundaries of sexual 'normalcy' within the boundaries of two cultures. The scope of this thesis did not allow for a more extensive analysis of these characters and this theme; further connections can be made between gender, race, class and same-sex desire. By rejecting universal markers of identity and questioning cultural homogeneity, such works are critical since they represent voices which challenge Canadian mainstream literature which has historically excluded women, people of non-Western heritage, gays and lesbians.

As some critics predict, future works will not neatly subscribe to the umbrella term 'Asian American.' since 'trying to link the literatures of historically, culturally and linguistically diverse ethnic groups will become increasingly straining as these communities multiply" (Cheung 4). Others, such as Bennet Lee, foresee the fusions of new perspectives creating greater diversity within the Chinese Canadian community and more material for writers to explore:

Perhaps there will continue to be a period in which mainly second-and third-generation writers rediscover their past, build on their own cultural myths here in Canada and perfect their craft before they can move on. There is a rich and diverse world to explore because of the continuing infusion of ethnic Chinese from many places, bringing their own versions of Chinese culture. The clash of these very different traditions within the Chinese-Canadian universe, 
with its shifting generational perspectives, economic classes, habits, languages and social problems, and in interaction with the rest of Canadian society, provides wonderful themes for aspiring writers to tackle (7).

Displacement is becoming increasingly commonplace for peoples of all cultures. The forces of globalization have increased our awareness of both physical and symbolic borders, adding to the ever-present 'push' and 'pull' forces of forced or chosen migrations. A consciousness of borders and people living outside borders or the contexts of their home-cultures will increasingly become the norm. Therefore, in future, literatures reflecting the experience of those living on or between borders will be written and studied with a greater urgency. 


\section{NOTES}

1 One poem written sometime between 1910 and 1940 states,

I beat my breast when I think of China and cry bitterly

like Ruan Ji.

Our country's wealth is being drained by foreigners, causing us to suffer national humiliations.

My fellow countrymen, have foresight, plan to be resolute,

And vow to conquer the U.S. and avenge previous wrongs! (Cheung 295).

2 The distinction between the terms 'ethnic majority' and 'ethnic minority' writing are from Prof. Enoch Padolsky's essays on Canadian literature.

${ }^{3}$ See Pei-Yi Wu's The Confucian's Progress: Autobiographical Writings in Traditional China (1990).

4 The almost 'legendary' battle of words between Kingston and Frank Chin in the early 1980s is often mentioned in discussions of The Woman Warrior and Chinese American literature. In 1999 Oxford University Press published a casebook on The Woman Warrior containing Chin's, "The Most Popular Book in China." Here Chin mocks those who value certain works for their insight into Chinese and Chinese American cultures:

Kingston and Hwang [a well-known Chinese American playwright] confirm the white fantasy that everything sick and sickening about the white self-image is really Chinese... Reviewers and critics ripe for the cycle of Christian Chinese-American autobiography and Charlie Chan become accomplices to making the fake China and Chinese America of Kingston and Hwang real with the force of history. The source of their vision of Chinese American art and history is white fantasy, not Chinese-American history" (Wong 28).

Kingston's own response to Chin was to write theoretical essays on her work and how one can read The Woman Warrior as memoir. Kingston also wrote more fiction foregrounding strong Chinese American male characters with China Men (1977) and Tripmaster Monkey: His Fake Book (1987) . Wong's “Autobiography as Guided Chinatown Tour? Maxine Hong Kingston's The Woman Warrior and the Chinese American Autobiographical Controversy," also offers insights on the controversies surrounding Kingston's work.

5 Lien Chao notes that although Inalienable Rice was not noticed outside the community it "marks the birth of the community-based literature" whereas Many Mouthed Birds, a second anthology "enters Canadian literature as a new landmark, signifying continuous growth" (33). 
${ }^{6}$ Although it cannot be assumed that 'Chinese' is only considered an adjective for all writers, for the sake of consistency and in effort to show how both nationalities and traditions have informed these writers" works, the unhyphenated forms of "Chinese American" and "Chinese Canadian" will be used throughout this essay.

${ }^{7}$ Ling has also published Between Worlds: Women Writers of Chinese Ancestry written after she asked the question 'What have women who look like me contributed to the literature of this country?' Ling came up with more than three dozen writers of Chinese descent.

${ }^{8}$ For more on ancestral veneration in other cultures, see Julia Ching's Chinese Religions.

${ }^{9}$ Brogan speaks of ethnicity as 'performance' (22)

10 Kingston intended for The Woman Warrior to be classified as a novel, but her original publisher (Knopf) "thought it would sell better as nonfiction and labeled the first printing as such" (Outka 1). Vintage International later re-issued the work under the indecisive "Nonfiction/Literature" label.

${ }^{11}$ Franco mainly refers to South American novelists who take the role of commemorating the dead through their work as "becoming surrogates for Antigone herself" (130). In Euripides play of the same name, Antigone refuses to give in to the state (represented by her father) and instead follows the ancient ritual of burying her dead brother.

${ }^{12}$ Recent films have brought this historical fact to audiences in North America. Fighting women have appeared in popular films such as Ang Lee's Crouching Tiger, Hidden Dragon (2000) and Jet Lee's Fong Sai Yuk (1993) in which a mother and son comprise a tremendously skillful fighting team. Disney has also produced a version of the life $\mathrm{Fa} \mathrm{Mu}$ Lan with the animated film Mu Lan (1997).

13 Asserting the importance of 'the unseen and the unheard' is also central to the works Wayson Choy and Sky Lee.

${ }^{14}$ For more on Kingston's Chinese sources see Yan Gao's The Art of Parody: Maxine Hong Kingston's Use of Chinese Sources. Gao writes that "[i]n order to fully appreciate Kingston's works, we need to decode the construction of Kingston's Chinese myths" (7).

${ }^{15}$ Even in China Men it is the women who control what is told and their voices come into the narrative in the form of letters and through the memories of the men. Also, writers such as Anita Desai and Gabrielle Garcia Marquez acknowledge the importance of women as the "keepers of the tales" in their respective cultures (Rushdie, Imaginary Homelands, 300).

${ }^{16}$ The Woman Warrior has five chapters. In China, offerings to the dead, 'perfected' during the Shang dynasty (16-11 cent. B.C.), were made in the form of a system called the "Five 
Rituals." The ancestors were offered five sacrifices in the form of food and musical performances (Hsu The Written Word 890).

17 The narrator does refer to the aunt's newborn as "the little ghost" (15) presumably because the baby has not lived long enough to form an identity.

18 Though the narrator does discover that "kuei" means "ghost," the term "Ho Chi Kuei," however, confuses the narrator and sends her running for her dictionary, but the meanings are full of contradiction. Gao clarifies this by stating "Ho Chi Kuei" means "curious kids" (33). Still, the term itself is very ambiguous. According to Gao, the word 'kuei' goes beyond the usual two translations of the word meaning non-Chinese person or the Western concept of 'a spirit'. Gao explains the word may signify a spirit, or some sort of evil, or a term used for scolding children (32).

19 Rodriguez uses Todorov's theory of the fantastic to illustrate that Kingston's incorporation of supernatural identities (ghosts) or 'fictions,' "often appropriated from generational and communal folklore" (usually her mother's stories), work to reinforce the strength of her constructions and her 'autobiography' as a whole.

${ }^{20}$ It is clear throughout The Woman Warrior that Kingston 'plays' with multiple meanings in both Chinese and American cultural traditions. For instance, "white tiger" is also a Chinese swearword which means a "worthless female" (Wogowitsch 29).

21 This reading of the "White Tigers" section is inspired by Prof. Linda Hutcheon (private correspondence, 1994).

22 Just before Brave Orchid confronts the Sitting Ghost one of her fellow students states, "'[t]he haunting begins at midnight" (WW 67).

23 The narrator indicates she has problems negotiating her way through language and speech. Both she and her sister said nothing during their early years in school: "the other Chinese girls did not talk either, so I knew the silence had to do with being a Chinese girl" (166). There is also the scene in this chapter when the narrator tortures and taunts her 'double': another Chinese girl who rarely speaks.

24 In the author's note to the novel, Choy states that he used Vancouver's Chinatown as one of the sources which "contained the key information that helped to ground my early memories of Vancouver's Chinatown." Anderson's is a comprehensive and detailed work that traces the evolution of Chinatown from a western perspective and illustrates "the process by which the concept of a Chinese race fed into political practices that reproduced the racial concept and its underlying social relations" from the time of the early immigrants arrival through to the 1970s (Anderson 107). Anderson uses Edward Said's notion of "Orientalism" to show how white attitudes of racial superiority informed the ideology of racial difference. 
25 In Chinese Religions Julia Ching shows this focus in the work of Lao Tzu: "The world had a beginning / And this beginning could be the mother of the world / When you know the mother / Go on to know the child. / After you have known the child / Go back to holding fast to the mother, / And to the end of your days you will not meet with danger"(95).

${ }^{26}$ This figure, as he appears in oral legends around the world, is traditionally thought of as one who is powerful and yet whose own personal gratification and physical appetites sometimes dominates his behaviour (Jung 104). However, in Chinese oral storytelling traditions, Monkey is intended to personify more than just primal instincts by "symboliz[ing] man's intelligence and ambitions" (Hayward Scott 93).

${ }^{27}$ One story tells of how Buddha imprisons Monkey under a mountain, thus immobilizing him for 500 years - his punishment of immobility might seem all too familiar to a child (Mead 248).

${ }^{28}$ It should be stated that Wong Suk (like Poh-Poh / the 'Old One') is honored and respected by the family both for his age and experience. Wong Suk had worked for the Canadian Pacific Railroad and his 'paper years' read that he is in his 70s. Liang's father states, "paperyears...always different from Chinese years"(49). Liang says she understands that "adding years...made one Honourable. The more life-years relatives and friends added to your paper-years, the more Honourable one became" (48).

${ }^{29}$ Sek-Lung's section centres upon the process of his early years of public school which also reinforces the parallels between how he is 'schooled' in both cultures.

${ }^{30}$ Althusser's theories show how Western societies have what he called 'Ideological State Apparatuses (ISAs) represented in the form of the educational system, the arts, the sciences and the media. The various ISAs dictate the beliefs of the ruling class or dominant culture in such a way that the citizens (or various subjects) do not realize they are being indoctrinated into various ideologies thus "constituting' concrete individuals as subjects" (Makaryk 232).

${ }^{31}$ Many writers and historians dispute the claim that most early Chinese immigrants were "sojourners" never intending to settle in North America and become citizens. Kingston's China Men is an extended elegy that records the lives of the men who left China in order to 'sojourn' in "The Gold Mountain." The issue, according to some historians, is more complex than a simple "racist rejection" vs. "sojourner mentality" argument. However, historians do cite a period of formal discrimination against the Chinese in Canada (18751947) and argue that "racist rejection forced the Chinese to be sojourners and to think in terms of returning to China" (Con 80). Both in America and Canada, a series of discriminatory laws were specifically enacted to keep Chinese men and women from becoming permanent citizens of either country. In China Men, Kingston tells the stories of the men as an act of avenging their almost forgotten legacy. Her narrator states that the Chinese men who built the railroad strengthened post-war America: "after the Civil War, China Men banded the nation North and South, East and West with crisscrossing steel. They 
were the binding and building ancestors of this place" (146). China Men also illustrates the many challenges the men faced in America and in their process of eventually becoming 'official' American citizens: harsh work conditions, starvation, discrimination, loneliness and isolation.

${ }^{32}$ Kingston's preferred title for China Men was Gold Mountain Heroes (Sledge 19)

33 The definition reminds one of the narrator's questions on Chinese culture in The Woman Warrior: "What is Chinese tradition and what is the movies?" (6)

34 Here, as elsewhere in the novel, it is significant that 'nationality' words (nouns and adjectives) such as 'chinese' are not capitalized. This must be deliberate on Lee's part perhaps as a way to de-emphasize national or racial identity and foreground other aspects of the character's identity.

${ }^{35}$ In an interview Lee states that this real-life case was the impetus for her novel (Silvera 387).

${ }^{36}$ Hermia's very name exemplifies a double identity and origins that are complicated by illegitimacy. 'Hermia' is derived from the 'Hermaphroditus' who in Greek mythology was the son of Hermes (the Messenger/traveller god) and Aprhodite (the goddess of beauty and love). Hermaphroditus was physically united with the nymph Salmacis, thereby acquiring the characteristics of both sexes (Harris 1028). Her name represents the perfect balance of male and female characteristics. She also has a father who seems as powerful as any god ("a notoriously ruthless and powerful Hong Kong gangster" 39).

${ }^{37}$ Kingston's narrator puts forward a similar argument when she notes how language affects women, specifically the plethora of misogynistic proverbs and expressions in Chinese: ' $[t]$ here is a Chinese word for the female $I$ - which is 'slave.' Break the women with their own tongues!"(47) 


\section{Works Cited and Consulted}

\section{Primary Texts}

Choy, Wayson. The Jade Peony. Vancouver: Douglas \& MacIntyre, 1995.

Kingston, Maxine Hong. The Woman Warrior. New York: Vintage Books, 1975.

Lee, Sky. Disappearing Moon Cafe. Vancouver: Douglas \& MacIntyre, 1990.

\section{Secondary Texts}

Anderson, Kay. Vancouver's Chinatown: Racial Discourse in Canada, 18751980. Montreal: McGill-Queen's UP, 1991.

Barber, Katherine, ed. The Canadian Oxford Dictionary. Toronto: Oxford UP, 1998.

Beauregard, Guy. “Asian Canadian Literature: Can. Lit.'s Obscene Supplement?" Essays on Canadian Writing. 67 (1999): 53-75.

Bemrose, John. "Breaking the Silence of Chinatown: An Author Conjures Up A World of Secrets." Rev. of The Jade Peony. Maclean's. 1 April 1996: 64.

Booth, Wayne C. "Individualism and The Mystery of the Social Self or, Does Amnesty Have a Leg to Stand On?" Freedom and Interpretation. Ed. Barbara Johnson. New York: Basic Books, 1993.

Bow, Leslie. Betrayal and Other Acts of Subversion: Feminism and Sexual Politics in Asian American Women's Literature. Princeton, N.J.: U of Princeton Press, 2001.

Brogan, Kathleen. Cultural Haunting: Ghosts and Ethnicity in Recent American Literature. Charlottesville: UP of Virginia, 1998.

Bromley, Roger. Narratives for a New Belonging: Diasporic Cultural Fictions. Edinburgh: Edinburgh UP, 2000.

Butler, Thomas, ed. Memory: History, Culture and the Mind. Oxford: Basil Blackwell Ltd., 1989.

Chalykoff, Lisa. "Encountering Anomalies: A Cultural Study of Chinese Migrants to Early Canada." Painting the Maple: Essays on Race, Gender, and the Construction of Canada. Eds. Strong-Boag, Sherrill Grace, Avigail Eisenberg and Joan Anderson. Vancouver: UBC Press, 1998. 
Chang, Joan Chiung-huei. Transforming Chinese American Literature: A Study of History, Sexuality and Ethnicity. New York: P.Lang, 2000.

Chao, Lien. Beyond Silence: Chinese Literature in English. Toronto: Tsar, 1997.

Chao, Paul. Chinese Kinship. London: Kegan Paul Int. Ltd., 1993.

Ch'en, Kenneth. Buddhism in China: A Historical Survey. New Jersey: Princeton UP, 1964.

Cheung, King-Kok Cheung. An Interethnic Companion to Asian American Literature. Cambridge: Cambridge UP, 1997.

Chin, Jean Lau, ed. Relationships Among Asian American Women. Washington: American Psychological Association, 2000.

Ching, Julia. Chinese Religions. London: MacMillan Press Ltd., 1993.

Chow, Rey. Writing Diaspora: Tactics of Intervention in Contemporary Cultural Studies. Bloomington: Indiana UP, 1993.

Choy, Wayson. "The Importance of Story: The Hunger for Personal Narrative." Journal of Business Administration and Policy Analysis. 24-6 (1996): 92-106.

Choy, Wayson. Paper Shadows: A Chinatown Childhood. Toronto: Viking, 1999.

Chung, Ling and Kenneth Rexroth, eds. The Orchid Boat: Women Poets of China. New York: The Seabury Press, 1972.

Clements, Jonathan. The Little Book of Chinese Proverbs. London: Siena, 1999.

Con, Harry, Ronald J. Con, Graham Johnson, Edgar Wickberg and William E. Wilmott, eds. From China to Canada: A History of The Chinese Communities in Canada. Toronto: McClelland \& Stewart Ltd., 1982.

Conway, Jill Ker. When Memory Speaks: Exploring the Art of Autobiography. New York: Vintage Books, 1999.

Couser, G. Thomas. “Authority.” Auto/Biography Studies. 10 (1) 1995: 34-49.

David, Catherine, Frederic Lenoir and Jean-Phillipe de Tonnac, eds. Conversations About the End of Time. London: Penguin Press, 1999. 
Deer, Glenn. "An Interview with Wayson Choy.” Canadian Literature. 163 (1999): 34-44.

Fisher, Dexter, ed. Minority Language and Literature. New York: MLA, 1977.

Franco, Jean. Plotting Women: Gender and Representation in Mexico. New York: Columbia UP, 1989.

Fu, Shen. Six Records of a Floating Life. Trans. Leonard Pratt and Chiang Su-hui. New York: Penguin, 1983.

Gambone, Phillip. Rev. of "The Jade Peony." The New York Times Book Review. 10 August 1997: 15.

Gao, Yan. The Art of Parody: Maxine Hong Kingston's Use of Chinese Sources. New York: Peter Lang Publishing Inc., 1996.

Harris, Stephen L. and Gloria Platzner. Classical Mythology: Images and Insights. Mountain View, California: Mayfield Publishing Co., 1995.

Hayward Scott, Dorothea. Chinese Popular Literature and the Child. Chicago: American Library Association, 1980.

Heer, Jeet. "Dragon Ladies and Little Yellow Men?" This. November/December 2000: 20-21.

Henderson, George, and Thompson Olasiji. Migrants, Immigrants, and Slaves: Racial and Ethnic Groups in America. New York: UP of America Inc., 1995.

Holmon, Hugh C. and William Harmon. A Handbook to Literature, 6th ed. New York: MacMillan Publishing Co., 1992.

Hsu, James C.H. The Written Word in Ancient China. Volume 2. Hong Kong: Vincent Printing, 1996.

Hsu, Vivian. "Maxine Hong Kingston as Psycho-Autobiographer and Ethnographer." International Journal of Women's Studies. 6 (1983): 429-442.

Huggan, Graham. "The Latitudes of Romance: Representations of Chinese Canada in Bowering's To All Appearances A Lady and Lee's Disappearing Moon Cafe." Canadian Literature. 140 (1994): 38-52.

Huntley, E.D. Maxine Hong Kingston: A Critical Companion. Westport, Conn.: Greenwood Press, 2001. 
Hutcheon, Linda and Marion Richmond, eds. Other Solitudes: Canadian Multicultural Fictions. Toronto: Oxford UP, 1990.

Jin Guo: Voices of Chinese Canadian Women. Toronto: Toronto Women's Press, 1992.

Johnson, Barbara. ed. Freedom and Interpretation: The Oxford Amnesty Lectures 1992.

New York: Harper Collins Pub. Inc., 1993.

Juhansz, Suzanne. "Narrative Technique and Female Identity." Contemporary American Women Writers: Narrative Strategies. eds. Catherine

Rainwater and William J. Scheick. Lexington: UP of Kentucky, 1985.

Jung, Carl G. The Portable Jung. New York: Penguin, 1971.

King, Nicola. Memory, Narrative, Identity: Remembering the Self. Edinburg: Edinburgh UP, 2000.

Kingston, Maxine Hong. China Men. New York: Vintage Books, 1977.

Kingston, Maxine Hong. Tripmaster Monkey: His Fake Book. New York: Vintage Books, 1987.

Kohn, Michael H., trans. The Shambhala Dictionary of Buddhism and Zen. By Ingrid Fischer-Schreiber, Franz-Karl Ehrhard and Michael S. Diener. Boston: Shambhala, 1991.

Lee, Bennett and Jim Wong-Chu. Many-Mouthed Birds: Contemporary Writing by Chinese Canadians. Vancouver: Douglas \& MacIntyre, 1991.

Lee, Christopher. "Engaging Chineseness in Wayson Choy's The Jade Peony. Canadian Literature. 163 (1999): 18-33.

Lee, Sky, Lee Maracle, Daphne Marlatt, Betsy Warland. eds. Telling It:

Women and Language Across Cultures. Vancouver: Press Gang Publishers, 1990.

Lejeune, Phillipe. On Autobiography. Minneapolis: U of Minnesota P, 1989.

Ling, Amy. Between Worlds: Women Writers of Chinese Ancestry. New York: Pergamon Press, 1990.

Ling, Amy. Yellow Light: The Flowering of Asian American Arts. ed. Philadelphia: Temple UP, 1999. 
Liu, Hsieh. The Literary Mind and the Carving of Dragons: A Study of Thought and Pattern in Chinese Literature. Trans. Vincent Yu-chung Shih. Hong Kong: Chinese UP, 1983.

Ma, Sheng-Mei. Immigrant Subjectivities in Asian American and Asian Diaspora Literatures. New York: SUNY Press, 1998.

MacIntyre, Alasdair. After Virtue. Notre Dame, Indiana: University of Notre Dame Press, 1984.

Makaryk, Irena R. ed. Encyclopedia of Contemporary Literary Theory: Approaches, Scholars, Terms. Toronto: U of T Press, 1993.

Mason, Julie. "The World Between.” Rev. of The Jade Peony. Canadian Forum. May 1996: 37-8.

Matson, Trish. Rev. of The Jade Peony. "Meaningful Hauntings." Event. 25 (1996): 139-143.

Matsuoka, Atsuko and John Sorenson. Ghosts and Shadows: Constructions of Identity and Community in an African Diaspora. Toronto: UofT Press, 2001.

Mead, Margaret and Martha Wolfenstein. Childhood in Contemporary Cultures. Chicago: U of Chicago Press, 1955.

Mostow, Joshua S. Rev. of Disappearing Moon Café. "Complex Art of the Mosaic." Canadian Literature. 132 (1992): 174-5.

Ng, Maria N. "Chop Suey Writing: Sui Sin Far, Wayson Choy, and Judy Fong Bates." Essays on Canadian Literature. 65 (1998): 171-185.

Nicholson, Linda. The Play of Reason: From the Modern to the Postmodern. New York: Cornell UP, 1999.

Ong, Aihwa. "Women Out of China: Travelling Tales and Travelling Theories in Post-Colonial Feminism." Women Writing Culture. eds. R. Behar and D. Gordon, Berkeley: U of California Press, 1995: 350-372.

Padolsky, Enoch. "Cultural Diversity and Canadian Literature: A Pluralistic Approach to Majority and Minority Writing in Canada." International Journal of Canadian Studies (1991): 111 - 128.

- - - "Canadian Minority Writing and Acculturation Options" Canadian Review of Comparative Literatures. 16 (1989): 600- 618. 
Palmer, Martin and Zhao Xiaomin. Essential Chinese Mythology: Stories That Change the World. London: Thorsons, 1997.

Peepre-Bordessa, Mari. "Resistance and the Demon Mother in Diaspora Literature: Sky Lee and Denise Chong Speak Back to the Motherland." International Journal of Canadian Studies. 18 (1998): 79-92.

Pfaff, Timothy. "Talk With Mrs. Kingston." The New York Times Magazine. 15 June 1980.

Quigley, Ellen. "Unveiling the Ghost: Denise Chong's Feminist Negotiations of Confucian Autobiography in The Concubine's Children." Essays on Canadian Writing. 63 (1998): 237-253.

Quill \& Quire. Rev. of The Jade Peony. 62 (1996): 32.

Rabine, Leslie W. "No Lost Paradise: Social Gender and Symbolic Gender in the Writings of Maxine Hong Kingston." Signs 12 (1987): 471-92.

Rabinowitz, Paula. "Eccentric Memories: A Conversation with Maxine Hong Kingston." Michigan Quarterly Review 26 (1987): 177-87.

Rainwater, Catherine and William J. Scheick. eds. Contemporary American Women Writers: Narrative Strategies. Lexington: UP of Kentucky, 1985.

Rimstead, Roxanne. "Oral Histories and Cultural Memory." Essays on Canadian Writing. (60) Winter 1996.

Riseman, Tom. Introduction to The I Ching. Wellingborough, UK: The Aquarian Press, 1980.

Rodriguez, Barbara. Autobiographical Inscriptions: Form, Personhood, and the American Woman of Color. New York: Oxford UP, 1999.

Rushdie, Salman. Imaginary Homelands. London: Penguin Books, 1981.

Sacred Symbols. Tao. London: Thames and Hudson Ltd., 1996.

Said, Edward W. Orientalism. New York: Random House, 1978.

Scott, Dorothea Hayward. Chinese Popular Literature and the Child. Chicago: American Library Association, 1980.

Shin, Ann. "Revenge of the Chinky Chinaman." This. November/December 2000: $18-19$. 
Silvera, Makeda, ed. The Other Woman: Women of Colour in Contemporary Canadian Literature. Toronto: Sistervision Press, 1995.

Simmons, Diane. Maxine Hong Kingston. New York: Twayne Publishers, 1999.

Skandera-Trombley, Laura E., ed. Critical Essays on Maxine Hong Kingston. New York: G.K. Hall \& Co., 1998.

Skenazy, Paul and Tera Martin. eds. Conversations with Maxine Hong Kingston. Jackson: UP of Mississippi, 1998.

Sledge, Linda Ching. "Maxine Hong Kingston's China Men: The Family Historian as Epic Poet." MELUS 7 (1980): 3-22.

Slowik, Mary. "When the Ghosts Speak: Oral and Written Narrative Forms in Maxine Hong Kingston's China Men. Conversations with Maxine Hong Kingston. eds. Paul Skenazy and Tera Martin. Jackson: UP of Mississippi, 1998.

Sontag, Kate and David Graham, eds. After Confession: Poetry as Autobiography. Saint Paul, Minn.: Graywolf Press, 2001.

Stange, Mary Zeiss. "Treading the Narrative Way Between Myth and Madness: Maxine Hong Kingston and Contemporary Women's Autobiography." Journal of Feminist Studies in Religion. 1980:15 - 28.

Steedman, Carolyn. Past Tenses: Essays on Writing, Autobiography and History. London: Rivers Orman Press, 1992.

Swartz, Sarah Silberstein and Margie Wolfe, eds. From Memory to Transformation: Jewish Women's Voices. Toronto: Second Story Press, 1998.

Van Luven, Lynne. "Voices from the Past Echo through the Present: Choy's The Jade Peony and Lai's When Fox is a Thousand." Canadian Culture and Literature And a Taiwan Perspective. Eds. Steven Totosy de Zepetnek and Yiu-nam Leung. Calgary: U of Alberta, 1998.

VanSpanckeren, Kathryn. "The Asian Literary Background of The Woman Warrior." Approaches to Teaching Kingston's The Woman Warrior". Ed. Shirley Geok-lin Lim. New York: The Modern Language Association of America, 1991.

Walsh, Hokenson Jan. "Intercultural Autobiography" Autobiography Studies: A/B. 10 (1) 1995: 92-113. 
Weber, Hancok and Higginbotham. "Women, Power and Mental Health." Women's Health: Complexities and Differences. Eds. Sheryl Burt Ruzek, Virginia L. Olesen and Adele E. Clarke. Columbus: Ohio State UP, 1997.

Western Literature Association. A Literary History of the American West. Fort Worth: Texas Christian UP, 1987.

Wilhelm, Richard. The I Ching or Book of Changes. Transl. Cary F. Baynes. New Jersey: Princeton UP, 1997.

Winsboro, Bonnie. Supernatural Forces: Belief, Difference, and Power in Contemporary Works by Ethnic Women. Amherst: U of Massachusetts Press, 1993.

Wogowitsch, Margit. Narrative Strategies and Multicultural Identity: Maxine Hong Kingston in Context. Wien: W. Braumuller, 1995.

Wong, Sau-Ling Cynthia. ed. Maxine Hong Kingston's 'The Woman Warrior': A Casebook. New York: Oxford UP, 1999.

Wu, Cheng'en. Journey to the West. Transl. W.J.F. Jenner. Beijing: Foreign Languages Press, 1997.

Wu, Pei-Yi. The Confucian's Progress: Autobiographical Writings in Traditional China. New Jersey: Princeton UP, 1990.

Zelinsky, Wilbur. The Enigma of Ethnicity: Another American Dilemma. Iowa City: U of Iowa P, 2001. 
166 